\title{
Evaluation and Field Validation of Eddy-Current Array Probes for Steam Generator Tube Inspection
}

Prepared by

C. V. Dodd, J. R. Pate

Oak Ridge National Laboratory

Prepared for

U.S. Nuclear Regulatory Commission 


\section{AVAILABILITY NOTICE}

Availability of Reference Materials Cited in NRC Publications

Most documents cited in NRC publications will be available from one of the following sources:

1. The NRC Public Document Room, 2120 L Street, NW., Lower Level. Washington, DC 20555-0001

2. The Superintendent of Documents, U.S. Government Printing Office, P. O. Box 37082 , Washington, DC 20402-9328

3. The National Technical Information Service, Springfield, VA 22161-0002

Although the listing that follows represents the majority of documents cited in NRC publications, it is not intended to be exhaustlve.

Referenced documents available for inspection and copying for a fee from the NRC Public Document Room include NRC correspondence and internal NRC memoranda; NRC bulletins, circulars, information notices, inspection and investigation notices; licensee event reports; vendor reports and correspondence: Commission papers; and appllcant and licensee documents and correspondence.

The following documents in the NUREG series are available for purchase from the Government Printing Office: formal NRC staff and contractor reports. NRC-sponsored conference proceedings, international agreement reports, grantee reports, and NRC booklets and brochures. Also available are regulatory guides, NRC regulatlons In the Code of Federal Regulations, and Nuclear Regulatory Commission Issuances.

Documents avallable from the National Technical Information Service include NUREG-series reports and technical reports prepared by other Federal agencies and reports prepared by the Atomic Energy Commission, forerunner agency to the Nuclear Regulatory Commission.

Documents available from public and special technical libraries include all open literature items, such as books, journal articles, and transactions. Federal Register notices. Federal and State legislation, and congressional reports can usually be obtained from these libraries.

Documents such as theses. dissertations. foreign reports and translations. and non-NRC conference proceedings are available for purchase from the organization sponsoring the publication cited.

Single copies of NRC draft reports are available free. to the extent of supply. upon written request to the Office of Administration, Distribution and Mail Services Section, U.S. Nuclear Regulatory Commission, Washington, DC 20555-0001.

Coples of industry codes and standards used in a substantive manner in the NRC regulatory process are maintained at the NRC Library. Two White Flint North, 11545 Rockville Pike. Rockville, MD 20852-2738, for use by the public. Codes and standards are usually copyrighted and may be purchased from the originating organizatlon or, if they are American National Standards, from the American National Standards Institute, 1430 Broadway, New York, NY 10018-3308.

\section{DISCLAIMER NOTICE}

This report was prepared as an account of work sponsored by an agency of the United States Government. Neither the United States Government nor any agency thereof, nor any of their employees, makes any warranty, expressed or implied, or assumes any legal liability or responsibility for any third party's use, or the results of such use, of any information, apparatus, product, or process disclosed in this report, or represents that its use by such third party would not infringe privately owned rights. 


\section{DISCLAIMER}

Portions of this document may be illegible in electronic image products. Images are produced from the best available original document. 



\section{Evaluation and Field Validation of Eddy-Current Array Probes for Steam Generator Tube Inspection}

Manuscript Completed: October 1994

Date Published: July 1996

Prepared by

C. V. Dodd, J. R. Pate

Oak Ridge National Laboratory

Managed by Lockheed Martin Energy Research Cornoration

Oak Ridge National Laboratory

Oak Ridge, TN 37831

\section{DISCLAIMER}

J. Muscara, NRC Project Manager

Prepared for Division of Engineering Technology Office of Nuclear Regulatory Research U.S. Nuclear Regulatory Commission Washington, DC 20555-0001

NRC Job Code B0417
This report was prepared as an account of work sponsored by an agency of the United States employees, makes any warranty, express or implient nor any agency thereof, nor any of their bility for the accuracy, completeness, or usefulped, or assuspes any legal liability or responsiprocess disclosed, or represents that its use would of any idformation, apparatus, product, or ence herein to any specific commercial use would not infringe privately owned rights. Refermanufacturer, or otherwise does not necessarily process, or service by trade name, trademark, mendation, or favoring by the United States constitute or imply its endorsement, recomand opinions of authors expressed herein Government or any agency thereof. The views United States Government or any agency theref not necessarily state or reflect those of the 
(cacer

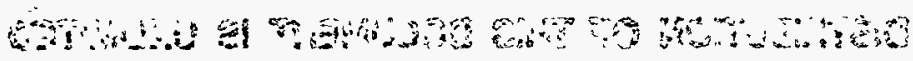




\begin{abstract}
The objective of the Improved Eddy-Current ISI for Steam Generator Tubing program is to upgrade and validate eddy-current inspections, including probes, instrumentation, and data processing techniques for inservice inspection of new, used, and repaired steam generator tubes; to improve defect detection, classification, and characterization as affected by diameter and thickness variations, denting, probe wobble, tube sheet, tube supports, copper and sludge deposits, even when defect types and other variables occur in combination; to transfer this advanced technology to NRC's mobile NDE laboratory and staff. This report describes the design of specialized high-speed 16-coil eddy-current array probes. Both pancake and reflection coils are considered. Test results from inspections using the probes in working steam generators are given. Computer programs developed for probe calculations are also supplied.
\end{abstract}




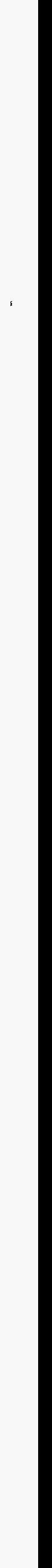




\section{Contents}

Abstract...

Page

\section{iii}

\section{Figures}

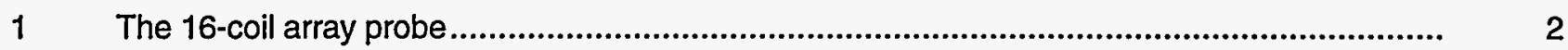

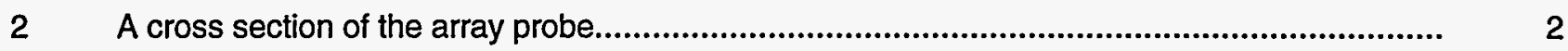

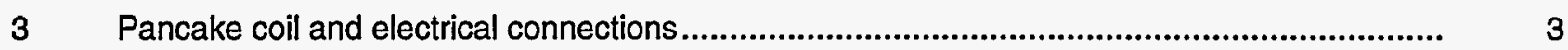

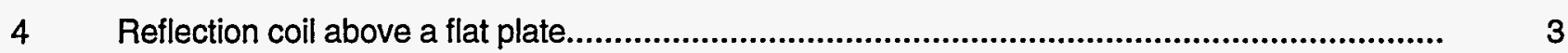

5 Variation in normalized coil impedance for different values

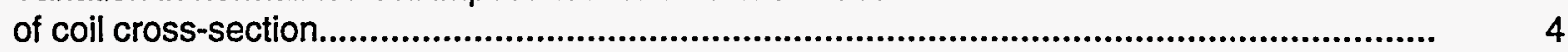

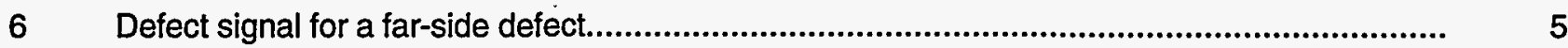

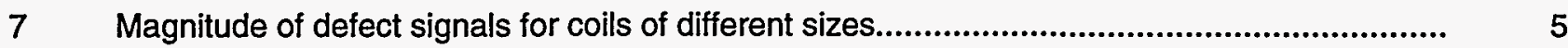

8

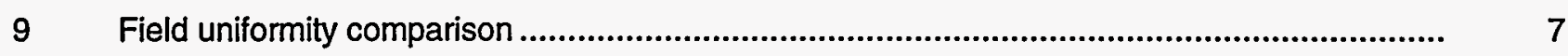

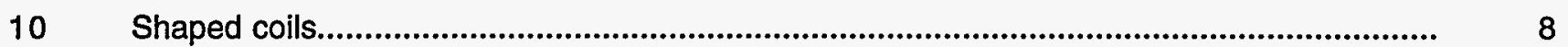


11 Circumferential groove standard.

12 Bobbin probe scan of tube row 35 Column 30 using Zetec

Eddynet software.

13 Pancake array scan of tube Row 35 Column 30 showing three indications

14 The vertical component of the $260 \mathrm{kHz}$ data from the reflection

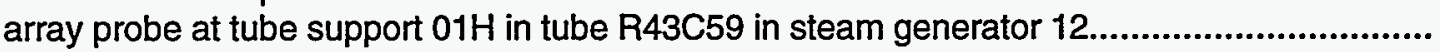

15 The vertical component of the $260 \mathrm{kHz}$ reflection array probe from tube support $01 \mathrm{H}$ in tube R43C59 of steam generator 12 with the tube support suppression mix applied 


\section{Evaluation and Field Validation of Eddy-Current Array Probes for Steam Generator Tube Inspection \\ C. V. Dodd and J. R. Pate}

\section{Introduction}

As the nation's steam generators have aged, new mechanisms for the degradation of steam generator tubes have appeared, and the frequency of forced outages due to major tube leak events has increased. To ensure that tube degradation is detected before it leads to a forced outage, it will be necessary to inspect during each outage a large number of the tubes in each steam generator using a technique which is sensitive to all forms of degradation. The primary method for the inspection of steam generator tubing is eddy-current testing, and while eddy-current testing can be used to perform a fast and reliable inspection, the eddy-current techniques currently being used for steam generator inspection are no longer adequate for the needs of the nuclear power industry.

The bobbin probe has traditionally been the primary method for the inspection of steam generator tubing. The probe consists of a pair of circumferentially-wound coils which are pulled through the tube at speeds of up to 40 inches per second, acquiring data as they travel. The probe's high speed and complete coverage of the tube circumference have made it a favorite of utilities with a tight outage schedule. However, since the probe induces eddy-currents in the tube wall with components only in the circumferential direction, the bobbin probe is not sensitive to circumferential cracks because these will not interrupt the flow of the induced currents.

Furthermore, since the probe looks at the entire tube circumference at one time, the ability to use bobbin probe data to distinguish between cracks and volumetric flaws is limited.

To overcome the sensitivity limitations of the bobbin probe, the rotating pancake probe (RPC) was introduced. The RPC consists of one or more small coils pressed against the inner surface of the tube wall. In order to inspect the entire circumference of the tube, it is necessary to rotate the coil as it is pulled through the tube. Unfortunately, this means that the RPC is quite slow, with an inspection speed of only 0.2 in per second. This is clearly too slow to inspect the large numbers of tubes that should be inspected, and utilities avoid this type of inspection when at all possible. The result has been forced outages for tube leaks. Plants such as Palo Verde 2, have had outages lasting several months while long sections of tubes were inspected using the RPC.

Clearly a new probe design which combines the speed of the bobbin probe with the sensitivity of the RPC is needed to ensure the detection of all types of defects and to improve the ability to characterize defects. Toward this end, ORNL has developed a 16-coil eddy-current array probe. This probe consists of 16 small coils pressed against the inner surface of the tube and distributed about its circumference. The data obtained with this probe are similar in nature to those from the RPC, allowing detection of cracks of any orientation, but since it is not necessary to rotate the probe to achieve full coverage of the tube circumference, inspection speeds approaching those of the bobbin coil are possible. 


\section{Array Probe Design}

The eddy-current array probes developed by ORNL consist of 16 small coils pressed against the inner surface of the tube as shown in Figure 1. The coils are divided into two

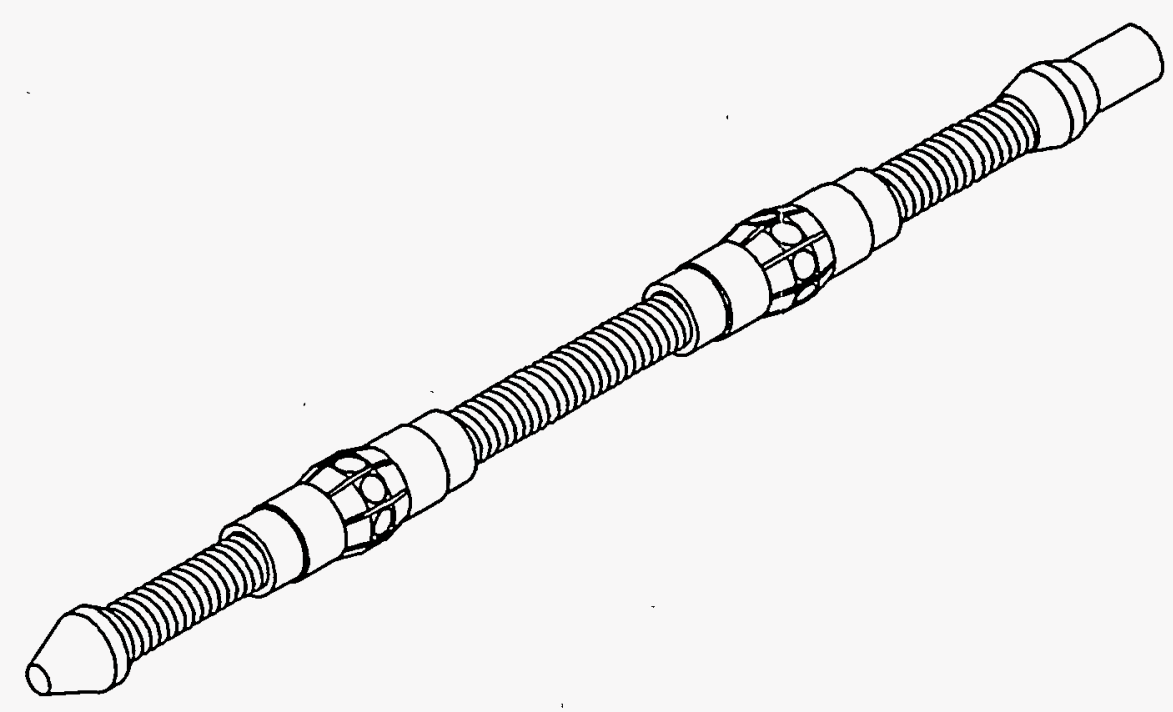

Figure 1 The 16-coil array probe

groups of eight coils each with the two groups being separated by a distance of approximately 4.5 inches in the axial direction. Each coil is mounted in an individual spring-loaded shoe to keep the coil pressed against the inner surface of the tube, which has a diameter of 0.775 inches, but if necessary the shoe will retract, allowing the probe to pass through a tube of diameter 0.720 inches. This makes it possible to inspect tubes with a significant amount of denting.

Figure 2 shows a cross section of one of the groups of eight coils. Neighboring coils in the same group are separated by 45 degrees in the circumferential direction. The coils in one group are centered in the regions between the coils in the other, resulting in there being 22.5 degrees between adjacent coils.

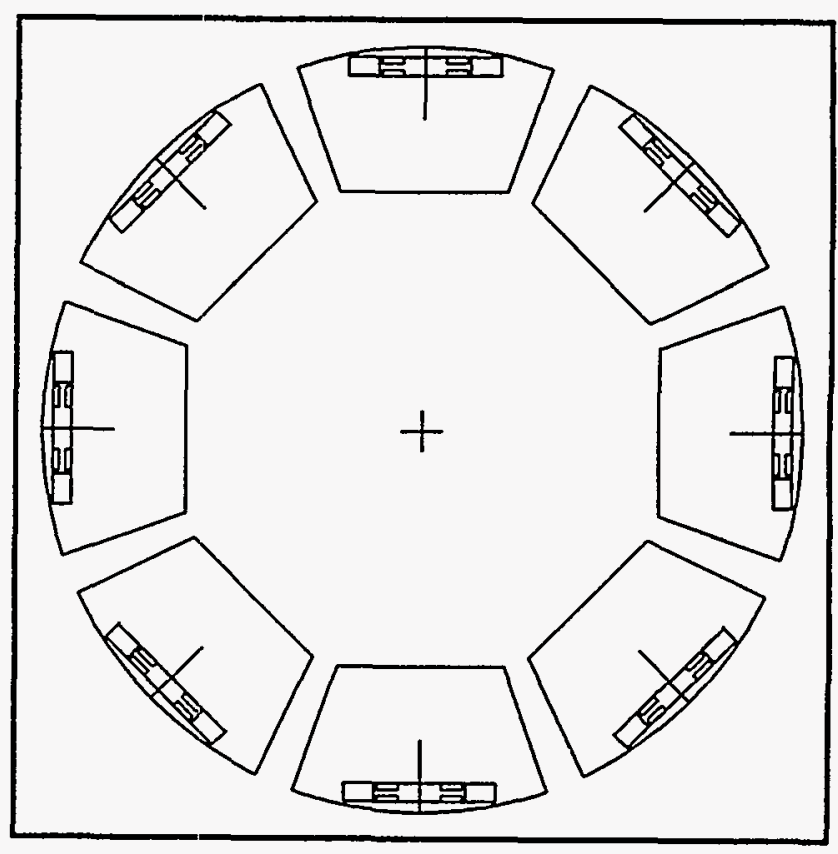

Figure 2 A cross section of the array probe 
While the array probe has been designed for and tested in only straight sections of tubes with an outer diameter of $7 / 8$ inches, Zetec, the company which manufactured the probe, feels that the probe can be constructed to inspect the U-bends of the tubes and that it can be scaled to inspect tubes with an outer diameter of $3 / 4$ inches.

\section{Individual Coil Design}

The individual coils which make up the 16-coil array probe were designed to maximize sensitivity to small defects on the outer diameter of the tube. Two array probes with different types of coils were designed and constructed; one probe contained the commonly used pancake coil, and the other contained reflection coils. Figure 3 shows a pancake coil and its electrical circuit. The pancake coil is used as the test coil in a typical bridge circuit, and a second identical coil placed is in a reference tube. The voltage measured is the difference between the test and reference signals, and since the probes will be nearly balanced, the signal can be amplified, increasing the sensitivity to small changes in the part being tested.

In Figure 4 we show a reflection coil and its electrical connections. The reflection coil consists of a driver coil which is used to induce eddy currents in the part being tested, and two smaller pickup coils in which a voltage is induced by the eddy currents in the part. The reflection coil can be designed in such a way to offer better discrimination to lift-off, the distance between the coil and the test part, than can be obtained with the pancake coil, and it therefore has a significant advantage over the pancake coil for steam generator inspection. The reflection coil circuit is similar to an induction bridge which is widely used for many types of highly accurate measurements.

Design studies were done for both of the types of coils in order to maximize their

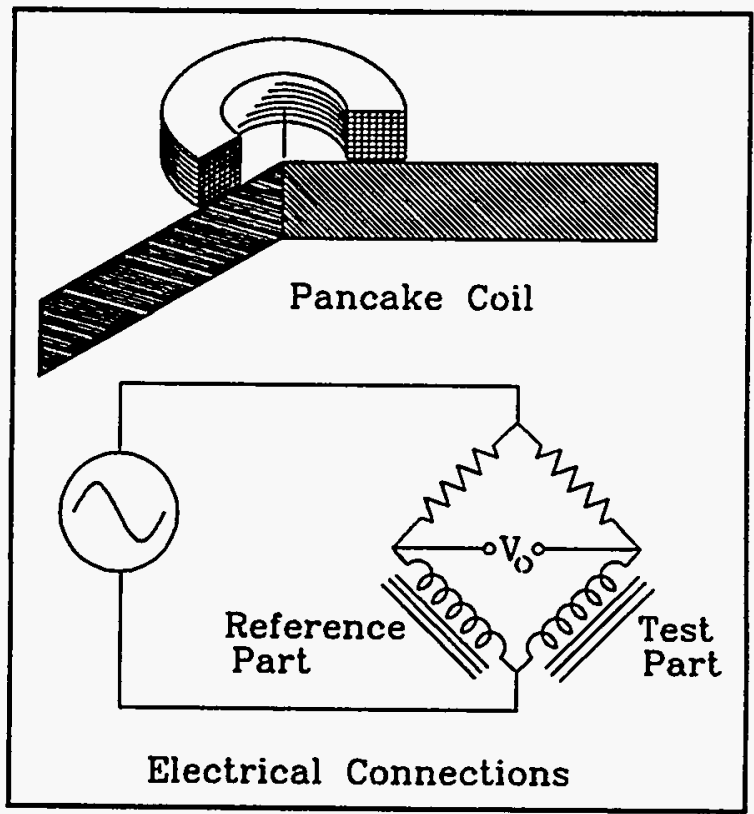

Figure 3 Pancake coil and electrical connections

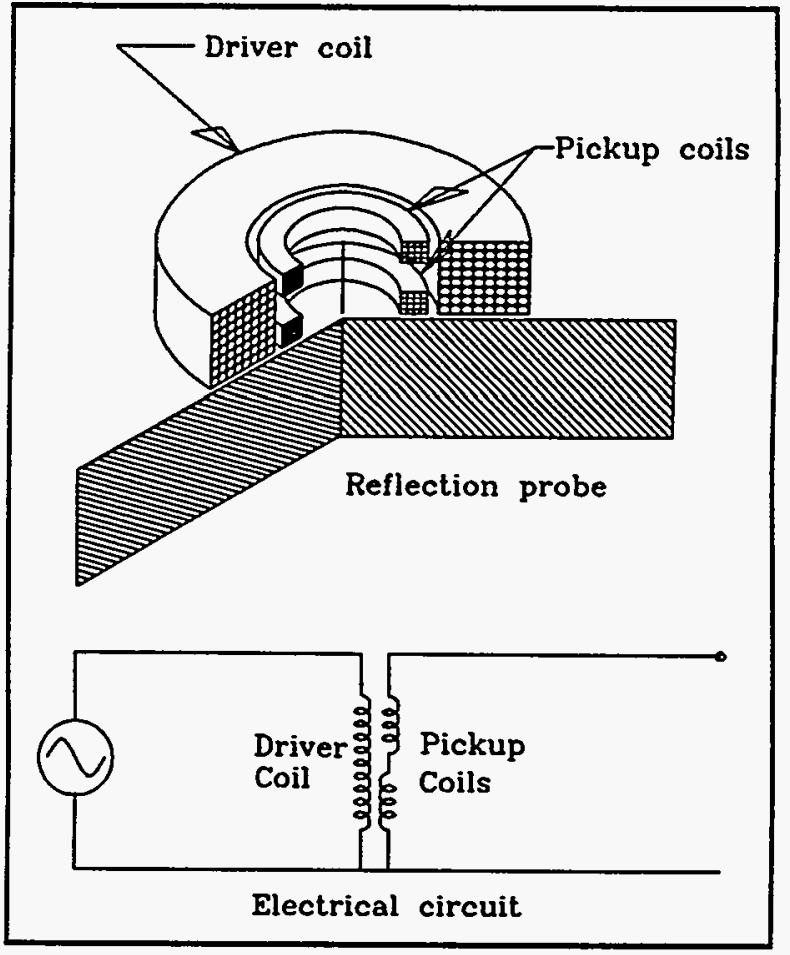

Figure 4 Reflection coil above a flat plate 
sensitivity to small defects on the far side of the tube wall and to minimize the effects of other variables. For the purpose of the design study, we considered the tube wall to be a flat plate. The first consideration was to make the coils as flat as was practical. Figure 5 illustrates how the normalized coil impedance depends on the shape of the coil cross section. From the figure it is evident that for a given value of the quantity $\omega \mu \sigma r^{2}$, the product of the inspection frequency, tube conductivity, tube permeability, and coil mean radius squared, increasing coil flatness increases the coil impedance change from its air value. Therefore, the coil is more sensitive to the properties of the part being tested when its turns are as close to the part as possible. There is a limit on the coil flatness, however, since if the coil is made too thin, its dc resistance becomes too high. In addition, the small defects that we wish to measure are usually on the far side of the conductor, so that the absolute flatness is not critical. It is recognized that as coils become flatter, the sensitivity to lift-off, conductivity variations, and other conductor property variations will also increase, but other methods will be used to reduce these effects.

A number of different pancake and reflection coil designs were tested using both analytical calculations and experimental measurements. The model used for most of the calculations was a point defect or a very small spherical defect. The reasoning was that if we could optimize for the smallest defects, detection of the larger ones would also be accomplished. Also, the mathematical model used for most of the calculations is only valid for small defects. 
In Figure 6 we show the calculations of the impedance change for the P90 pancake coil due to a point defect on the far side of a conducting plate as a function of the defect radial location for several different test frequencies. Notice that there is an optimum frequency for maximum sensitivity and an optimum radius. This gives an indication of the field spread of the coil.

We show in Figure 7 a plot of the defect signal for different size coils as a function of the distance from the center of the coil. The outer diameter of the coils was fixed at 0.240 inches by the size of the shoe in which the coil was mounted, and the inner radius was varied from 0.0 to 0.16 inches, causing the mean radius of the coil to vary from 0.06 to 0.1 inches. Both the maximum sensitivity and the radial distance at which the maximum sensitivity occurs vary with coil size. The maximum sensitivity occurs for the P75 at a radius of 0.080 inches, and for the P90 it occurs at 0.0875 inches. While the maximum sensitivity of the P90 is slightly less than that of the P75, the greater field spread of the P90 means that it is to be preferred for use in the array coil. Both the P75 and P90 coils were built and tested, and the results were similar to those expected.

A comparison study was performed between the reflection and pancake coils to measure the defect depth in the presence of other property variations. The signals from the pancake and reflection coils were computed using the programs IMPTST and MULRFD, respectively. Property variations (in the file NRCPRO.DAT) include a lift-off variation of 0.010 inches, tube wall thickness values of 0.050 inches, 0.040 inches, and 0.030 inches, and defect depth values of 0.000 inches, 0.005 inches, 0.010 inches, and 0.015 inches, with copper deposits, tube supports, and magnetite deposits on the outside of the tube at various locations. The copper was placed at 15 locations, the tube support at 12 locations, and the magnetite at 12 locations, for a total of 39 OD artifact property values. For each of these artifact property values there are four defect depth

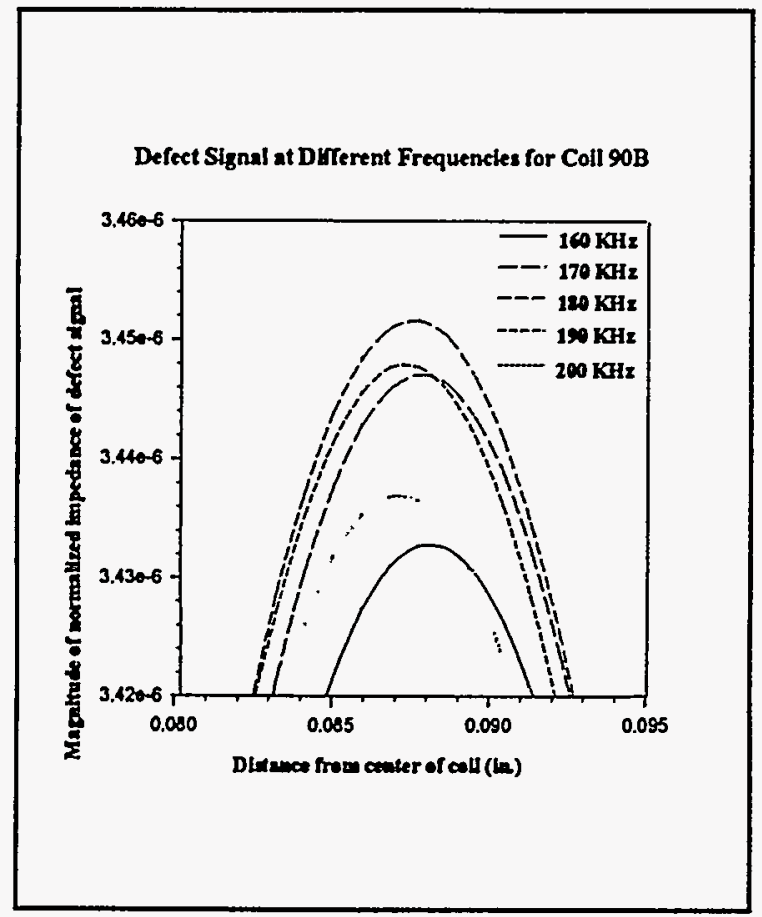

Figure 6 Defect signal for a far-side defect

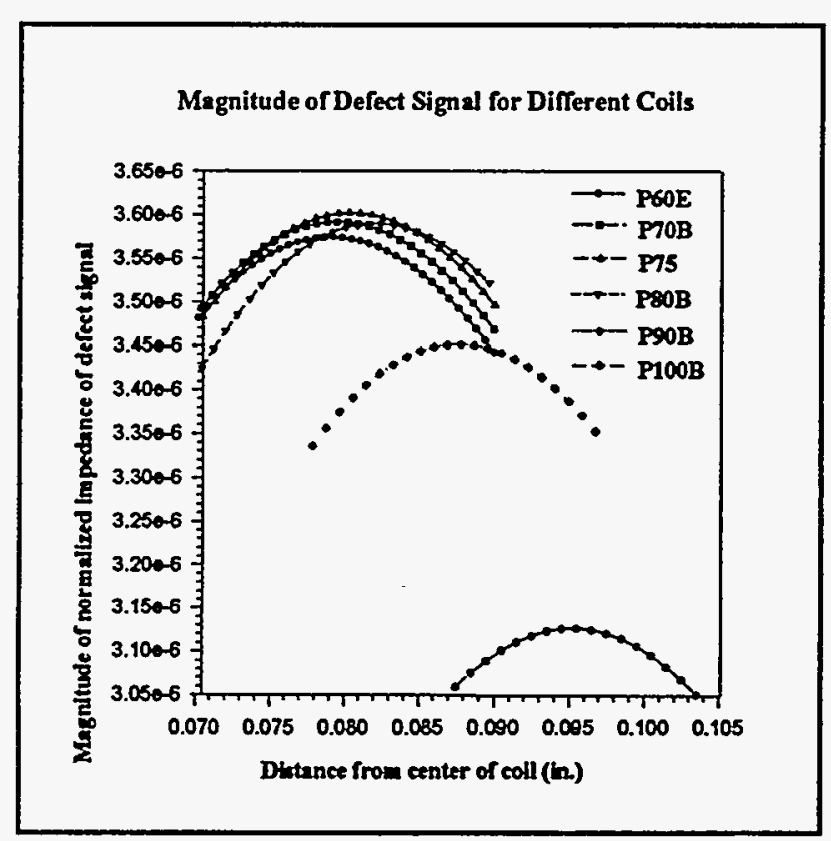

Figure 7 Magnitude of defect signals for coils of different sizes 
values and five lift-off values, for a total of 780 property combinations. The frequencies were varied from $10 \mathrm{kHz}$ to $1 \mathrm{MHz}$ in a $1,2,5$ sequence. The property variations for each of the three types of OD artifacts are summarized below.

\begin{tabular}{|l|l|l|}
\hline Region & Material & Thickness \\
\hline \hline 1 & Copper & Infinite \\
\hline 2 & Air & $0.5,0.005,0.003,0.001$ \\
\hline 3 & Inconel & $0.050,0.040,0.030$ \\
\hline 4 & Coil & \\
\hline
\end{tabular}

\begin{tabular}{|l|l|l|}
\hline Region & Material & Thickness \\
\hline \hline 1 & Tube Support & Infinite \\
\hline 2 & Air & $0.005,0.003,0.0001$ \\
\hline 3 & Inconel & $0.050,0.040,0.030$ \\
\hline 4 & Coil & \\
\hline
\end{tabular}

\begin{tabular}{|l|l|l|}
\hline Region & Material & Thickness \\
\hline \hline 1 & Magnetite & Infinite \\
\hline 2 & Air & $0.005,0.003,0.0001$ \\
\hline 3 & Inconel & $0.050,0.040,0.030$ \\
\hline 4 & Coil & \\
\hline
\end{tabular}

The best combination of three frequencies was chosen from the six frequencies used by running the program FINDFIT on the data for both coil types. Although this is only an approximation of the complexity of an actual problem, it does give an indication of how the multiple property fits can work without requiring an excessive amount of computer time. FINDFIT computes the best least squares fit of the property variations to the computed readings. 
In Figure 8 we show the results of the error in the measurement of defect depth for both the pancake and reflection coils. The defect depth measurement error is the RMS of the fit error and the drift error, and it is measured in percent of wall thickness. For both types of coils, the fit error dominates. The neural net analysis techniques would probably give a better fit with no significant increase in the drift. From this comparison, the reflection coil seems to offer a significant advantage over the pancake coil.

Another important factor is the ability of the coils to cover the entire circumference of the tube. To measure this ability the probes were used to scan an axial EDM notch of depth $40 \%$ of wall thickness and length 0.25 inches. The scan was conducted once with the center of the coil passing directly over the notch, and then it was repeated with an angle of 12 degrees between the center of the coil and the notch. The ratio of the response to the defect when the probe is at 12 degrees to the response when the probe is at 0 degrees is plotted in Figure 9. The figure shows that the sensitivity of the $\mathrm{P} 90$ is much more uniform than that of the P75 or the $\mathrm{P} 60$, and that the pancake coils have greater field uniformity than the reflection coils.

The zero lift-off, or the distance between the coil and the inner surface of tube, will also have an effect on the sensitivity to small defects on the far side of the tube wall. Both the sensitivity to and the resolution for small defects increases as the zero liftoff decreases. It is therefore best
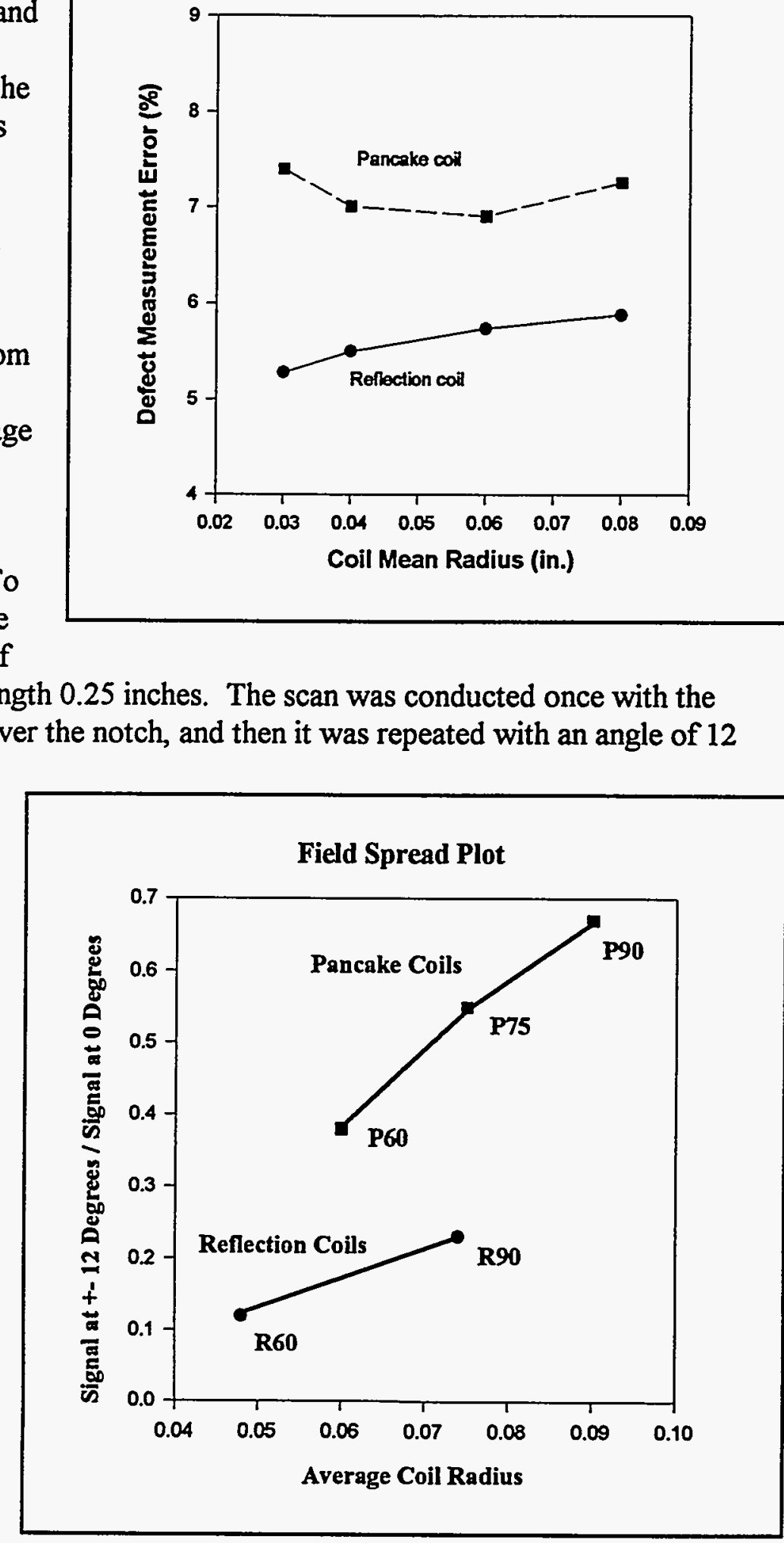

Figure 9 Field uniformity comparison 
to get the coil as close to the tube wall as is practical. If the coil is flat, the curvature of the tube increases the distance between the coil and the tube wall. One method of reducing this distance is to contour the coil to conform to the curvature of the tube, as shown in Figure 10. Coils of two different shapes were used, one with the coil cylindrically shaped to fit the tube wall, and another with the coil spherically shaped. The cylindrically shaped coil has smaller zero lift-off, but it appears to be very slightly more susceptible to lift-off effects than

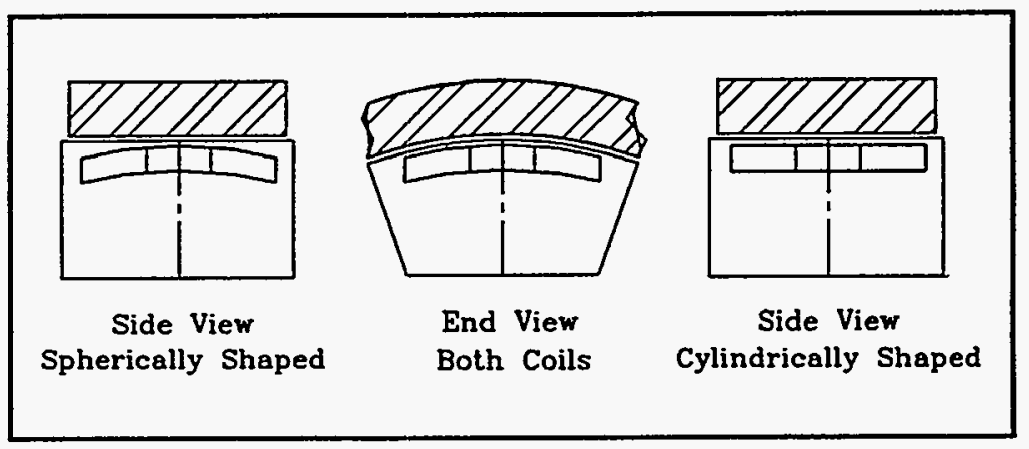

Figure 10 Shaped coils the spherically shaped coil. The spherically shaped coil was also easier to fabricate. An attempt was made to build a cylindrically shaped reflection probe, but it was not successful.

As a final consideration the number of turns in the coil was determined. The number of turns is a compromise between the ratio of the dc coil impedance changes to the ac impedance changes and the effects of probe wire capacitance. It is desirable (but not always possible) to have a low cable capacitance between the instrument and the probe so that the probe operates well below its resonant frequency because near the coil resonance a $5 \mathrm{pF}$ change in capacitance will lead to a signal change as large as that produced by a through-wall hole. For a 16-coil pancake array probe, 16 coaxial connections are needed, and for a 16-coil reflection array probe, 32 coaxial connections are needed. The initial reflection array probes were built using cable of capacitance $26 \mathrm{pF}$ per foot. Since that time, cable with a capacitance of $20 \mathrm{pF}$ per foot has been found for the reflection array, and cable with a capacitance of $17 \mathrm{pF}$ per foot has been found for the pancake array probe. The inductance of the coils is about 50 to 90 microhenries so that with 110 feet of low-loss cable, the resonant frequency can be as high as $650 \mathrm{kHz}$, which is slightly above the highest test frequency we have used in the field validation of the probes. The number of layers in the coil, the number of turns per layer, and the wire gage are computed by the program AIRCO.

\section{Instrumentation}

The MIZ-30 eddy-current instrument was designed and constructed by Zetec specifically for array probe inspections. It is a high-speed multiple-frequency digital instrument that can drive 16 individual coils in either a bridge arrangement with a reference probe or in a transmit-receive mode for the reflection coils. It is capable of taking 500 readings per second for all 16 coils at four frequencies. The gain and hardware null are also software adjustable. A Hewlett Packard workstation is used to control the instrument over a local area network. The configuration of the instrument is set by the acquisition operator. The configuration can be entered manually or a data file containing the setup information can be transmitted over the LAN from any other workstation on the network and stored in the appropriate file. The configuration file can contain the setup 
information for up to 16 different types of inspections. The probe is positioned on the face of the tubesheet (a Zetec SM-22 was used for the Prairie Island tests), and the probe pushed into the tube and then the probe pulled as the data are acquired and recorded. Up to 16 channels can be displayed so that the acquisition operator can verify that all the channels of the probe are working and can tell where the probe is in the tube. However, with the amount of data to be processed when all 16 channels were displayed, the computer lagged too far behind the actual probe motion so that it was much better to display only one channel most of the time. The acquisition computer also controlled the probe positioning and insertion, which lagged too far behind when the 16 channels were displayed. This problem is considerable when using a 700 series workstation.

\section{Prairie Island test results for array probes - first test}

The array probes were first tested at the Prairie Island Unit 2 steam generators on November 14, 1993. The system was assembled and tested on the Prairie Island mock-up the week before it was tested in the generators. The acquisition operators were not familiar with the MIZ-30, and some instructions were necessary before the acquisition programs could be successfully run. The probe pusher-pullers were designed to drive $3 / 8$ inch diameter polyurethane cable into the tubing, and since the array probes use $1 / 2$ inch diameter cable, a modification had to be made to the pusher-puller before it would drive the array probe cable. A special part had to be machined and another part had to be removed. One of the twister cables was discovered to be bad, and personnel from Conam, the company which performed the acquisition and primary analysis of the eddy-current data at Prairie Island, repaired it. Conam also suggested that we add enough extension cable ( 10 feet) to allow the MIZ-30 to be moved to an area with lower contamination, which we did.

The MZZ-30 and the cables were installed in the generator on Sunday morning, November 14. The pusher-puller in the steam generator had to be modified in the same manner as the one in the mock-up. Unfortunately, due to the contamination and other problems, it was much more difficult to modify, and the probe speed was limited to 15 inches per second by mechanical considerations.

A set of 48 tubes was selected for inspection based on the results of the regular eddycurrent inspection which had been completed. The reflection array probe was tested first. The gain in the original design of the MIZ-30 was not as high as was needed to obtain the best results with this type of coil, and the signal-to-noise ratio for the reflection was thus about the same as that for the Zetec rotating pancake coil (RPC). The pancake array with spherically shaped P60 coils was then tested. The signal level for this probe was greater than that for the Zetec RPC by a factor of 5 to 10 for the same gain setting. The data from the various coils were reviewed by Gary Henry of EPRI, who determined that the signal-to-noise ratio of the pancake array probe was higher than that of the Zetec RPC by about a factor of 5 . 
In order to do improved signal analysis a circumferential groove standard had to be used to calibrate each coil in the probe. Figure 11 shows a drawing of the standard used. The grooves

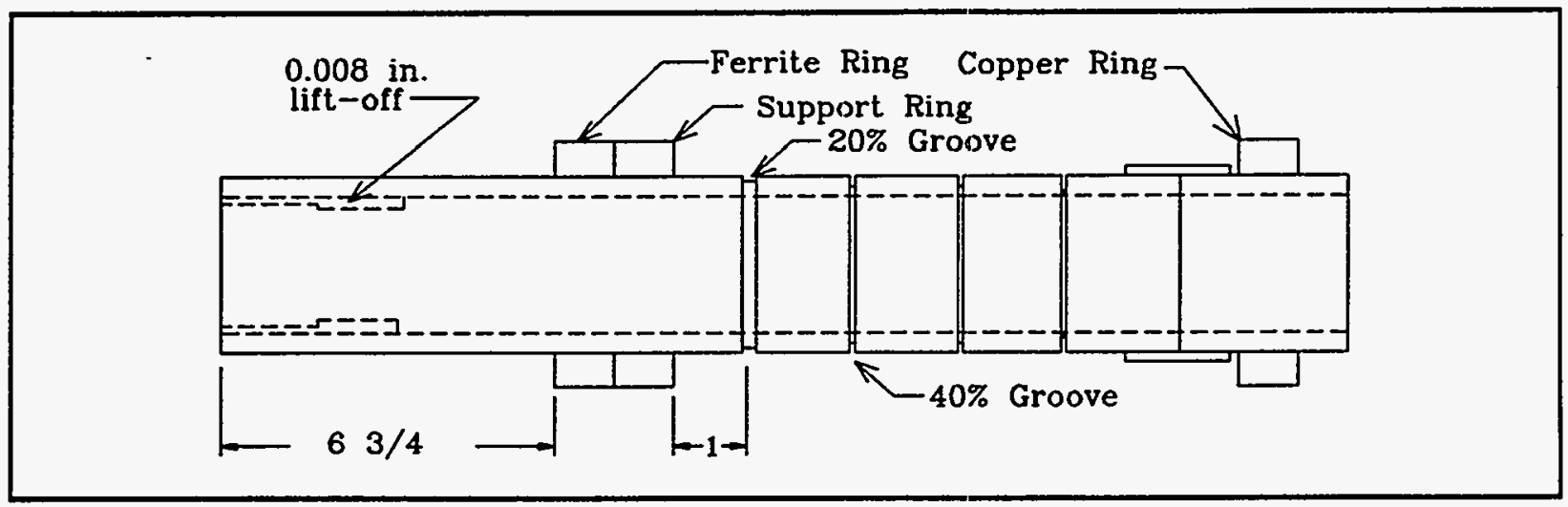

Figure 11 Circumferential groove standard

extend all the way around the circumference of the tube and have depths of $20 \%, 40 \%, 60 \%, 80 \%$ and $100 \%$ of wall thickness. In addition to the grooves the standard contained a ferrite ring (to simulate a magnetite deposit), a tube support ring, and a copper ring. Scanning the standard allowed us to perform mixes for the suppression of tube supports, magnetite, and copper. The data were analyzed at the site using the Zetec analysis software by analysts from Conam and Zetec. The data were also analyzed using the ORNL analysis software. Since the ORNL software was developed especially for array probe data, it is less cumbersome to use to perform mixes and other tasks. In general the array probes detected all indications that the bobbin coil detected. There were some calls made with the ORNL array probes that were not made with the bobbin coil, but these were all quite small and harmless. There were some indications at the tube supports, but none were judged to be serious. Figure 12 shows the bobbin coil scan of a section of tube R35C 30 and Figure 13 shows a plot of the pancake array probe data from the same section of the tube. There appear to be three small defects just above the tubesheet. 
Tube Comment:

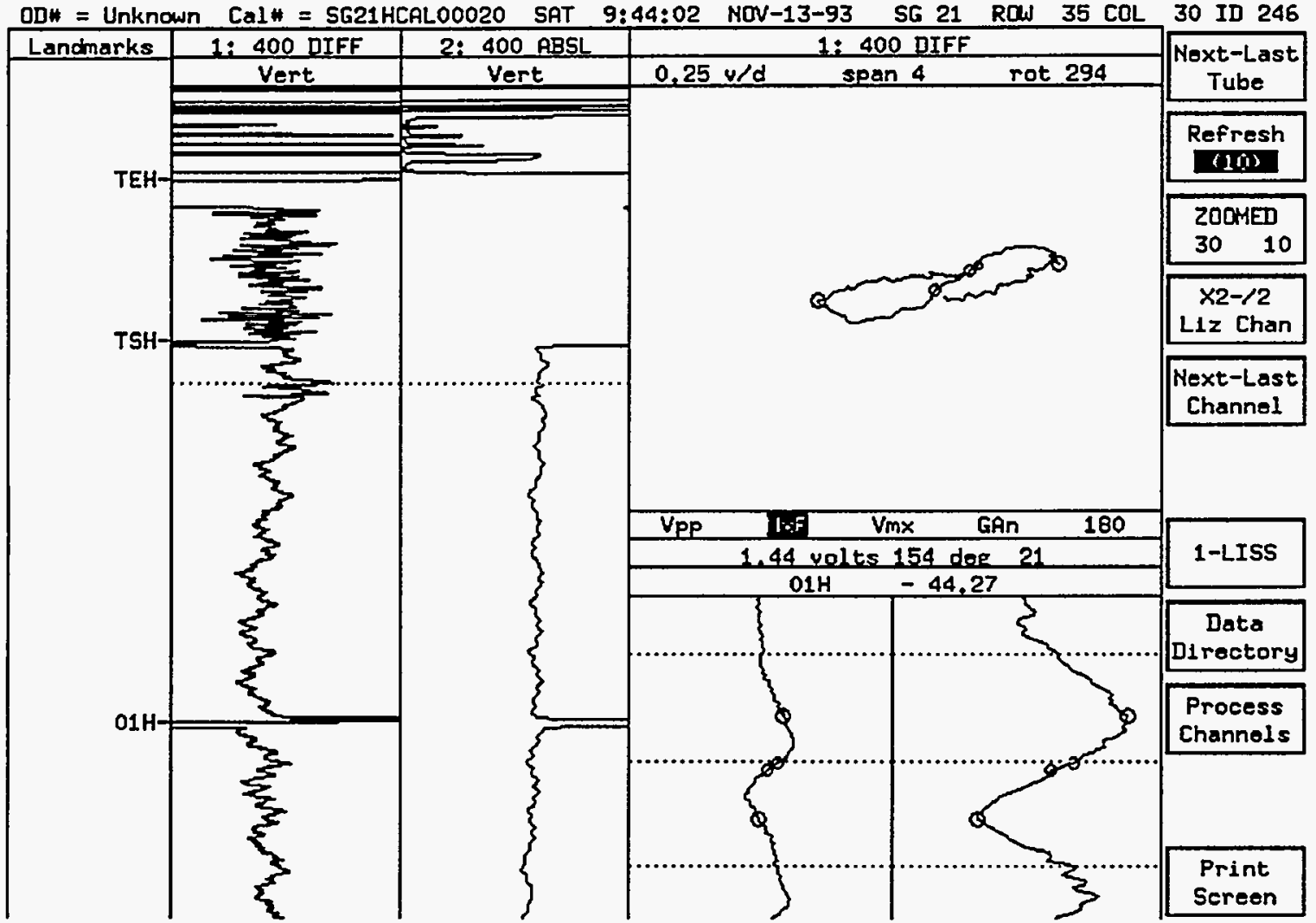

Figure 12 Bobbin probe scan of tube row 35 column 30 using Zetec Eddynet software 


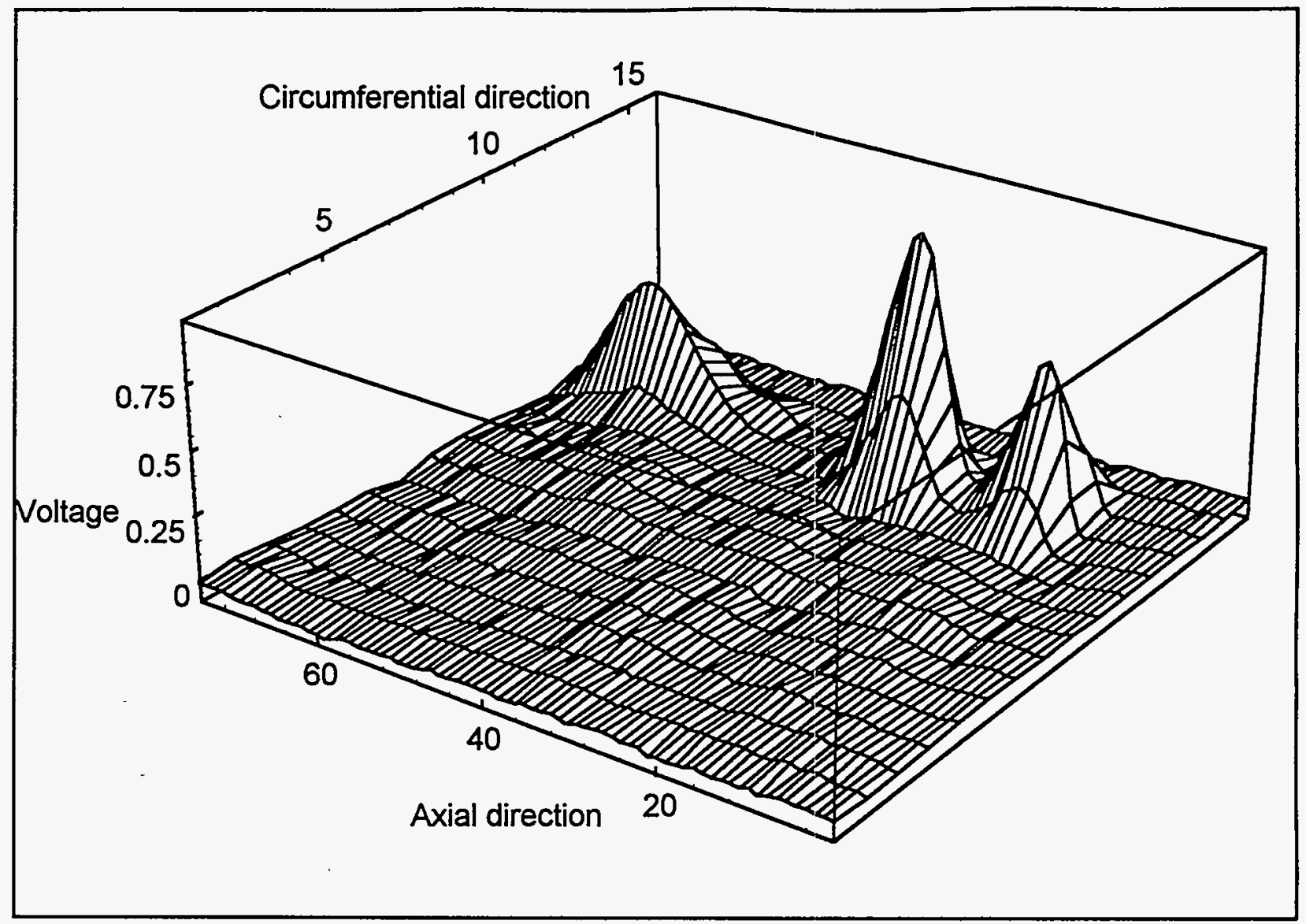

Figure 13 Pancake array scan of tube Row 35 Column 30 showing three indications 


\section{Speed trial studies}

Near the end of the test, a special production test was run. In order to simulate the production inspection conditions, two adjacent tubes from the test group were selected. The probe was inserted in one tube after the other, alternating between the tubes. This simulated the conditions that would obtain if the tubes were being tested by going in a straight line down a row of tubes. A total of 17 inspections were performed at a rate of 68 seconds per tube or 53 tubes per hour for inspection of 30 feet of tubing. In these tests the insertion speed was limited to 15 inches per second due to mechanical problems. An insertion speed of 40 inches per second would improve the inspection rate by 20 percent to 68 tubes per hour. The array probes were tested at a pull speed of 15 inches per second, which is about 75 times faster then the pull speed $(0.2$ inches per second) of the RPC. At this pull speed there was more than adequate resolution.

\section{Prairie Island test results for array probes - second test}

The second test at Prairie Island was conducted on the steam generators of Unit 1 on Saturday, May 29, 1994. The plan was to perform an eddy-current test on selected tubes using the contaminated pancake and reflection array probes that had been stored at the plant since they were used in the inspection of Unit 2 in November 1993. Uncontaminated probes and cables were sent directly to Prairie Island from Zetec (where our MIZ-30 had been upgraded). Upon its arrival, the instrument was checked out with both types of array probes. The reflection probe exhibited a "touch effect", in which the signal changed if the connectors were touched. This had been noticed during development and checkout at Zetec, and it was found that if the connectors were wrapped in bubble padding, the effect disappeared.

One of the channels of the pancake array probe was not working. This probe had been tested at Zetec and all of the channels had been working properly then. The problem was traced to one of the extension cables (two are required for the pancake array probes) and this cable was repaired. A Conam technician examined the connectors and said that one of them was not wired well. He repaired the lead and broke two more in the process and then fixed those. The probes were then tested, and it was found that all channels were working. The data obtained on standard runs looked very good for both probes, and the signal-to-noise ratio appeared to be about the same for the reflection and pancake array probes.

There was a delay of several days due to problems in getting access to the generators, problems in setting up for the production eddy-current inspections, and problems in data acquisition over the network used for these tests. The problems were finally resolved, but only after a delay of several days. The ORNL inspection, which came at the end of the other eddycurrent tests, was delayed from Monday until 3:00 a.m. Saturday.

During this time extensive testing and mixing with both types of array probes were performed. One important discovery was that a better mix was obtained if the ferrite ring was placed directly against the tube support ring, to simulate magnetite adjacent to the support. The mixes obtained using this showed very little residual and very little distortion of the $20 \%$ defect. Preliminary results using the Zetec mix showed that scans of the actual tube had very little 
residual, and that small defects at the tube supports could be easily detected. The ORNL analysis program would not run on the data due to an upgrade that Zetec had made in their software.

Fifty tubes were selected to be tested with both the reflection and pancake array probes.

Our acquisition window was only 12 hours, which included the time necessary to make modifications to the pusher-puller and the time required to run the cable. We used a ten foot twister cable and a 50 foot extension cable for both probes. The data were evaluated at Prairie Island by the Conam analysts. The data from Unit 1, which is older than Unit 2, showed many more magnetite deposits. The pancake array probe had one channel missing. It was not possible to tell if the missing channel was due to another broken connection in the extension cable or if the contaminated array probe used in the previous inspection had a broken coil. Due to the fact that we already had problems with the extension cable we decided not to contaminate our spare probe. Therefore, the test of the pancake array probe was run with only 15 of the 16 coils working. In spite of the high cost of extension cables, future inspections should be performed with at least one spare set of all cables and probes.

We did not experience as much difficulty in getting the pusher-puller to drive the cable as we had at the first inspection. In addition, the computer (a Hewlett Packard 700 series workstation) used was fast enough to take the data and send it to the analysis building in very near real time. While the program did abort twice at the start of the test, for the remainder of the test we had no problems. However, we experienced problems with the SM-22 positioner. It seemed to lose its location on the generator after about the first hour of testing. This required extensive time to locate plugs and other artifacts to verify the position of the tubes. It is possible that some of the tubes scanned were not the ones indicated, although the operators used every reasonable precaution.

Several valuable lessons were obtained from the tests at a small cost to our programs. The new MIZ-30 appears to give good, low-noise data. We were able to copy the setup file for the MIZ-30 acquisition which had been prepared earlier from an optical disk into the proper directory (named /miz30d) on the acquisition computer and rename it so that it was used for the acquisition. It would have been faster to do this over the LAN, but the operator who knew how to do it was not on duty at the time. Copying the setup file saved a great deal of time that would have been required to type in the proper settings and also reduced the chances of making an error. However, the setup for the individual coils in the array probe did not match since we used the old, contaminated probes that were used in the last outage rather than the similar but not identical ones that were used for testing before the inspection. The setup for the individual channels is obtained from the acquisition header, and if the correct individual values are used, that data analyst does not have to reset these. With 16 coils for each of the four frequencies, the setup time can be considerable using the Zetec software. Any mixes that are used require considerable time with the Zetec software. The scan of the tubing in the generator had a larger lift-off variation than we encountered in the scans of the standard, which made the data appear noisy at first. When the proper adjustments were made, the problem was corrected.

The ORNL analysis program was modified to match the new Zetec acquisition format and the data were analyzed at ORNL. In general, the array probes were able to detect all of the defects that the bobbin and RPC inspections showed. Figure 14 shows the vertical component of the reflection array probe data taken at $260 \mathrm{kHz}$ at tube support $01 \mathrm{H}$ of tube R43C59 in steam 
generator 12. The dark horizontal band across the plot is the tube support, and the bright spot near the center of the graph appears to be a defect. Figure 15 shows the same data with the tube support suppression mix applied. Here we see that the dark band representing the tube support has been eliminated while the bright spot has been amplified, indicating that it is indeed a defect. 


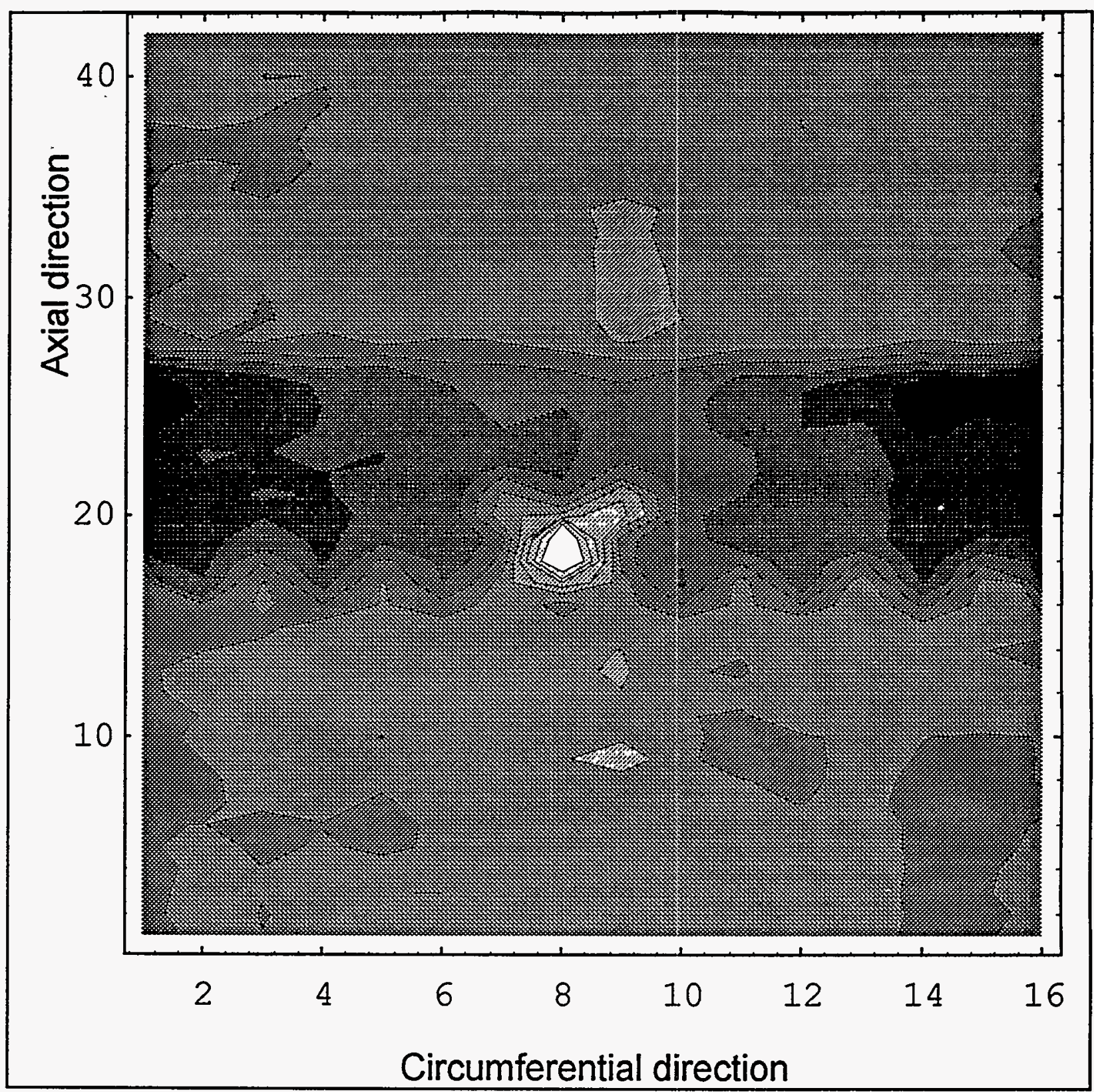

Figure 14 The vertical component of the $260 \mathrm{kHz}$ data from the reflection array probe at tube support $01 \mathrm{H}$ in tube R43C59 in steam generator 12 . 


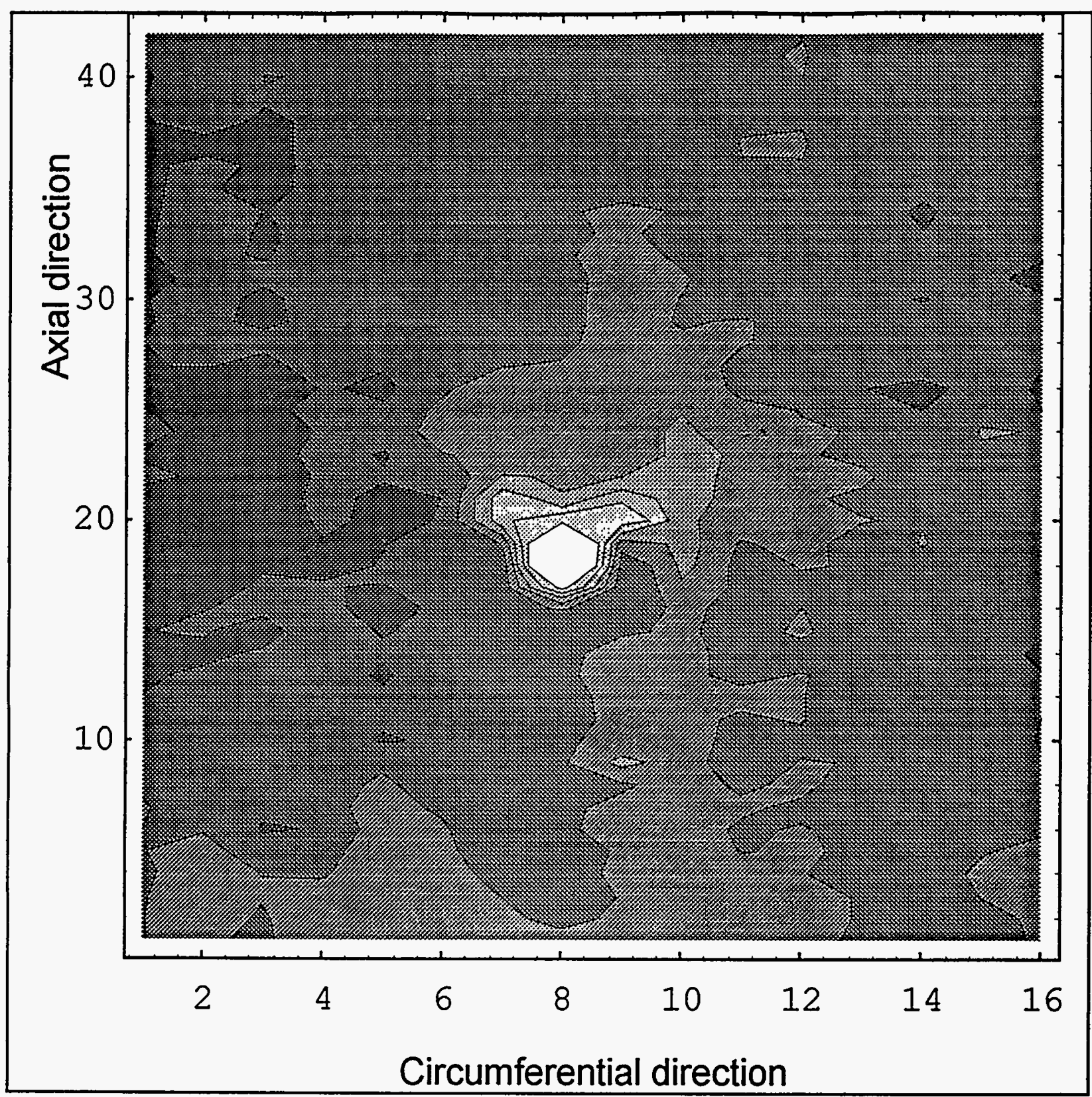

Figure 15 The vertical component of the $260 \mathrm{kHz}$ reflection array probe data from tube support $01 \mathrm{H}$ in tube R43C59 of steam generator 12 with the tube support suppression mix applied. 
APPENDIX A 


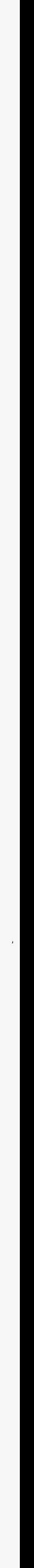




\section{Appendix A: Computation of eddy-current signals for a pancake coil}

The program IMPTST.F calculates the impedance change of a pancake coil in response to a defect in a flat plate. The program is very similar to ones described in an earlier report. The program is listed below.

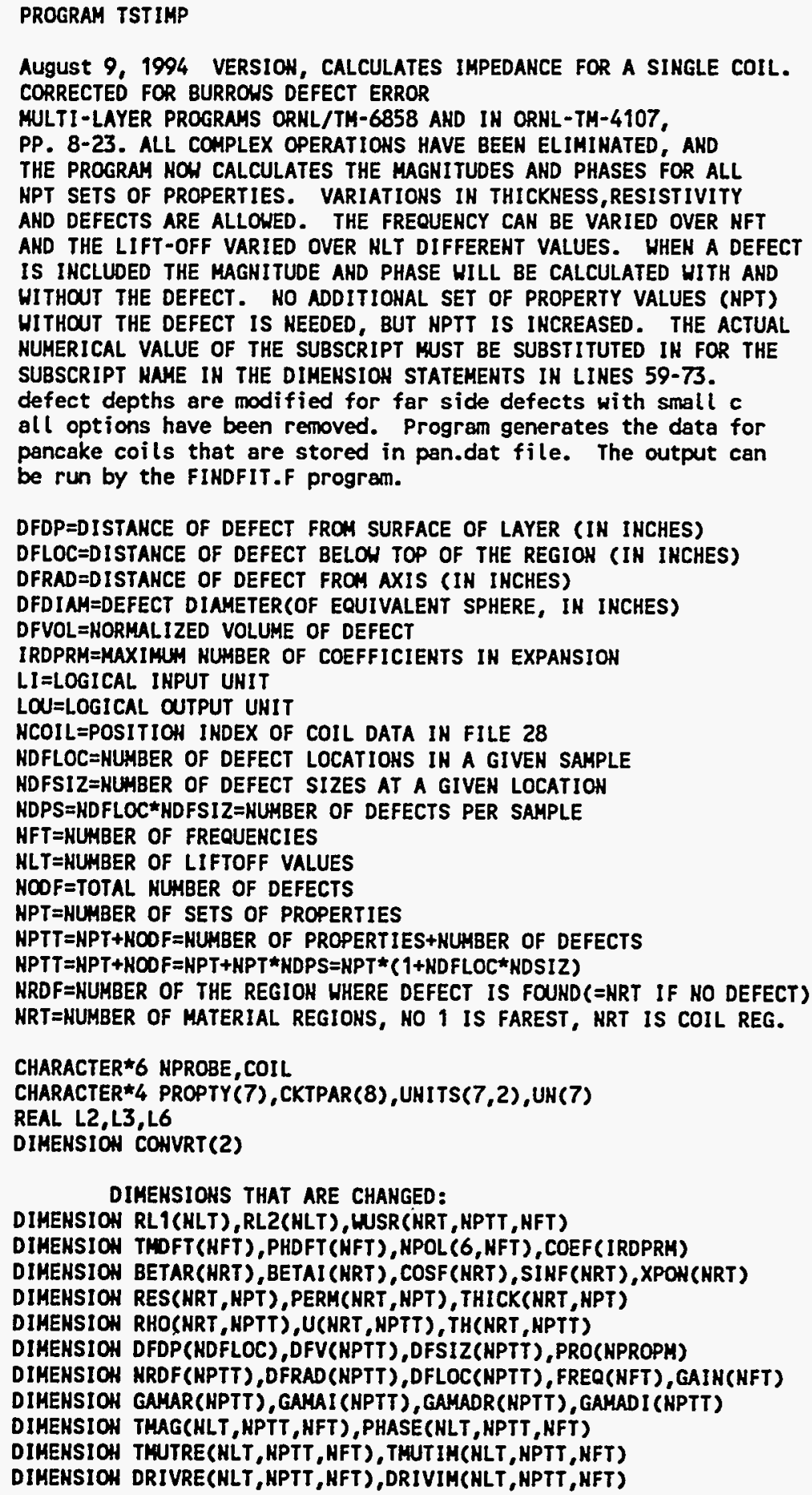




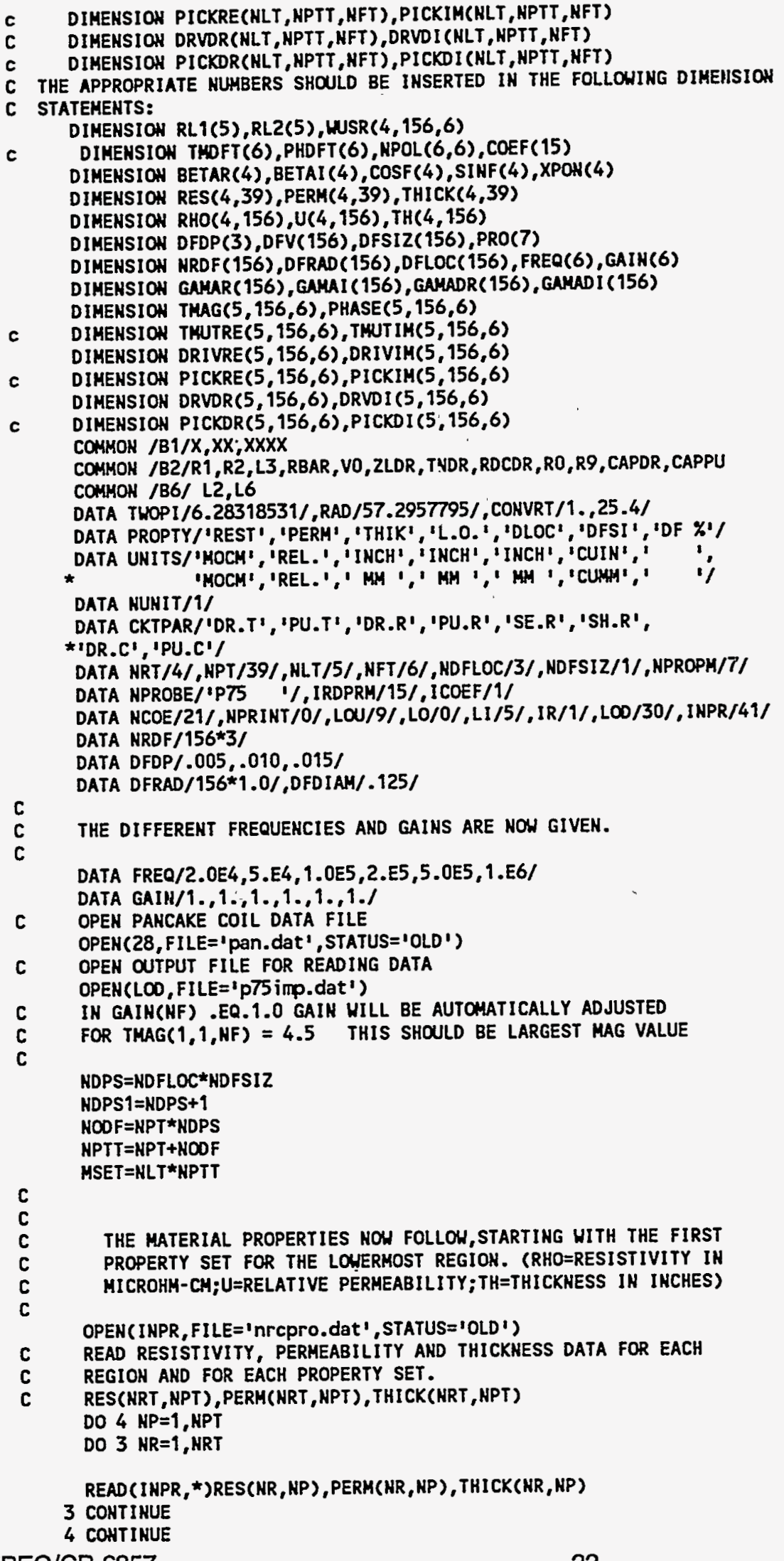


C RES(KRT, HPT), PERH(KRT, NPT), THICK(NRT, NPT)

C TIME AKD DATE ARE PRIHTED

1 continue

c 1 CALL GETTIM(IHR, IMK, ISE,IFR)

c CALL GETDAT(IYR,IMO,IDA)

c IYR=IYR-1900

2 FORMAT('TSTIMP COIL $', 16)$

WRITE(LOU, 2)HPROBE

WRITE $(L 0,2)$ HPROBE

URITE(LO, 865) NFT, MSET, NPROPH, HPTT

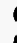

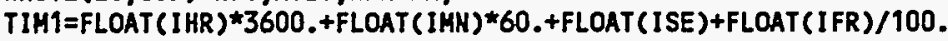

THE IHPUT DATA FOR THE PARAMETERS OF THE COILS

ARE READ FROH FILE 28. SEE FIG.2, P.4

AND FIG.4, P.7, ORHL-TM-4107, FOR DEFINITIONS.

10 READ $(28,11)$ COIL, RBAR, R1 , R2 , L3, L6, RDCDR , THDR

11 FORMAT $(A 6,5 \mathrm{FB} .4, \mathrm{F1O} .4, \mathrm{FB} .1)$

c 12 WRITE(0,11)COIL, RBAR, R1,R2,L3, L6, RDCDR, TKDR

IF(COIL.EQ.'END ')URITE(O,*)' COIL NOT FOUND:

IF(COIL.EQ.'END ')GO TO 900

IF(COIL.NE. HPROBE)GO TO 10

C

L2=HORMALIZED LIFTOFF IKCREMENT.

$L 2=.008 /(R B A R \star F L O A T(H L T-1))$

C

THE CIRCUIT PARAMETERS ARE HOW GIVEN.

RO=DRIVER SERIES RESISTAHCE(OHMS)

R9=PICKUP SHUNT RESISTAKCE(OHMS)

CAPDR=DRIVER SHUNT CAPACITAHCE(FARADS)

CAPPU=PICKUP SHUNT CAPACITAKCE(FARADS)

VO=DRIVER OUTPUT VOLTAGE(RMS VOLTS)

$R 0=40$.

$R 9=1 . E 6$

CAPDR $=8.0 E-10$

CAPPU $=8.0 E-10$

VO $=3.535$

C

SET UP PROPERTIES FOR THE INTEGRATION

CHVT $=$ CONVRT $($ HUHI $T$ )

DINORM $=$ DFDIAM/RBAR

VOLFAC $=$ DIHORM*DIHORM*DINORM $/ 8$.

DFVOL=THOPI *VOLFAC/1.5

DO 15 NS=1, NPT

DO 15 HD $=1$, NDPS 1

$M P=($ NS - 1) *NDPS $1+N D$

DO 15 NR=1, NRT

$R H O(H R, N P)=R E S(N R, H S)$

$T H(H R, N P)=T H I C K(N R, N S)$

$U(H R, H P)=P E R M(N R, H S)$

IF(NR.NE.NRDF(NP)) GO TO 15

IF (ND.EQ.1) DFV(HP) $=0$.

IF(ND.EQ.1) GO TO 15

C $\quad$ DFLOC (NP) $=D F D P(N D-1)$

C DEFECT IS LOCATED FROH THE BACK SIDE OF REGION NRDF(NP)

DFLOC $(N P)=T H(H R, N P)-D F D P(N D-1)$

C DFV(NP) $=(2 \star D F L O C(N P) / R B A R) \star \star 3 \star T W O P I / 12$.

C DEFECT IS A 0.125 DIA HOLE HITH SEN FACT CALCULATED AT 1/2 DEPTH $\operatorname{DFV}(N P)=(2 * D F D P(N D-1) * .012272) /(R B A R) \star \star 3$ 15 CONTINUE

c

COMPUTE RECIPROCALS FOR LATER USE, TO AVOID DIVISIONS INSIDE LOOPS.

20 RRBAR $=1 . /$ RBAR 
THE PERMEABILITY IS CHANGED TO SORT(.5)/U(N) AHD THE THICKMESS IS CHANGED TO TH(N)*U(H)/RBAR.

DO $30 \mathrm{MP}=1$, NPTT

IF(NPRINT.HE.O) WRITE(LOU,25)

25 FORHAT (1X)

DO $30 \mathrm{NR}=1$, HRT

$T H(H R, N P)=U(N R, H P) * T H(H R, H P) \star R R B A R$

$U(N R, N P)=.707106781 / U(N R, M P)$

IF(HR.ME.NRDF(NP)) GO TO 30

DFLOC (NP) $=.70710678 q$ DFLOC(NP) *RRBAR/U(NR, NP)

C

DFRAD (HP) $\Rightarrow$ DFRAD (NP)*RRBAR DFRAD IS ALREADY NORMALIZED

30 CONTINUE

THE IHTEGRATION IS PERFORMED BY THE MIDPOINT METHOD, EVALUATING AT THE CENTER OF THE IHTERVAL; FOR $X$ LARGE THE INTEGRAL CONVERGES RAPIDLY,SO LARGER INTERVALS

ARE TAKEN.

IH THE INTEGRATION DRIVER IMPEDANCE AND AIR 1 ARE CALCULATED.

Si $=0.01$

$S 2=5.0$

$B 1=0.0$

$B 2=S 2$

C

C

INITIALIZE ALL SUMS TO ZERO AND CALCULATE THE VALUES OF WUSR(HR, MP, NF).

DO $50 \mathrm{NF}=1, \mathrm{NFT}$

$R C O N=.360198724 * R B A R * R B A{ }^{*}$ FREQ(NF)

DO $50 \mathrm{NP}=1$, NPTT

DO $40 \mathrm{NL}=1, \mathrm{NLT}$

c

c THUTIH(NL, NP, NF $)=0$.

DRIVRE(NL, NP, NF) $=0$.

DRIVIH(NL, NP, NF) $=0$.

c $\quad$ PICKRE(NL,NP,NF $)=0$.

c PICKIM(NL, HP , NF) $=0$.

$\operatorname{DRVDR}(N L, N P, N F)=0$.

DRVDI $(N L, N P, N F)=0$.

C $\quad \operatorname{PICKDR}(\mathrm{NL}, \mathrm{NP}, \mathrm{HF})=0$.

c $\quad \operatorname{PICKDI}(\mathrm{NL}, \mathrm{NP}, \mathrm{NF})=0$.

40 CONTINUE

DO $50 \mathrm{NR}=1$, NRT

50 CONTINUE

UUSR (HR , HP , NF) $=R C O N /(R H O(H R, H P) \star U(N R, N P))$

AIR $1=0$.

C $\quad$ AIR2 $=0$.

$6011=(B 2-B 1) / S 1$

$X=B 1-S 1 * 0.5$

DO $70 I=1, I 1$

$x=x+51$

$x x=x^{\star x} x$

$\mathrm{XXXX}=\mathrm{XX} \mathrm{X}^{\star} \mathrm{XX}$

CALL DCOIL(S1, NLT, NPYT, NRT, HFT, RL1, RL2, GAMAR, GAMAI

1 , GAMADR , GAMADI ,ORIVRE, DRIVIM, DRVDR, DRVDI, BETAR

2, BETAI , COSF, SINF , XPON, WUSR ,U, TH, NRDF ,DFRAD, DFLOC, FREQ,AIR1)

70 CONTIMUE

$B 1=B 2$

$B 2=B 2+S 2$

S1 $=0.05$

IF (X.LT. 9.) GO TO 60

si $=0.1$

IF (X. LT. 29.) GO TO 60

$S 1=0.2$

IF (X .LT. 39.) GO TO 60 


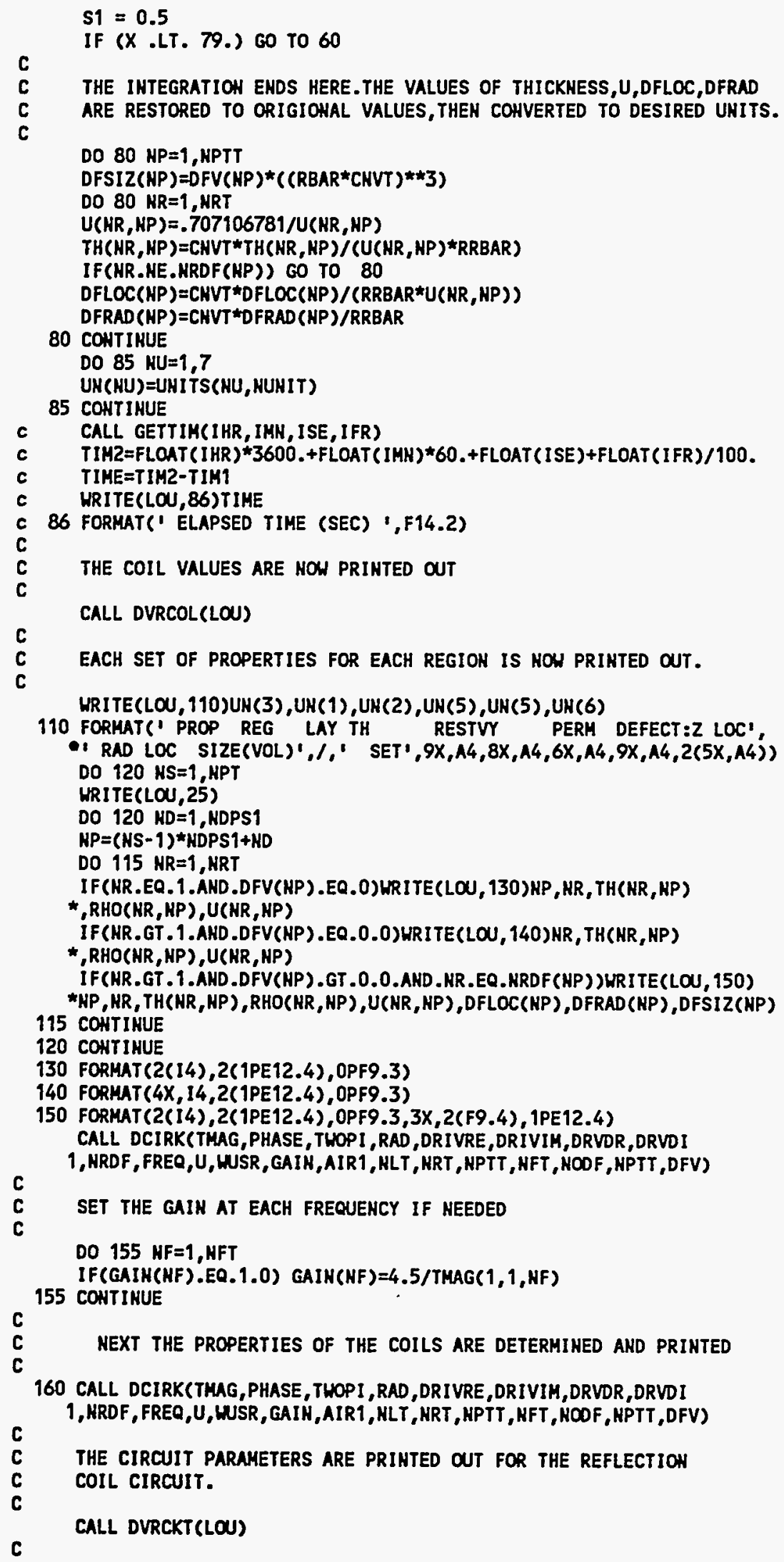


C WRITE IHITIAL INFORMATION IN DIRECT ACCESS FILE LOO ON DISK

C

MRITE $(L \infty, 855)$ HPROBE

855 FORMAT (A6)

URITE(LOO, 865) NFT, MSET, HPROPH, NPTT

865 FORMAT $(4(1 \mathrm{X}, 15))$

MRITE(LO0,870)(FREQ(NF), HF=1, HFT)

WRITE(LO0,870)(GAIN(NF), NF=1, NFT)

870 FORMAT(6) 1PE12.4)

WRITE(LO0,875) (PROPTY(HPR), HPR=1, HPROPH)

875 FORMAT $(7(1 X, A 4))$

C SET REGION FOR WHICH WE WILL. WRITE PROPERTY VALUES NREG $=3$

DO $830 \mathrm{HP}=1$, HPTT

DO $820 \mathrm{HL}=1, \mathrm{NLT}$

$M=(N P-1) * N L T+N L$

PRO(1) $=$ RHO(NREG , NP)

PRO(2) $=U($ HREG , HP)

PRO (3) $=$ TH (NREG, NP)

PRO(4) $=($ FLOAT $(N L-1) * L 2) * R B A R * C H V T$

c PRO(5) $=D F L O C(N P)$

C FIT DEFECT DEPTH FRON THE BACKSIDE

PRO(5) $=$ TH (NREG, HP) -DFLOC (HP)

IF(DFLOC (HP) .EQ.O.)PRO(5) $=0$.

$P R O(6)=D F S I Z(H P)$

c $\quad P R O(7)=100^{\star} D F L O C$ (NP)/TH(HREG, HP)

$P R O(7)=100 *(T H(N R E G, H P)-D F L O C(N P)) / T H(H R E G, N P)$

IF (DFLOC(HP) .EQ.O.)PRO(7) $=0$.

WRITE(LOD, 840) (TMAG(NL,NP, NF), PHASE(NL, NP, NF), NF=1,NFT),

*(PROC $(H), K=1, N P R O P M)$

820 CONTINUE

830 COHTINUE

C 840 FORMAT( $3(F 7.4,1 X, F 8.2,1 X), 7(F 8.4,1 X))$

840 FORMAT $(6(F 7.4,1 X, F 8.2,1 X), 7(F 8.4,\{X))$

900 STOP

END

C

SUBROUTINE DCIRK (TMAG, PHASE, TWOPI, RAD, DRIVRE, DRIVIM, DRVDR, DRVDI

1 , NRDF , FREQ U, WUSR, GAIN , AIR1, NLT , NRT, NPT , NFT , NODF, MPTT , DFV)

c

C COMPUTES MAGNITUDES AND PHASES OF OUTPUT VOLTAGE

C FOR VARIOUS PROPERTIES, FREQUENCIES AND LIFTOFFS.

C DIMENSION THAG(NLT, NPTT, HFT), PHASE(HLT, NPTT, HFT),

*U(NRT, NPTT), WUSR (NRT, MPTT, NFT), NRDF (NPTT), FREQ(NFT), GAIN(NFT),

$\star_{D R I V R E}(N L T, N P T T, N F T), D R I V I M(N L T, H P T T, N F T), D R V D R(H L T, N P T T, N F T)$,

^DRVDI (NLT, HPTT, NFT), DFV(NPTT)

COMMON /B2/R1,R2,RL3, RBAR, VO,ZLDR, THOR , ROCDR , RO,R9, CAPDR, CAPPU

C $T 1=T$ TDR/ $((R 2-R T) * R L 3)$

$T 2=T H P U /((R 4-R 3) * R L 4)$

COLFAC $=1.0027518 E-7 *$ RBAR

DVRFAC $=$ COLFAC*T $1 * T 1$

cC PICFAC=COLFAC*T2*T2

c ZHUTFC=COLFAC*T1*T2

ZLDR=DVRFAC*AIR1

c ZLPU=PICFAC*AIR2

DO $100 \mathrm{MF}=1, \mathrm{HFT}$

$U=T W O P I$ I FREQ $(N F)$

DVRF $=D V R F A C * U$

C PICF $=$ PICFAC $* W$

c ZMUTF=ZNUTFC*H

$Q T=V O * R Q * G A I N(N F)$

$X 1=W * R 0 * C A P D R$

$X 2=W * R 9 * C A P P U$

Z1Z2RE $=X 1 * X 2-1$.

$2122 I M=-x 1-x 2$

DO $60 \mathrm{HP}=1$, $\mathrm{NPTT}$

$D E F=-.1193662 * D F V(N P) * W U S R(N R D F(N P), N P, N F) * U(N R D F(N P), N P)$ 
Do $50 \mathrm{NL}=1, \mathrm{NLT}$

c ZHUR=ZHUTF* (THUTRE(NL,NP,NF)+DEF*(DRVDR(HL, MP, MF)*

ॠPICKDI (NL, NP, NF)+PICKDR(NL, NP, HF)*DRVDI $(H L, N P, H F))$ )

ZMUI =ZHUTF* (THUT IM(NL, NP, NF)-DEF* (DRVDR(NL,NP, NF)*

*PICKDR(NL,HP, HF)-DRVDI (HL, HP, NF)*PICKDI(NL,NP, HF )))

ZDRR =-DVRF* (DRIVIK(NL, NP, HF)-DEF*(DRVDR(NL, NP, NF)*

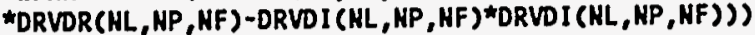

ZORI=DVRF* (DRIVRE (HL, HP, HF $)+A I R 1+2 * D E F *$

*(DRVDR(NL, HP, HF)*DRVDI (NL, HP, MF)))

THAG $(H L, H P, H F)=G A I H(N F) * S Q R T(Z D R R * Z D R R+Z D R I * Z D R I)$

PHASE (NL NP, NF) $=$ RAD* (ATAH2(ZDRI, ZDRR))

50 CONTINUE

60 CONTINUE

100 COHTINUE

RETURH

END

C

SUBROUTIHE PRFVLT(LOU, THAG, PHASE, NRT, NPT, MFT, NLT, NODF, NPTT, RLI, *HRDF, FREO,GAIH)

C PRINTS OUT THE MAGHITUDES AND PHASES FOR THE DIFFERENT PROPERTY SETS, FREQUENCIES AND DEFECTS.

REAL L2,L6

DIMENSIOH RL1(NLT), THAG(NLT, NPTT, NFT), PHASE(NLT,NPTT,NFT)

DIMENSIOH HRDF(HPTT), FREO(NFT), GAIH(NFT)

COMHON /BG/ LR,LG

RL. $Y(1)=L 6$

DO $10 \mathrm{HL}=2$, HLT

$R L 1(N L)=R L 1(H L-1)+L 2$

10 CONTIKUE

DO $110 \mathrm{HF}=1$, NFT

WRITE(LOU,190)

WRITE(LOU,150) FREQ(NF),GAIN(NF)

WRITE(LOW, 160)(RLI(NL), KL=1, HLT)

KRITE(LOU, 165)

DO $100 \mathrm{NP}=1$, MPT

WRITE(LOU, 170) NP, (TMAG(NL, HP, NF), NL $=1, N L T)$

HRITE(LOU, 180) (PHASE (HL, NP , HF), HL =1, NLT)

WRITE(LOU, 190)

100 COHTINUE

110 CONTINUE

150 FORMAT(' FREQUENCY ', 1PE13.5,' GAIN ', 1PE13.5)

160 FORMAT( 1 PROP LFT OF $1,9(F 9.4)$ )

165 FORMAT (' SET')

170 FORHAT(1X,15, 1 MAG $1,9(F 9.4))$

180 FORHAT(' PHA $1,9(F 9.3)$ )

190 FORMAT ( $1 X)$

RETURN

END

$c$
$c$
$c$
$c$

SUBROUTIMES FOR THE MULTI LAYER DESIGN PROGRAMS FOR COIL IMPEDAMCE

SUBROUTIHE GAMAML (13 JULY 1977)

SUBROUT IHE GAMAKL (NRT, MPT, NP, MFT, HF ,BETAR, BETAI , COSF, SIHF , XPON

1 , WUSR , U, TH, GAMAR, GAMAI , GMHADR, GAMADI , DFT, DFR , NRDF)

C

CALCULATES THE GAHMA FACTOR AND THE GAMAD FACTOR FOR AHY GIVEN SET OF MATERIAL PROPERTIES CONSISTIHG FOR PLAHER LAYERS WITH ARBITRARY RESISTIVITIES, THICKNESSES, AHD DEFECTS.

DIMENSION BETAR(HRT),BETAI (HRT), COSF(HRT),SINF(HRT), XPOH(HRT)

DIMENSION WUSR (NRT, HPT, HFT), U(NRT, NPT), TH(NRT, NPT)

DIMENSIOW GAMAR(HPT), GAMAI (MPT), GAHADR (NPT), GAMADI (NPT), DFT (NPT)

1,DFR(NPT), HRDF(NPT)

C

A MATERIAL UITHOUT A DEFECT IS CALCULATED 
40 CALL CPXOOT(GAMAR(NP), GAMAI (HP), VIR, V1I, VZR, V2I)

CALL CPXOOT (GAMADR (NP) , GAMADI (NP), VDR, VOI , VZR, V2I) RETURH

END

C

VIHITM SUBROUTINE (13 JULY 1977)

SUBROUTIHE VINITMSNSRT, HRT, NPT, MP , BETAR, BETAI , V1R, V1I , V2R, VZI

1 , VDR, VDI ,NRDF, COSD , SIND, XPOND)

C SUBROUTINE TO CALCULATE THE INITIAL VIJ MATRIX

C AHD TRANSFORM TO REGION HSRT+1.

DIMENSION MRDF(NPT), BETAR (NRT), BETAI(NRT)

MR $=$ HSRT

NSC $=N R+1$

V1R $=$ BETAR (HSC) - BETAR (NR)

VII $=$ BETAI (HSC)-BETAI (NR)

VZR=BETAR (NSC)+BETAR (NR)

V2I =BETAI (HSC)+BETAI (HR)

IF(HR.EQ.NRDF(NP)) GO TO 50

VDR $=0.0$

VDI $=0.0$

RETURN

50 VDR $=(B E T A R(N S C) *$ COSD $+B E T A I(H S C) * S I H D) * 2 / X P O N D$

VDI $=(B E T A I(N S C) * C O S D-B E T A R(N S C) * S I N D) * 2 / X P O H D$

RETURN

END

c

SUBROUTINE VAATRMCNSTP, HSRT, NRT, NPT, NP,BETAR, BETAI, COSF, SINF, XPON, IVIR, V1I , V2R, VZI , VDR, VDI , NRDF, COSD, SIND, XPOND)

C TRANSFORMATION FROH REGION NSRT TO REGION NSTP

DIHENSION BETAR(NRT),BETAI (NRT), COSF(NRT),SINF(NRT), XPON(HRT) DIMENSIOH NRDF(NPT)

NR=NSRT

C MAIN LOOP

C DEFINE OLD VALUES AS THE CURRENT VALUE OF VJ2(NP)

20 VIRO=VIR

VIIO=VII

V2RO $=V 2 R$

$\mathrm{V} 210=\mathrm{V} 21$

$$
N S C=N R+1
$$

C DEFINE THE BETA FUNCTIONS AND EXPONENTIAL FUNCTIONS USED IN THE

C TRANSFORHATION CALCULATIONS BETHEEN NR AND HR+1.

$B 1=B E T A R$ ( HSC)+BETAR(NR)

$B 2=B E T A I$ ( $N S C)+B E T A I$ (NR) 
$B 3=B E T A R(N S C)-B E T A R($ HR)

$B 4=B E T A I$ (NSC)-BETAI (HR)

$X P 1=\operatorname{COSF}($ HR)/XPON(HR)

XP2=SIHF (HR)/XPOH(HR)

$X P 3=\operatorname{COSF}(H R) \star X P O H(H R)$

XP4=SIHF (NR) XPON(HR)

C THE REAL \& IM PARTS OF THE TRANSFORHATION MATRIX,TIJ,ARE HOW

C CALCULATED.

$T 11 R=B 1 * X P 1+B 2 * X P 2$

$T 111=B 2 \star X P 1-B 1 \star \times P 2$

$T 12 R=B 3 * X P 3-B 4 * \times P 4$

$T 12 I=B 4 * X P 3+B 3 \star X P 4$

$T 21 R=B 3 * X P 1+B 4^{*} \times P 2$

$T 21 I=B 4 * X P 1-B 3 * X P 2$

$T 22 R=B 1 * X P 3-B 2 * \times P 4$

$T 22 I=82 * X P 3+B 1 * \times P 4$

C

TRANSFORM FROH VJ2(NR) TO VI2(NR+1)

$V 1 R=T 11 R * V 1 R O-T 111 * V 110+T 12 R * V 2 R O-T 12 I * V 210$

$V 1 I=T 111 * V 1 R 0+T 11 R * V 110+T 121 * V 2 R O+T 12 R * V 210$

$V 2 R=T 21 R * V 1 R O-T 21 I * V 110+T 22 R * V 2 R O-T 22 I * V 210$

$V 2 I=T 21 I * V 1 R O+T 21 R * V 1 I 0+T 22 I * V 2 R O+T 22 R * V 210$

IF(HR.LT.NRDF(HP)) GO TO 50

IF(NR.GT.NRDF(HP)) GO TO 40

C IHITIAL VDR, VDI CALCULATIOH IN THE DEFECT REGION

TGF $1=\operatorname{COSF}($ KR $) * \operatorname{COSD}+\operatorname{SIHF}($ HR $) * S I H D$

$T G F 2=\operatorname{COSF}(H R) * S I H D-S I H F(H R) * \operatorname{COSD}$

XP $1=X P O N D / X P O H(H R)$

VOR $=\left(V 1 R O * T G F 1-V 110^{*} T G F 2\right) * X P 1+(V 2 R O * T G F 1+V 210 * T G F 2) / X P 1$

VDI $=\left(V 1 R O * T G F 2+V 110^{*} T G F 1\right) * X P 1-\left(V 2 R 0^{*} T G F 2-V 210^{*} T G F 1\right) / X P 1$

C

CALCULATIONS FOR REGIONS ABOVE THE DEFECT.

40 VDRO $=$ VDR

VDIO=VDI

VDR=2*(BETAR(HSC)*VDRO-BETAI (HSC)*VDIO)

VDI $=2 \star(B E T A I$ (HSC) *VDRO+BETAR (NSC)*VDIO)

C INCREMENT REGIOH COUHT \&EXIT IF WE HAVE REACHED THE STOP (NSTP) REG.

$50 \quad H R=N R+1$

IF (NR.LT.NSTP) GO TO 20

RETURN

EHD

C

C SUBROUTIHE BETAM (13 JULY 1977)

SUBROUTIHE BETAMCHR, NRT, NP, NPT, NF, MFT, BETAR, BETAI , COSF, SIHF, XPON 1 ,WUSR, U, TH, COSD, SIND, XPOHD,DFT,NRDF)

DIMENSION BETAR(HRT),BETAI (HRT), COSF (HRT), SIHF(HRT), XPOH(HRT)

DIMENSIOH WUSR (HRT, MPT, HFT),U(NRT, HPT), TH(HRT, NPT)

DIMEHSION DFT (NPT), MRDF (HPT)

COHAON $/ B 1 / X, X X, X X X X$

C START BETA CALCULATIONS AT UPPERMOST REGIOH AND WORK DOWN

C AHAY FROM COIL.

HR= HRT

BETAR(HR) $=X$

BETAI (NR) $=0$.

C SET EXPOHEHT SUH TO ZERO AHD START CALCULATING BETAS. SUMEXP $=0$.

$20 \mathrm{HR}=\mathrm{HR}-1$

BETAR (HR $)=U(N R, H P) * S Q R T(X X+S O R T(X X X X+W U S R(H R, H P, N F) * W U S R(N R, N P, N F$

1)))

BETAI (NR $)=U(H R, N P) * U(N R, N P) * W U S R(N R, N P, N F) / B E T A R(H R)$

If (NR.EQ.1) GO TO 50

$X T H=B E T A R(H R)$ *TH(HR, HP)

SUMEXP $=S U M E X P+X T H$

IF (SUMEXP.GT.20.) GO TO 40

$X P O H(H R)=\operatorname{EXP}(X T H)$

$\operatorname{COSF}(H R)=\cos (B E T A I(N R) * T H(H R, H P))$

$\operatorname{SIHF}($ HR $)=\operatorname{SIH}(B E T A I(H R) \star T H(H R, H P))$

IF (NRDF(NP).HE.NR) GO TO 20

$25 \times P O H D=E X P\left(B E T A R(N R){ }^{*} D F T(N P)\right)$ 
$\operatorname{COSD}=\operatorname{COS}(B E T A I($ (AR)*DFT $($ NP $))$

$\operatorname{SIND}=\operatorname{SIN}(B E T A I(N R) * D F T(N P))$

IF(NR.NE.1) GO TO 20

40 RETURH

C

CALCULATE THE DEFECT VALUES IF IT IS IH REgION 1.

50 IF(NRDF (NP).EQ. 1)GO TO 25

RETURH

END

c

DCOIL (June 23, 1988)

SUBROUTIHE DCOILCS1, NLT, NPT, NRT, NFT, RL1, RL2, GAMAR, GAMAI

1, GAMADR, GAMDI ,DRIVRE, DRIVIM, DRVDR,DRVDI, BETAR

2,BETAI, COSF, SINF, XPON, WUSR,U, TH,HRDF,DFR,DFT, FREQ, AIR1)

DIMENSION BETAR(NRT), BETAI (NRT), COSF(NRT),SINF(NRT), XPON(NRT)

DIMENSIOH WUSR(NRT, NPT, NFT),U(NRT, NPT), TH(NRT, NPT)

DIMENSION RLI(NLT), RL2(NLT), HRDF(NPT),DFR(NPT),DFT(NPT), FREQ(NFT)

DIMENSION GAMAR(NPT), GAMAI (HPT), GAMADR (NPT), GAMADI (NPT)

1,DRIVRE(HLT, NPT, NFT), DRIVIM (NLT, HPT, NFT), DRVDR (HLT, HPT, HFT)

2,DRVDI (NLT, NPT, NFT)

REAL $13, L 2, L 6$

COHMON $/ B 1 / X, X X, X X X X$

COWMON /B2/R1,R2,L3, RBAR, VO,ZLDR, TNDR, RDCDR, RO,R9,CAPDR, CAPPU

COHMOH /B6/ L2,L6

CALCULATION OF THE COIL PART OF THE INTEGRAND. SUBPROGRAM FOR FOR PANCAKE TYPE COILS.

SUBROUTIKE BESSEL EVALUATES THE INTEGRAL OF

THE PRCOUCT OF THE BESSEL FUHCTION J1(X) AND ITS

ARGUNEHT, $X$.

CALL BESSEL (XJR2, $X, R 2)$

CALL BESSEL (XJR1, $X, R 1)$

c

CALL BESSEL (XJR4,X,R4)

C CALL BESSEL (XJR3, $X, R 3)$

$D 21=X J R 2-X J R 1$

$D 43=X J R 4-X J R 3$

$56=S 1 * 043$

$s 3=s 6 * 021$

$S 7=S 1 * 021$

$S 4=S 1 * D 21 * D 21$

c

$55=56 * 043$

$\operatorname{EX3}=\operatorname{EXP}\left(-X^{\star} L 3\right)$

$M 1=1 .-E X 3$

$\operatorname{EX4}=\operatorname{EXP}\left(-X^{\star}(4)\right.$

$H 2=1 .-E X 4$

EX5 $=\operatorname{EXP}(-X * L 5)$

$W 3=E X 3 /\left(E X 4{ }^{\star} E X 4 \star E X 5 \star E X 5\right)$

UPDATE OF AIR VALUES

$A I R 1=A I R 1+(S 4+S 4) *(X * L 3-W 1)$

$Q 3=X * L 4-W 2$

AIR2 $=A I R 2+(S 5+S 5) \star(03+Q 3-W 2 * W 2 * W 3)$

BYPASS THE UPDATE OF MUTUAL IHDUCTANCE QUANTITIES FOR LARGE $X$.

IF (X .GT. 30.0) GO TO 200

$\operatorname{EX1}=\operatorname{EXP}(-X \star L 2)$

$\operatorname{EX7}=\operatorname{EXP}\left(-X^{\star} L 6\right)$

EX2 $=E X 1 * E X 1$

EX6 $=E \times 7 * E \times 7$

c $\quad W=9 .-E X 4 * W 3$

$W 6=E \times 6^{*} * 1$

c $\quad W 7=E X 5 * W 2 * W 4$

NUREG/CR-6357 


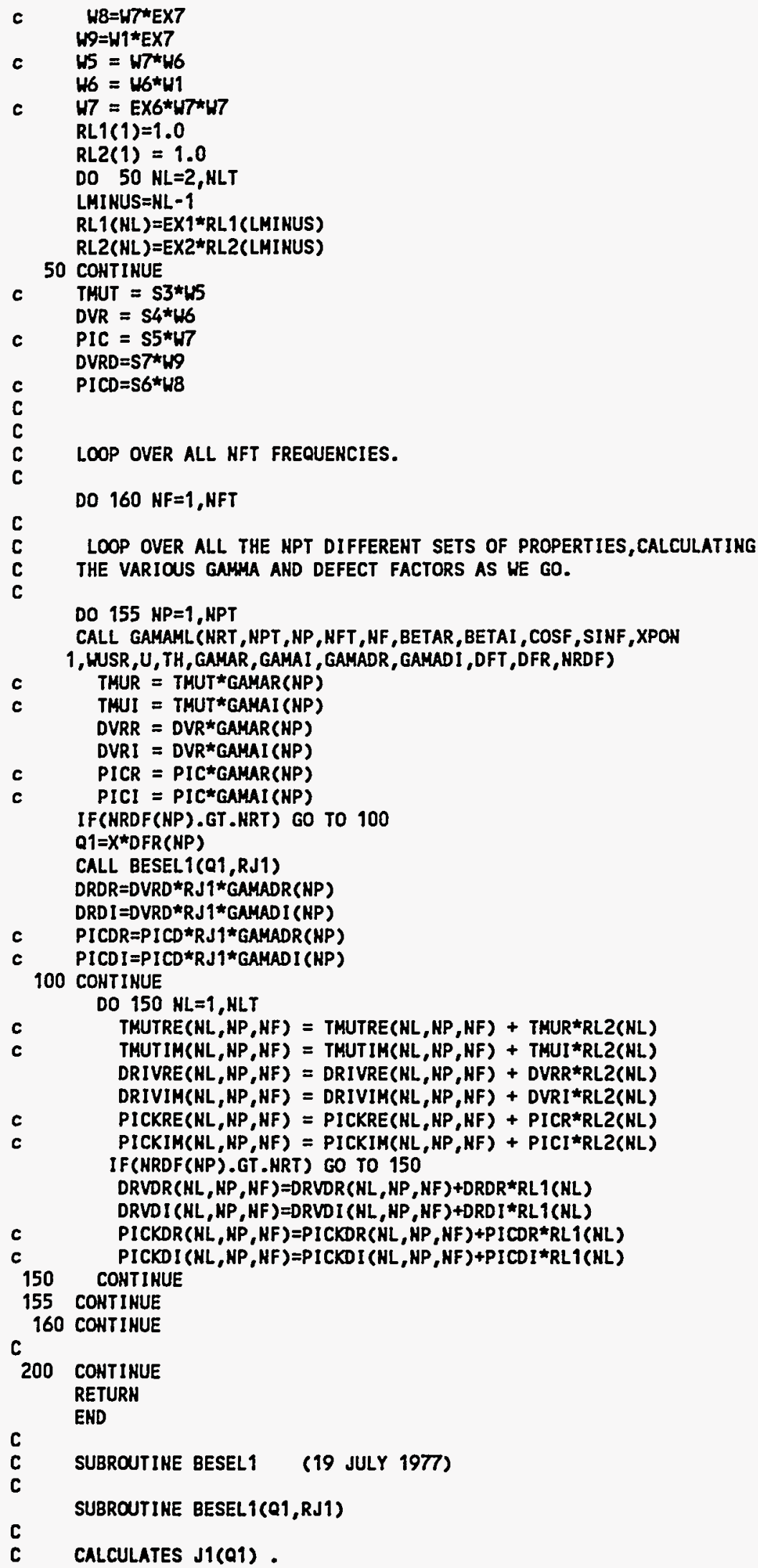


IF(Q1.GT.3) GO TO 20

Q1S=01*01

Q2S $=((2.1 E-11 * 01 S-5.38 E-9) * 01 S+6.757 E-7) * 01 S-5.42443 E-5$

$Q 2 S=((Q 2 S * 01 S+2.60415 E-3) * 01 S-6.25 E-2) * 01 S+.5$

RJ1 $=01 * 02 S$

RETURN

20 03S=(( $-.14604057 / 01+.27617679) / 01-.20210391) / 01+4.61835 E-3) / 01$

$03 S=((03 S+.14937) / 01+4.68 E-6) / 01+.79788456$

$04 S=(((-.21262014 / 01+.19397232) / 01+6.022188 E-2) / 01-.17222733) / 01$

$04 S=((04 S+5.085 E-4) / 01+.37498836) / 01-2.35619449+01$

RJ1 $=035 * \cos (Q 4 S) / S Q R T$ (Q1)

RETURH

END

$c$

SUBROUTINE DVRCOL

(20 JULY 1977)

SUBROUTINE DVRCOL(LOU)

c

SUBROUTINE TO PRINT OUT THE REFLECTION COIL PARAMETERS.(20 JULY 7 )

REAL L2,L3,L6

COHAON $/ B 2 / R 1, R 2, L 3$, RBAR, VO, ZLDR, TNDR , RDCDR , RO, R9, CAPDR , CAPPU

CONHON /B6/ L2,L6

WRITE(LOU,50)RBAR

WRITE(LOU,60)

URITE(LOU, 70)R1,R2, L3, THDR, L6

c

URITE(LOU,80)R3, R4,L4, TNPU, 15

URITE(LOU,90)

50 FORMAT('MEAN RADIUS ',F12.5,' IHCHES; NORMALIZED COIL DIMENSIONS')

60 FORMAT(' COIL INN. RAD OUT. RAD LENGTH TURIIS EA

10 LIFT OFF')

70 FORMAT(' DRIVER ', 3(F12.4),F12.1,F14.4)

C 80 FORMAT(' PICK-UP $1,3(F 12.4), F 12.1, F 14.4$ )

90 FORMAT(1X)

RETURN

END

c

C SUBROUTIHE DVRCKT (20 JULY 1977)

C

SUBROUTINE DVRCKT(LOU)

REAL L3

COHHOW /B2/R1,R2,L3, RBAR, VO, ZLDR, TNDR, RDCDR , RO , R9, CAPDR , CAPPU

$W L C D R=1 . /$ SQRT (ZLOR*CAPDR)

C HLCPU $=1 . /$ SART (ZLPU*CAPPU)

WRITE(LOU,50)

WRITE(LOU, 60)RO, RDCDR, CAPDR, ZLDR, HLCDR, VO

c

URITE(LOU, 70)R9, RDCPU, CAPPU, ZLPU, HLCPU

URITE(LOU,80)

50 FORHATS

i RES.FREQ DRIV VOLT ')

60 FORHATS' DVR CKT ',2(F12.3),3(1PE11.4), OPF11.4)

C 70 FORHAT(' PICK CKT',2(F12.3),3(1PE11.4), OPF11.4)

80 FORMAT( $1 \mathrm{X}$ )

RETURH

END

C
CPXQOT SUBROUTIHE
(18 MAY 1977)

SUBROUTINE CPXQOT (GAMR, GAMI, V12R, V12I, V22R, V22I)

C CALCULATES THE COMPLEX QUOTIENT OF V12/V22, WHICH IS THE GAMMA

C FACTOR

Q4 $=\mathrm{V} 221 / \mathrm{V} 22 \mathrm{R}$

$Q 3=1 . /(V 22 R+V 22 I * Q 4)$

$04=-03 * 04$

GAMR $=V 12 R * 03-V 12 I * Q 4$

GAMI $=V 12 R * Q 4+V 12 I * 03$

RETURH

NUREG/CR-6357 


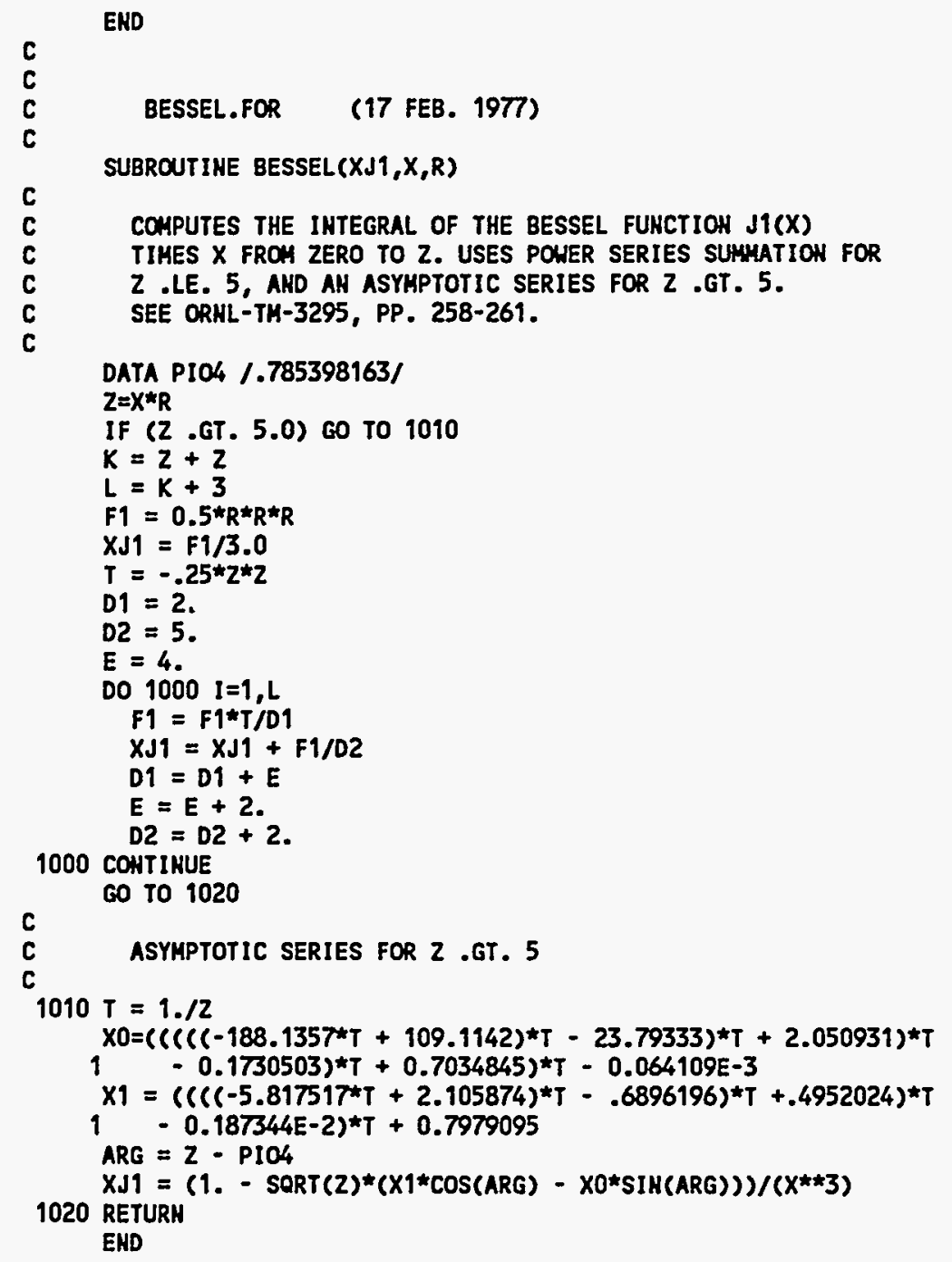



APPENDIX B 


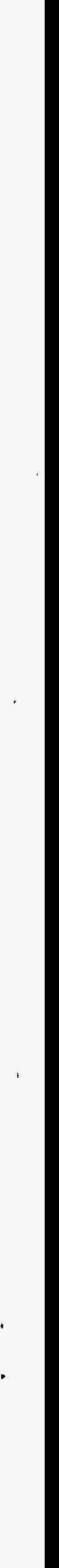




\section{Appendix B: Computation of eddy-current signals for a reflection coil}

Program MULRFD.F calculates the voltage change induced in a reflection coil by a defect in a flat plate. The program has been described in an earlier report. It is listed below.

\section{PROGRAM NRCRFD1}

September 21, 1994 VERSIOH, CORRECTED FOR BURROUS DEFECT ERROR MULTI-LAYER PROGRAHS ORHL/TH-6858 AND IN ORNL-TM-4107, PP. 8-23. ALL COMPLEX OPERATIOHS HAVE BEEH ELIHIHATED, AHD THE PROGRAM HOW CALCULATES THE MAGNITUDES AND PHASES FOR ALL HPT SETS OF PROPERTIES. VARIATIOHS IH THICKNESS, RESISTIVITY AHD DEFECTS ARE ALLOWED. THE FREQUENCY CAN BE VARIED OVER NFT AHD THE LIFT-OFF VARIED OVER NLT DIFFERENT VALUES. WHEN A DEFECT IS IHCLUDED THE MAGNITUDE AKD PHASE WILL BE CALCULATED WITH AKD WITHOUT THE DEFECT. HO ADDITIONAL SET OF PROPERTY VALUES (NPT) HITHOUT THE DEFECT IS MEEDED, BUT APTT IS IHCREASED. THE ACTUAL NUMERICAL VALUE OF THE SUBSCRIPT MUST BE SUBSTITUTED IN FOR THE SUBSCRIPT HAME IN THE DIMENSION STATEMENTS IH LINES 59-73. defect depths are modified for far side defects with small c all options have been removed, and calculated data is stored. properties are read from a data file rather than put in program

DFDP=DISTAKCE OF DEFECT FROH SURFACE OF LAYER (IN INCHES) DFLOC $=D I S T A H C E$ OF DEFECT BELON TOP OF THE REGION (IH INCHES) DFRAD=DISTAHCE OF DEFECT FROH AXIS (IN IHCHES) DFDIAM=DEFECT DIAMETER(OF EQUIVALENT SPHERE, IN INCHES) DFVOL=NORMALIZED VOLUME OF DEFECT LI=LOGICAL INPUT UNIT LOU=LOGICAL OUTPUT UHIT HCOIL=POSITION IHDEX OF COIL DATA IN FILE 28 NDFLOC=NUHBER OF DEFECT LOCATIONS IN A GIVEN SAMPLE RDFSIZ=HUMBER OF DEFECT SIZES AT A GIVEN LOCATION NDPS=NDFLOC*NDFSIZ=NUMBER OF DEFECTS PER SAMPLE NFT =NUMBER OF FREQUENCIES MLT $=$ HUMBER OF LIFTOFF VALUES NODF=TOTAL NUMBER OF DEFECTS NPT $=$ HUMBER OF SETS OF PROPERTIES $M P T T=N P T+H O O F=N U M B E R$ OF PROPERTIES+NUMBER OF DEFECTS $N P T T=N P T+N O O F=N P T+H P T * K D P S=N P T *(1+H D F L O C * N D S I Z)$ HRDF=NUMBER OF THE REGION HHERE DEFECT IS FOUND(=HRT IF NO DEFECT) NRT=NUHBER OF MATERIAL REGIOHS, NO 1 IS FAREST, HRT IS COIL REG.

CHARACTER $* 6$ NPROBE, COIL

CHARACTER 44 PROPTY (7), CKTPAR( $(8), U N I T S(7,2), U N(7)$

REAL L2,L3,L4,L5,L6

DIMENSION COHVRT(2)

DIMENSIOHS THAT ARE CHANGED:

DIMEHSION RL1(NLT), RL2(NLT), WUSR(NRT, HPTT, NFT)

DIMEHSIOH TMDFT(HFT), PHDFT (NFT), NPOL (6, KFT)

DIMENSION BETAR(NRT), BETAI (NRT), COSF (NRT), SINF(NRT), XPOH(HRT)

DIMEHSIOH RES(HRT, HPT), PERM(HRT, HPT), THICK(HRT, HPT)

DIMENSIOH RHO(NRT, HPTT), U(NRT, HPTT), TH(NRT, HPTT)

DIMEHSIOH DFDP(HDFLOC),DFV(HPTT), DFSIZ(HPTT), PRO(HPROPH)

DIMENSIOH HRDF(HPTT),DFRAD(HPTT),DFLOC(HPTT), FREQ(NFT), GAIH(HFT)

DIMEHSIOH GAMAR (HPTT), GNMAI (HPTT), GAMADR (HPTT), GNMADI (NPTT)

DIMENSIOH TMAG(NLT, NPTT, NFT), PHASE (HLT, HPTT, HFT)

DIMENSION THUTRE (NLT, NPTT, NFT), TMUTIM(NLT, NPTT, NFT)

DIMENSIOH DRIVRE(NLT, HPTT, HFT), DRIVIM(NLT, HPTT, HFT)

DIMENSION PICKRE (HLT, NPTT, HFT), PICKIM(HLT, MPTT, NFT)

DIMEHSION DRVDR(NLT, HPTT, HFT), PICKDR (NLT, HPTT, HFT)

DIMENSION DRVDI (HLT, HPTT, HFT), PICKDI (NLT, NPTT, MFT) 
DIMENSION THOFT $(6), \operatorname{PHDFT}(6), \operatorname{NPOL}(6,6)$

DIMENSION BETAR(4), BETAI (4), $\operatorname{COSF}(4), \operatorname{SINF}(4), X P O N(4)$

DIMEHSIOH RES $(4,39)$, PERH $(4,39)$, THICK $(4,39)$

DIMEHSIOH RHO $(4,156), \mathrm{U}(4,156), \operatorname{TH}(4,156)$

DIHENSIOH DFDP(3),DFV(156),DFSI2(156),PRO(7)

DIMENSION MRDF(156),DFRAD(156), DFLOC (156), FREQ(6), GAIN(6)

DIMENSION GAMAR(156), GAMAI (156), GAMADR(156), GAMADI (156)

DIMENSION TMAG $(5,156,6)$, PHASE $(5,156,6)$

DIMENSION TMUTRE $(5,156,6)$, TWUTIM $(5,156,6)$

DIMENSION DRIVRE $(5,156,6)$, DRIVIM $(5,156,6)$

DIHENSIOH PICKRE $(5,156,6)$,PICKIM $(5,156,6)$

DIMENSION DRVDR $(5,156,6), \operatorname{PICKOR}(5,156,6)$

DIMENSION DRVDI $(5,156,6), \operatorname{PICKDI}(5,156,6)$

COMON $/ B 1 / X, X X, X X X X$

COWMON $/ 82 / R T, R 2, R 3, R 4, L 3, L 4, R B A R, V O, Z L D R, Z L P U$,

-TNDR, TNPU, RDCDR, RDCPU, RO, R9, CAPDR, CAPPU

COMMON /B6/ L2,L5,L6

DATA TWOPI/6.28318531/,RAD/57.2957795/,CONVRT/1.,25.4/

DATA PROPTY/'REST', 'PERM', 'THIK', 'L.O.' ', 'DLOC', 'DFSI', 'DF $\%$ '/

DATA UNITS/'MOCM: 'REL.' IINCH', INCH', IHCH', 'CUIN',

DATA NUNIT/1/

DATA CKTPAR/'DR.T', 'PU.T', 'DR.R', 'PU.R', 'SE.R', 'SH.R',

"DR.C', 'PU.C'/

DATA NRT/4/,NPT/39/,NLT/5/,NFT/6/,NDFLOC/3/,NDFSIZ/1/,NPROPH/7/

DATA MPROBE/'RB3D $\%$

DATA NPRIHT/O/,LOU/O/,LO/O/,LI/5/,IR/1/,LOO/30/,IMPR/41/

DATA NRDF/156*3/

DATA DFDP/.005, .010,.015/

DATA DFRAD/156*0.832/,DFDIAH/.125/

THE DIFFERENT FREQUENCIES AND GAINS ARE NOW GIVEN.

DATA FREQ/2.0E4,5.E4,1.0E5,2.0E5,5.0E5,1.0E6/

DATA GAIN/1.,1.,1.,1.,1.,1.1

OPEN (28, FILE $=$ ' ref .dat' , STATUS $=$ ' OLD' $)$

C

OPEH OUTPUT FILE FOR URITING DATA

OPEN(LOO, FILE= ' r83dref.dat')

C IN GAIN(NF) EQ.1.0 GAIN WILL BE AUTOMATICALLY ADJUSTED

C FOR $\operatorname{TMAG}(1,1, \mathrm{NF})=4.5$ THIS SHOULD BE LARGEST HAG VALUE

C

NDPS $=$ HDFLOC* $*$ NDSIZ

KDPS $1=$ KDPS +1

NOOF $=$ NPT $*$ NDPS

NPTT $=$ NPT + NODF

MSET $=$ NLT*NPTT

C

c

C READ RESISTIVITY, PERMEABILITY AND THICKMESS DATA FOR EACH

C REGION AMD FOR EACH PROPERTY SET.

C RES(HRT, HPT), PERM(NRT, NPT), THICK(NRT,NPT)

DO $4 \mathrm{NP}=1$, NPT

DO 3 NR=1,NRT

READ (INPR *)RES(

WRITE(LO, *)HP, NR, RES (NR, NP), PERH(NR , NP), THICK(NR, NP)

3 CONTINUE

4 CONTIMUE

C PROGRAM NAME AND COIL TYPE ARE PRINTED OUT

1 CONTINUE

2 FORMAT('HRCRFDI COIL ',A6) 


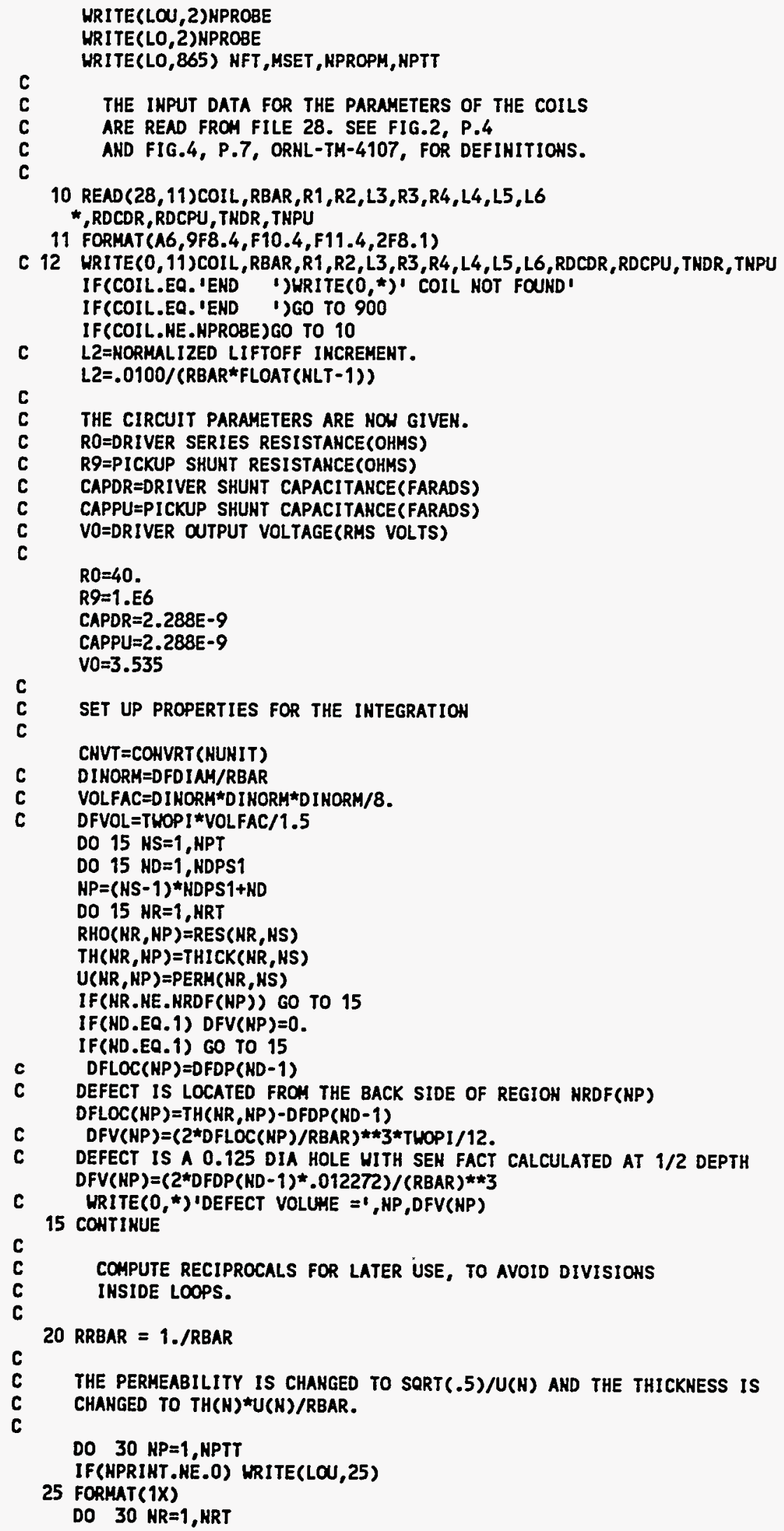


$T H(N R, H P)=U(N R, H P) * T H(N R, H P) * R R B A R$

$U(N R, N P)=.707106781 / U($ HR, NP)

IF(HR. HE. KRDF(HP)) GO TO 30

DFLOC $(H P)=.707106781 * D F L O C(H P) * R R B A R / U(H R, H P)$

DFRAD(NP) =DFRAD (HP)*RRBAR DFRAD IS ALREADY NORHALIZED 30 CONTINUE

$$
\begin{array}{ccc}
\vdots \\
\vdots \\
\vdots \\
\vdots \\
\vdots \\
\vdots
\end{array}
$$

THE INTEGRATION IS PERFORHED BY THE MIDPOINT METHOD, EVALUATING AT THE CENTER OF THE IHTERVAL; FOR $X$ LARGE THE INTEGRAL CONVERGES RAPIDLY, SO LARGER IHTERVALS ARE TAKEN.

IN THE IHTEGRATION THUT, DRIVER, PICKUP, AIR1, AKD AIR2 ARE CALCULATED.

$$
\begin{aligned}
& s 1=0.01 \\
& s 2=5.0 \\
& B 1=0.0 \\
& B 2=s 2
\end{aligned}
$$

C

\section{INITIALIZE ALL SUMS TO ZERO AND CALCULATE THE VALUES OF} WUSR(NR,NP,NF).

C

DO $50 \mathrm{HF}=1$, HFT

$R C O N=.360198724 * R B A R * R B A R * F R E Q(N F)$

DO $50 \mathrm{HP}=1$, MPIT

DO $40 \mathrm{NL}=1, \mathrm{NLT}$

TMUTRE (NL, NP, NF) $=0$.

THUT IM(NL, HP , NF $)=0$.

DRIVRE (NL, MP, NF) $=0$.

DRIVIM(NL, HP, HF) $=0$.

PICKRE(NL, HP, MF ) $=0$.

PICKIH(NL, HP, HF $)=0$.

$\operatorname{ORVDR}(N L, N P, N F)=0$.

DRVDI (NL, NP, NF) $=0$.

PICKDR (NL , HP , NF) $=0$.

40 CONTINUE

PICKDI (NL, NP,NF) $=0$.

DO 50 MR= 1 , NRT

50 CONTINUE

$\operatorname{HSR}(N R, H P, N F)=R C O N /(R H O(N R, N P) \star U(N R, H P))$

AIR1 $=0$.

C

AIR2 $=0$.

$6011=(B 2-B 1) / S 1$

$X=81-51 * 0.5$

DO $70 I=1,11$

$x=x+51$

$x x=x \star x$

$X X X X=X X^{\star} X X$

CALL RFCOLHCS1, HLT, MPTT, NRT, NFT, RL1, RL2, GAMAR, GAMAI

1, GAMADR, GAMADI , TMUTRE, THUTIM, DRIVRE, DRIVIH, PICKRE, PICKIM

2,DRVDR, DRVDI ,PICKDR , PICKDI , BETAR, BETAI , COSF, SIHF, XPON

C

3,WUSR,U, TH, NRDF, DFRAD ,DFLOC,AIRI,AIRZ)

70 CONTINUE

$\mathrm{B} 1=\mathrm{B2}$

$\mathrm{B} 2=\mathrm{B2}+\mathrm{S2}$

s1 $=0.05$

IF (X.LT. 9.) 60 TO 60

$s 1=0.1$

IF (X .LT. 29.) GO TO 60

si $=0.2$

IF (X.LT. 39.) GO TO 60

$s 1=0.5$

IF (X.LT. 79.) G0 TO 60

C

C THE INTEGRATION ENDS HERE.THE VALUES OF THICKMESS,U,DFLOC,DFRAD

C ARE RESTORED TO ORIGIOHAL VALUES, THEN COHVERTED TO DESIRED UHITS. 
C

DO $80 \mathrm{NP}=1, \mathrm{NPTT}$

DFSIZ(NP) $=$ DFV $(N P) \star((R B A R * C N V T) * * 3)$

DO 80 HR $=1$, HRT

$U(N R, N P)=.707106781 / U(N R, H P)$

TH( $(N R, H P)=C N V T * T H(N R, H P) /(U(H R, N P) * R R B A R)$

IF(HR. HE. HRDF(HP)) GO TO 80

DFLOC(NP) $=C H V T * D F L O C(N P) /(R R B A R * U(N R, N P))$

DFRAD $(K P)=C N V T$ DFRAD (HP) $/$ RRBAR

80 CONTINUE

$D O 85 \mathrm{NU}=1,7$

UH(NU) $=$ UHITS (NU, NUHIT)

85 CONTIMUE

c

C

THE COIL VALUES ARE MON PRIHTED OUT

CALL PRFCOLCLOU)

c

c

EACH SET OF PROPERTIES FOR EACH REGION IS HON PRINTED OUT.

HRITE(LOU, 110)UN(3),UN(1),UN(2),UN(5),UN(5),UN(6)

110 FORMAT(' PROP REG LAY TH RESTVY PERH DEFECT:Z LOC', * 1 RAD LOC SIZE(VOL)' ' ' ' SET I, 9X,A4, 8X,A4, 6X,A4, 9X,A4, 2(5X,A4))

DO 120 HS $=1$, HPT

WRITE(LOU, 25)

DO $120 \mathrm{MD}=1$, NDPS 1

NP $=($ HS -1 ) * $\mathrm{HDPS} 1+\mathrm{HD}$

DO 115 KR=1, HRT

IF (NR.EQ.1.AKD.DFV(HP) .EQ.0)URITE(LOU, 130)HP, HR, TH(MR,NP)

$\star, R H O(N R, H P), U(H R, N P)$

IF (HR.GT . 1.AHD.DFV(NP).EQ.0.0)HRITE(LOU, 140)HR, TH(NR, NP)

$\star, R H O(N R, H P), U(H R, H P)$

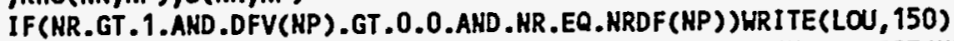

*HP , NR, TH (HR , NP) , RHO(NR, NP) ,U(NR, NP), DFLOC(NP), DFRAD(NP), DFSIZ(NP)

115 CONTIHUE

120 CONTINUE

130 FORMAT(2(14),2(1PE12.4),0PF9.3)

140 FORMAT ( $4 X, 14,2$ (1PE12.4), OPF9.3)

150 FORMAT(2(14),2(1PE12.4), OPF9.3,3X,2(F9.4), 1PE12.4)

CALL RFCIRK(TMAG, PHASE, THOPI, RAD, TMUTRE, TMUTIH, DRIVRE

1,DRIVIM, PICKRE, PICKIM, ORVDR, DRVDI , PICKDR, PICKDI , HRDF, FREO

2,U, WUSR, GAIH, AIRT , AIR2, HLT, HRT, HFT, NPTT, DFV)

C SET THE GAIN AT EACH FREOUENCY IF MEEDED

C

DO $155 \mathrm{MF}=1, \mathrm{HFT}$

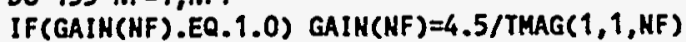

155 CONTINUE

c

C MEXT THE PROPERTIES OF THE COILS ARE OETERMIHED AKD PRINTED

C

160 CALL RFCIRKCTHAG, PHASE, THOPI, RAD, THUTRE, TMUTIM, ORIVRE 1,DRIVIM, PICKRE, PICKIM, ORVOR, DRVDI , PICKDR , PICKDI , HRDF , FREO

$2, U$, WUSR, GAIH, AIRI, AIR2, NLT, NRT, HFT, NPTT, DFV)

C

C THE CIRCUIT PARAMETERS ARE PRINTED OUT FOR THE REFLECTIOH

C COIL CIRCUIT.

CALL PRFCKT(LOU)

C HRITE IHITIAL IMFORMATIOH IH DIRECT ACCESS FILE LOO OH DISK

c

URITE(LOD, 855) MPROBE

855

FORHAT (A6)

WRITE (LOD, 865) HFT, MSET, HPROPH, HPTT

865

FORMAT $(4(1 X, 15))$

WRITE(LOO,870)(FREQ(HF), KF=1, KFT) 
URITE(LOD,870)(GAIH(HF), NF=1, NFT)

870 FORMAT(6(1PE12.4))

URITE(LO0,875)PROPTY(3), PROPTY(4)

875 FORMAT $(7(1 X, \wedge 4))$

C SET REGIOH FOR WHICH WE HILL WRITE PROPERTY VALUES

NREG $=3$

DO 830 NP $=1$, NPTT

DO $820 \mathrm{NL}=1$, NLT

$M=(H P-1) * H L T+H L$.

PRO (1) $=$ RKO (NREG, NP)

PRO(2) $=U($ HREG, HP)

PRO(3) $=$ TH (NREG, NP)

PRO $(4)=($ FLOAT $(N L-1) \star(2) \star R B A R \star C H V T$

C $\quad P R O(5)=D F L O C(N P)$

C FIT DEFECT DEPTH FROH THE BACKSIDE

PRO(5)=TH (MREG, HP) -DFLOC (NP)

IF(DFLOC(HP) .EQ.0.)PRO(5) $=0$.

$P R O(6)=D F S 12(N P)$

c $\quad P R O(7)=100 * D F L O C(N P) / T H(N R E G, N P)$

PRO (7) $=100 *($ TH (NREG, HP) $-D F L O C(N P)) / T H(N R E G, N P)$

IF(DFLOC(NP) .EQ.0.)PRO(7) $=0$.

WRITE(LDO, 840) (TMAG(NL, NP, NF), PHASE(NL, NP, MF), NF=1, HFT),

*(PROCN), N=1, NPROPH)

820 CONTINUE

830 CONTINUE

C 840 FORMAT $(3(F 7.4,1 X, F 8.2,1 X), 7(F 8.4,1 X))$

840 FORMAT $(6(F 7.4,1 X, F 8.2,1 X), 7(F 8.4,1 X))$

900 STOP

END

SUBROUTINE RFCIRK(TMAG, PHASE, THOPI, RAD, TMUTRE, TMUTIM,DRIVRE, *DRIVIM, PICKRE, PICKIM, DRVDR, DRVDI, PICKDR, PICKDI , NRDF, FREQ,

*U,WUSR, GAIN, AIR1, AIR2, NLT, NRT , NFT, NPTT, DFV)

C

C COMPUTES MAGHITUDES AND PHASES OF OUTPUT VOLTAGE

C FOR VARIOUS PROPERTIES, FREQUENCIES AKD LIFTOFFS.

c

DIMENSIOH TMAG(NLT, NPTT, NFT), PHASE(NLT,NPTT, MFT), *U(NRT, NPTT), WUSR (NRT, NPTT, NFT), NRDF (NPTT), FREQ(NFT), GAIN(NFT), *TMUTRE(NLT, HPTT, HFT), TMUTIM(NLT, NPTT, NFT), DRIVRE (HLT, NPTT, NFT), *DRIVIM(NLT, NPTT, NFT), PICKRE (NLT, NPTT, NFT), PICKIM(NLT,NPTT,NFT)

DIMENSION DRVDR (NLT, NPTT, NFT), PICKDR (NLT, NPTT, NFT), DFV(NPTT)

DIMENSION DRVDI (NLT, NPTT, HFT), PICKDI (NLT, NPTT, NFT)

COMON /B2/R1,R2,R3, R4,RL3, RL4,RBAR, VO, ZLDR, ZLPU,

TNDR, THPU, RDCDR, RDCPU, RO, R9, CAPDR, CAPPU

$T 9=T H D R /((R 2-R 1) * R L 3)$

$T 2=T N P U /((R 4-R 3) * R L 4)$

COLFAC $=1.0027518 E-7 * R B A R$

DVRFAC $=$ COLFAC $* T 1 * T 1$

PICFAC $=$ COLFAC*T2*T2

ZHUTFC $=$ COLFAC*T1*T2

ZLDR=DVRFAC*AIR1

ZLPU =PICFAC*AIR2

DO $100 \mathrm{NF}=1, \mathrm{NFT}$

$H=T H O P I \star F R E Q(H F)$

DVRF=DVRFAC*

$P I C F=P I C F A C * U$

ZMUTF=ZMUTFC ${ }^{\star H}$

$Q T=V O * R 9 *$ GAIN(NF)

$X I=W * R 0 * C A P D R$

$X 2=N * R 9 * C A P P U$

$21 Z 2 R E=X 1 * \times 2-1$.

$21221 M=-x 1-X 2$

DO $60 \mathrm{NP}=1$, NPTT

$D E F=-.1193662 * D F V(H P) *$ WUSR (HRDF (NP), NP , NF) *U(HRDF (NP), NP)

DO $50 \mathrm{NL}=1, \mathrm{NLT}$

ZHUR=ZMUTF* (THUTRE(NL, HP, NF)+DEF*(DRVDR(NL, NP, NF)*

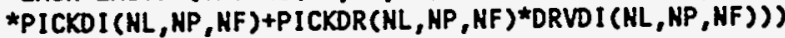


ZWUI =2HUTF* (THUTIM(HL, HP, NF)-DEF* (DRVDR(NL, HP, HF)*

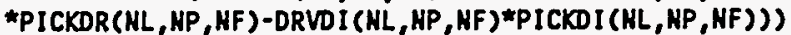
$20 R R=-D V R F \star(D R I V I M(N L, H P, N F)-D E F *$ (DRVR (NL, HP, HF)*

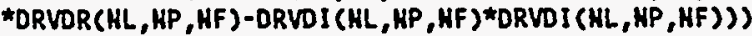

ZDRI =DVRF* (DRIVRE(HL, HP, HF) +AIR1+2*DEF*

* (DRVDR (HL, MP, NF)*ORVDI (NL, NP, MF)))

ZPUR =-PICF* (PICKIHC (ML, HP, HF) $-D E F \star(P I C K D R(N L, H P, H F) *$

*PICKDR(HL, HP , HF)-PICKDI (NL, HP , HF) \#PICKDI(NL,NP, HF)))

$Z P U I=P I C F *(P I C K R E(H L, H P, H F)+A I R 2+2 * D E F *$

*(PICKDR(HL, HP, HF)*PICKDI (HL, HP, HF)))

$Z P R=2 D R R+R D C D R$

$C 1=2 P R * X I+20 R I$

$C 2=X 1 * Z D R I-R 0-2 P R$

$Z P R=2 P U R+R D C P U$

$C 3=2 P R^{\star} \times 2+2 P U I$

$C 4=X 2 \approx Z P U I-R 9-2 P R$

25SQRE $=(2 M N R+Z M U I) *(Z M U R-Z M U I)$

$Z P R=Z M U R \star Z M U I$

$25 S Q I M=2 P R+2 P R$

DEHRE $=2122 R E * Z 5 S$ SQRE $-212214 * Z 5$ SOIM+C1*C3-C2*C4

DEHIM $=2122 R E * 25 S Q I M+21221 M * 25 S Q R E+C 1 * C 4+C 2 * C 3$

$T$ THMRE $=Q T * Z M U I$

$T H M I M=-Q T \star Z M U R$

TMAG(HL, HP ,HF) $=S Q R T((T H H R E \star 22+T H H I M \star \star 2) /(D E N R E \star 2+D E H I M \star \star 2))$

PHASE (NL, MP, HF) $=R A D *$ (ATAH2 (THMIM*DENRE-THMRE*DENIH, THMRE*DEHRE+THMIM*DEHIM)

50 CONTINUE

60 COHTINUE

100 COHTIHUE

RETURH

EHD

c

SUBROUTIHE PRFVLT (LOU, TMAG, PHASE, HFT, HLT, HPTT, RLI, *FREQ, GAIH)

C

PRIMTS OUT THE MAGNITUDES AND PHASES FOR THE DIFFERENT PROPERTY SETS, FREQUENCIES AHD DEFECTS.

REAL L2,L5,L6

DIMENSION RLI(HLT), TMAG(NLT, NPTT, NFT), PHASE(NLT, NPTT, HFT)

DIMENSIOH FREQ(HFT), GAIN(HFT)

COHHOH /B6/ L2,L5,L6

$\mathrm{RL}(1)=\mathrm{L} 6$

DO $10 \mathrm{NL}=2$, NLT

$R L 1(H L)=R L 1(H L-1)+L 2$

10 CONTIHUE

DO 110 NF $=1$, NFT

URITE(LOU, 190)

HRITE(LOU, 150) FREQ(HF), GAIH(HF)

URITE(LOU, 160)(RL1(HL), HL $=1, N L T)$

URITE(LOU, 165)

DO 100 KP $=1$, NPTT

HRITE(LOU, 170) MP, (TMAG(HL, HP, HF), NL $=1, N L T)$

URITE(LOU, 180) (PHÁSE(NL,HP,HF), HL=1, NLT)

URITE(LOU, 190)

100 CONTIHUE

110 COHTINUE

150 FORHAT(' FREQUENCY ',1PE13.5,' GAIN ', IPE13.5)

160 FORMAT(' PROP LFT OF $1,9($ F9.4))

165 FORMAT(' SET')

170 FORMAT(1X,15,1 MAG $1,9(F 9.4))$

180 FORMAT(

190 FORMAT(1X)

PHA 1,9(F9.3)

RETURH

END

C

SUBROUTIMES FOR THE MULTI LAYER DESIGH PROGRAMS FOR REFLECTION TYPE COILS. 
SUBROUTINE GAMAYL(NRT, APT, MP, NFT, NF, BETAR, BETAI, COSF, SIHF ,XPOH 1 , WUSR ,U, TH, GAMAR, GAMAI , GAMADR, GAMADI , DFT , NRDF)

CALCULATES THE GAMHA FACTOR AND THE GAMAD FACTOR FOR ANY GIVEN SET OF MATERIAL PROPERTIES CONSISTIHG FOR PLANER LAYERS WITH ARBITRARY RESISTIVITIES, THICKHESSES, AHD DEFECTS.

DIMENSION BETAR(HRT), BETAI (HRT), COSF (NRT), SIHF(NRT), XPOH(NRT)

DIHENSIOW WSR(NRT, MPT, NFT), U(NRT, HPT), TH (NRT, HPT)

DIMENSION GAMAR(NPT), GAMAI (NPT), GAMADR (NPT), GAMADI (NPT), DFT(NPT)

1. $\operatorname{NRDF}$ (NPT)

C

A MATERIAL WITHOUT A DEFECT IS CALCULATED

AT THE SAME TIME AS THE MATERIAL HITH DEFECTS.

CALCULATE THE BETA VALUES THAT HILL BE USED AND THE LONERMOST REGION THAT HILL BE SEEN BY THE COIL.

CALL BETAM(NSRT, NRT, MP, NPT, NF, NFT , BETAR, BETAI , COSF ,SINF, XPON 1 , WSR,U, TH, COSD,SIHD, XPOHD,DFT, NRDF)

CALCULATE THE INITIAL VALUES OF VI\&V? MATRICES AKD THE DEFECT MATRIX, VD, IF THE DEFECT IS IN THE INITIAL REGION.IT IS SET TO 0 OTHERWISE.

CALL VINITMCHSRT, HRT, NPT, NP, BETAR, BETAI , V1R, V1I , V2R, V2I

1, VDR, VDI ,NRDF, COSD , SIND, XPOND)

HSRT $=$ NSRT +1

IF(NSRT.GE.NRT) GO TO 40

TRANSFORM FROM THE IHITIAL REGION +1 TO THE LAST REGION, NRT.

CALL VHATRMCNRT, NSRT, NRT, NPT, NP, BETAR, BETAI, COSF, SINF, XPON, IVIR, VII , V2R, V2I ,VDR, VDI, NRDF, COSD, SIND , XPOND)

C THE GAMHA FACTORS ARE CALCULATED FROH THE V-MATRICES.

40 CALL CPXQOT (GAMAR(NP), GAMAI (NP), V1R,V1I, V2R,V2I)

CALL CPXOOT (GAMADR (NP), GAMADI (NP), VDR, VDI, V2R, V2I) RETURH

END

C VIHITH SUBROUTIHE (13 JULY 1977)

SUBROUTINE VINITMCHSRT, HRT, NPT, NP, BETAR, BETAI, V1R, V1I, V2R, V2I

1 , VDR, VDI ,NRDF, COSD, SIND, XPOND)

C SUBROUTIHE TO CALCULATE THE INITIAL VIJ MATRIX

C AKD TRANSFORH TO REGION NSRT+ 1 .

DIMENSION NRDF (MPT), BETAR(NRT), BETAI (NRT)

HR=NSRT

NSC $=\mathrm{HR}+1$

$V 1 R=B E T A R(N S C)-B E T A R(N R)$

V1I=BETAI (NSC)-BETAI (NR)

VZR $=B E T A R(N S C)+B E T A R(N R)$

V2I = BETAI (NSC)+BETAI (NR)

IF(HR.EQ.NRDF(NP)) 60 TO 50

VDR $=0.0$

VDI $=0.0$

RETURH

50 VDR $=(B E T A R(H S C) * C O S D+B E T A I(N S C) * S I H D) * 2 / X P O H D$

VDI $=(B E T A I(N S C) * C O S D-B E T A R(H S C) * S I H D) * 2 / X P O N D$

RETURN

END

C

MMATRM SUBROUTINE (13 JULY 1977)

SUBROUTINE VMATRHCHSTP, NSRT, MRT, NPT, NP , BETAR, BETAI, COSF, SINF, XPON, 
1V1R, V11,V2R, V2I, VDR, VDI, NRDF, COSD, SIND , XPOND)

C TRAHSFORMATIOH FROM REGION NSRT TO REGION HSTP DIMENSION BETAR(NRT), BETAI (NRT), COSF (HRT), SINF(NRT), XPON(NRT) DIHENSION RRDF(HPT) HR=NSRT

C MAIN LOOP

c DEFIME OLD VALUES AS THE CURRENT VALUE OF VJ2(NP)

20 VIRO $=$ VIR

V1IO $=V 11$

$\mathrm{V} 2 \mathrm{RO}=\mathrm{V} 2 \mathrm{R}$

V210 $=\mathrm{V} 2$ !

$\mathrm{NSC}=\mathrm{NR}+1$

C DEFINE THE BETA FUMCTIOHS AND EXPONENTIAL FUNCTIOHS USED IH THE

C TRAMSFORMATION CALCULATIOHS BETWEEN NR AND NR+1.

B1=BETAR(NSC)+BETAR(NR)

$B 2=B E T A I($ NSC)+BETAI (NR)

$B 3=B E T A R$ (NSC) -BETAR(NR)

B4=BETAI (NSC) -BETAI (NR)

$X P 1=\operatorname{COSF}(H R) / X P O N(N R)$

XPZ $=S I H F(N R) / X P O N(N R)$

$X P 3=\operatorname{COSF}(H R) * X P O N(N R)$

XP4=SINF(HR)*XPON(NR)

C THE REAL \& IH PARTS OF THE TRANSFORHATIOH MATRIX,TIJ, ARE NON

C CALCULATED.

$T 11 R=B 1 * X P 1+B 2 \star X P 2$

$T 11 \mathrm{I}=\mathrm{B} 2 * \times P 1-\mathrm{B} 1 * \times P 2$

$T 12 R=B 3 * \times P 3-B 4 * X P 4$

$T 12 I=B 4 * X P 3+B 3 * X P 4$

$T 21 R=B 3^{*} X P 1+B 4^{*} \times P 2$

$T 211=B 4^{*} \times P 1-B 3 * X P 2$

$T 22 R=B 1 * \times P 3-B 2 * X P 4$

$T 22 I=B 2 * X P 3+B 1 * X P 4$

C TRANSFORM FROM VJ2(HR) TO VI2(HR+1)

$V I R=T 11 R$ *V1RO-T111*V110+T12R*V2RO-T121*V210

$V 1 I=T 11 I * V 1 R 0+T 11 R * V 110+T 12 I * V 2 R 0+T 12 R * V 210$

$V 2 R=T 21 R * V 1 R O-T 21 I * V 110+T 22 R * V 2 R O-T 22 I * V 210$

$V 2 I=T 21 I * V 1 R O+T 21 R * V 1 I O+T 22 I * V 2 R O+T 22 R * V 210$

IF(NR.LT.HRDF(HP)) GO TO 50

IF(NR.GT.NRDF(NP)) GO TO 40

C INITIAL VDR, VOI CALCULATION IH THE DEFECT REGION

TGF1 $=\operatorname{COSF}($ NR $) * \operatorname{COSD}+\operatorname{SIHF}($ HR $) * S I H D$

TGF2 $=\operatorname{COSF}($ HR $) \star S I H D-S I H F(H R) * \operatorname{COSD}$

XP1 $=$ XPOHD/XPOH(HR)

VDR $=(V 1 R O * T G F 1-V 110 * T G F 2) * X P 1+(V 2 R O * T G F 1+V 210 * T G F 2) / X P 1$

VDI $=\left(V 1 R O * T G F 2+V 1 I O^{*} T G F 1\right) * X P 1-\left(V 2 R O * T G F 2-V 210^{*} T G F 1\right) / X P 1$

C CALCULATIONS FOR REGIOHS ABOVE THE DEFECT.

40 VDRO $=$ VOR

VDIO=VDI

VDR $=2 *(B E T A R(H S C) * V D R O-B E T A I(N S C) *$ VDIO)

VDI $=2$ * (BETAI (HSC)*VDRO+BETAR (HSC)*VDIO)

C IHCREMEHT REGIOH COUNT \&EXIT IF ME HAVE REACHED THE STOP (NSTP) REG.

$50 \quad N R=H R+1$

IF (NR.LT.HSTP) GO TO 20

RETURA

c

END

C SUBROUTIHE BETAM (13 JULY 1977)

c

SUBROUTINE BETAM(NR, NRT, HP, NPT, NF, NFT, BETAR, BETAI, COSF, SIMF, XPOH

1 , WUSR,U, TH, COSD, SIND, XPOND, DFT, NRDF)

DIMENSION BETAR(NRT), BETAI(HRT), COSF(HRT), SIHF(NRT), XPON(HRT)

DIMENSIOH WUSR (HRT, NPT, NFT),U(NRT, NPT), TH(HRT, NPT)

DIMENSION DFT(NPT), NRDF(NPT)

COMHON /B1/X,XX,XXXX

C START BETA CALCULATIONS AT UPPERHOST REGIOH AND WORK DONH

C AMAY FROH COIL.

KR $=$ KRT

$\operatorname{BETAR}($ NR $)=X$ 
BETAI (HR) $=0$.

C

SET EXPOHEHT SUM TO ZERO AHD START CALCULATIHG BETAS.

SUWEXP $=0$.

$20 \mathrm{KR}=\mathrm{KR}-1$

BETAR (HR) $=U(N R, H P) * S O R T(X X+S Q R T(X X X X+W U S R(H R, N P, H F) * W U S R$ (NR , NP , HF

1)J)

BETAI (NR) $=U(N R$, KP) *U(NR, HP) *WUSR(NR , NP, HF)/BETAR(NR)

IF (NR.EQ.1) GO TO 50

$X T H=B E T A R(H R) * T H(H R$, NP)

SUMEXP $=$ SUMEXP+XTH

IF (SUMEXP.GT.20.) GO TO 40

$X P O H(H R)=E X P(X T H)$

$\operatorname{COSF}(N R)=\operatorname{COS}(B E T A I(H R) * T H(N R, N P))$

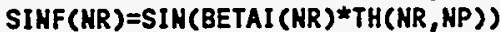

IF(NRDF(HP). KE. NR) CO TO 20

$25 \times P O H D=E X P(B E T A R(N R) * D F T(N P))$

$\operatorname{COSD}=\operatorname{COS}(B E T A I(N R) * D F T(N P))$

SIND $=$ SIN(BETAI $(H R) * D F T(N P))$

IF(NR.ME.1) GO TO 20

40 RETURH

C

CALCULATE THE DEFECT VALUES IF IT IS IN REgION 1.

50 IF(HRDF(NP).EQ.1)GO TO 25

RETURH

EKD

C

C

RFCOLM (13 JULY 1977)

SUBROUTIHE RFCOLM SS1,NLT, NPT , NRT, NFT, RL1, RL2, GAMAR, GAMAI

1 , GAMADR, GAMADI , TKUTRE, TMUT IM, DRIVRE, DRIVIM, PICKRE, PICKIM

2,DRVDR, DRVDI ,PICKDR, PICKDI , BETAR, BETAI , COSF , SINF , XPON

3 , WUSR, U, TH, NRDF , DFR, DFT, AIR1, AIR2)

DIMENSION BETAR(NRT), BETAI (NRT), COSF(NRT), SINF(NRT), XPON(NRT)

DIMENSIOH WUSR(NRT, NPT, NFT), U(NRT, NPT), TH(NRT, NPT)

DIMENSION RL1(NLT),RL2(NLT), NRDF(NPT),DFR(NPT),DFT(NPT)

DIMENSION GAMAR(NPT), GAMAI (NPT), GAMADR (NPT), GAMADI (NPT)

1, TMUTRE ( $H L T$, NPT, NFT), THUTIM(NLT, NPT, NFT), DRIVRE (NLT, HPT, HFT)

2,DRIVIM(NLT, NPT , NFT), PICKRE (NLT, NPT, NFT), PICKIM(NLT, NPT, HFT)

DIMENSION DRVDR(NLT, HPT, NFT), PICKDR (NLT, NPT, NFT)

DIMENSION DRVDI (NLT, HPT, NFT), PICKDI (NLT, NPT, HFT)

REAL L3, L4,L2,L5,L6

COHMON $/ B 1 / X, X X, X X X X$

COMMON /B2/R1, R2, R3, R4, L3, L4, RBAR, VO, ZLDR, ZLPU,

1 THDR, THPU, RDCDR, RDCPU, RO, R9, CAPDR, CAPPU

CONOW /B6/ L $2,15, L 6$

C

CALCULATIOH OF THE COIL PART OF THE INTEGRAND. SUBPROGRAM FOR FOR REFLECTION TYPE COILS.

SUBROUTINE BESSEL EVALUATES THE INTEGRAL OF THE PRODUCT OF THE BESSEL FUNCTION $J 1(X)$ AND ITS ARGUHENT, $X$.

CALL BESSEL(XJR2, $X, R 2)$

CALL BESSEL(XJR1, $X, R 1)$

CALL BESSEL (XJR4, $X, R 4$ )

CALL BESSEL (XJR3, $X, R 3)$

$D 21=X J R 2-X J R 1$

$D 43=X J R 4-X J R 3$

$S 6=S 1 * 043$

$S 3=S 6 * D 21$

$S 7=51 * 021$

$54=\$ 7 * 021$

$S 5=56 * 043$

$\operatorname{EX3}=\operatorname{EXP}\left(-X^{*} L 3\right)$

$H_{1}=1 .-E X 3$

$\operatorname{EX4}=\operatorname{EXP}\left(-X^{\star} L 4\right)$

$H 2=1 .-E X 4$ 
EX5 $=\operatorname{EXP}\left(-X^{\star} L 5\right)$

$W 3=E X 3 /(E X 4 \star E X 4 \star E X 5 \star E X 5)$

UPDATE OF AIR VALUES

AIR1 $=A I R 1+(S 4+S 4) *(X * L 3-W 1)$

$Q 3=X * L 4-H 2$

AIRZ $=A I R 2+(S 5+S 5) *(03+Q 3-W 2 * W 2 *(3)$

C

BYPASS THE UPDATE OF MUTUAL INDUCTAKCE QUANTITIES

FOR LARGE $X$.

IF (X.GT. 30.0) 60 TO 200

$\operatorname{EXI}=\operatorname{EXP}\left(-X^{\star} L 2\right)$

$\operatorname{EX7}=\operatorname{EXP}(-X * L 6)$

EX2=EX1*EX1

EX6 $=E X 7^{\star} E X 7$

$W_{4}=1 .-E \times 4 * W 3$

W6 $=$ EX6*W9

$W 7=E \times 5 * W 2 * W 4$

$\omega 8=47 \star E X 7$

W9=UT*EX7

$W 5=H 7^{*} W 6$

$W 6=W 6 * W 1$

$H 7=E \times 6 * W 7 * W 7$

$R L i(1)=1.0$

$R L 2(1)=1.0$

DO $50 \mathrm{HL}=2, \mathrm{HLT}$

LMINUS $=N L-1$

$R L 1(H L)=E \times 1 * R L 1$ (LMINUS)

$R L 2(N L)=E X 2 * R L 2$ (LMIHUS)

50 CONTINUE

THUT $=S 3 *$ WS

DVR $=54 * W 6$

$P I C=55 * H 7$

DVRD $=57 * 49$

PICD $=56 * 48$

C

C

C

C

LOOP OVER ALL NFT FREQUENCIES.

DO $160 \mathrm{NF}=1, \mathrm{HFT}$

LOOP OVER ALL. THE HPT DIFFERENT SETS OF PROPERTIES, CALCULATING THE VARIOUS GAMHA AHD DEFECT FACTORS AS WE GO.

DO 155 HP =1, NPT

CALL GAMAML (NRT, NPT, NP, NFT, HF, BETAR, BETAI, COSF, SINF, XPON

1 , WUSR, U, TH, GAMAR, GAMAI , GAMADR, GAMADI , DFT , HRDF)

TMUR = TWUT*GAMAR(HP)

THUI $=$ THUT ${ }^{\star}$ GAMAI (NP)

DVRR $=$ DVR ${ }^{\star}$ GAHAR(HP)

DVRI $=$ DVR*GAHAI (MP)

PICR = PIC*GAHAR(HP)

$P I C I=P I C * G A H A I(H P)$

IF(HRDF(MP).GT.NRT) GO TO 100

$Q 1=X * D F R$ (NP)

CALL BESELI(Q1,RJ1)

DRDR $=D V R D * R J 1 *$ GAMADR (NP)

DRDI =DVRD\#RJ I*GAMADI (NP)

PICOR=PICD*RJI*GAMADR (NP)

PICDI =PICD*RJI*GAMADI (NP)

100 CONTIKUE

DO $150 \mathrm{HL}=1, \mathrm{NLT}$

TMUTRE(HL, HP, MF) $=$ TWUTRE(HL, HP, NF) $+T H U R{ }^{*} R L 2(H L)$

THUTIM(NL, HP, MF) $=$ THUTIM(NL, HP, NF) + THUI *RL2(HL)

DRIVRE (NL, HP, HF) $=$ DRIVRE(NL, HP, NF) + DVRR*RL2(HL)

DRIVIH(NL, NP, NF) $=$ DRIVIM(HL, NP, HF $)+D V R I^{\star} R L 2(H L)$ 


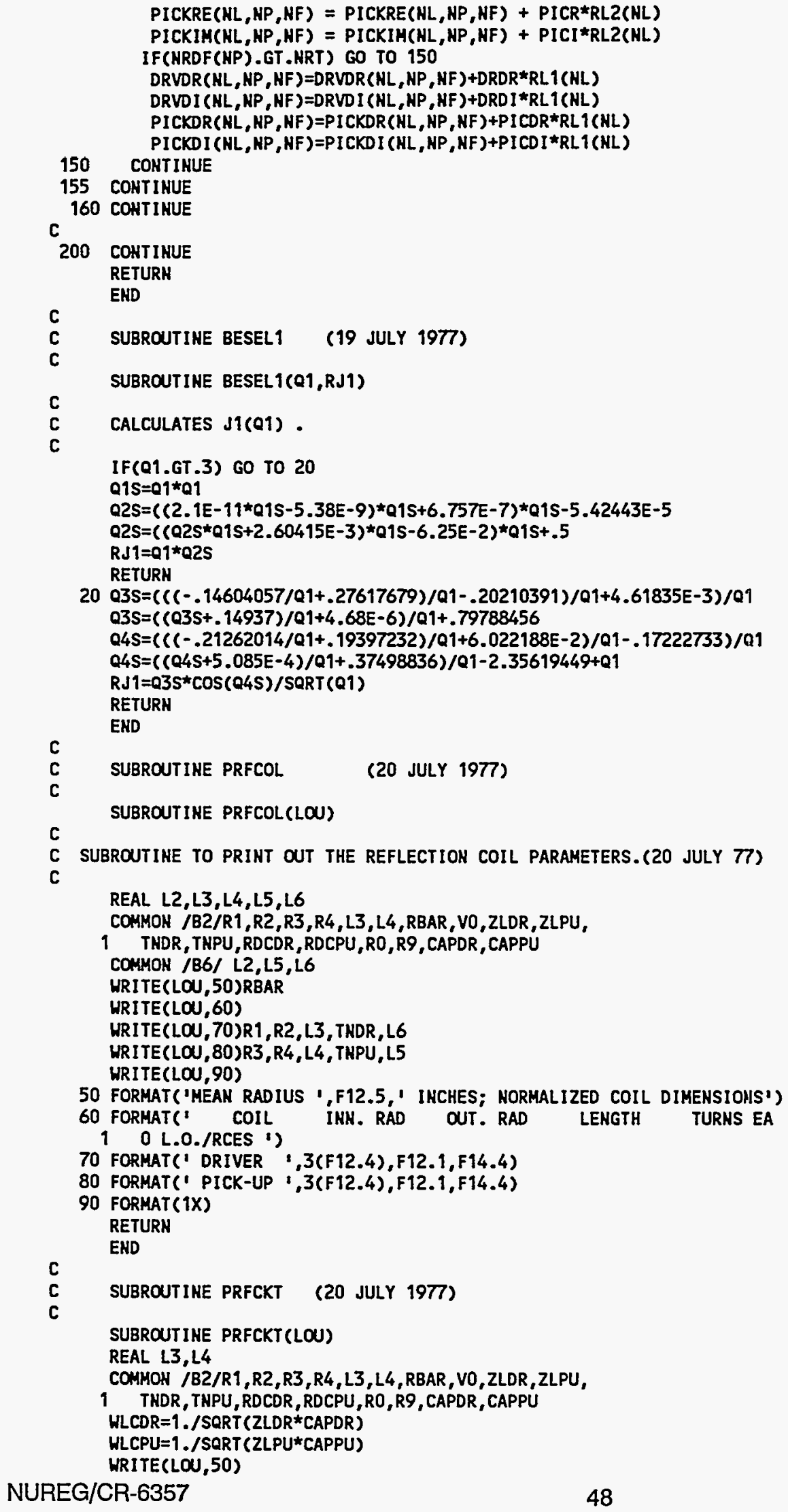




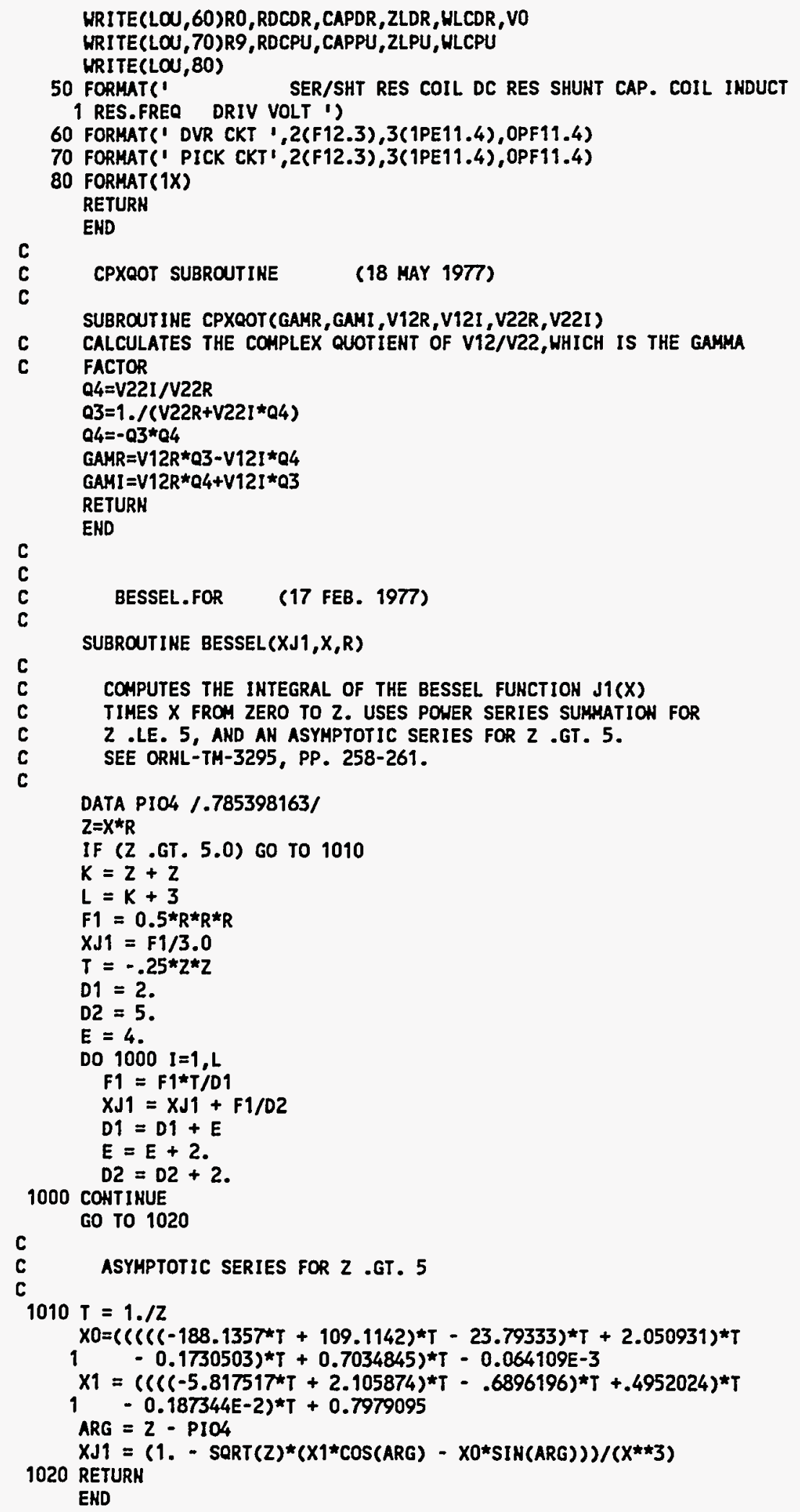


APPENDIX C 


\section{Appendix C: Least squares program}

Program FINDFIT.F finds the best polynomial to use to perform a fit of eddy-current data to some property of the part being tested. The techniques used have been described in earlier reports. The program is listed below.

PROGRAM FIHDFITH

VERSION August 9,1994

PROGRAM TO PERFORM A LEAST SQUARES FIT TO DATA READ IHTO A

DISK FILE BY NRCRFD, A VERSION OF MULRFD. THIS PROGRAM WILL CYCLE

THROUGH A SET OF FIT VALUES AND PRIHT THE BEST FIT AND RHS ERROR

AT EACH COHBIHATIOH OF FREQUENCIES. FAST VERSIOH, STORES READIHGS AND PROPS IN BIG ARRAY RATHER THAN READ FROH FILE EACH TIME.

COMPILE WITH FB (BIG ARRAY) OPTION.

IRDPRH=HAXIMUH HUHBER OF COEFFICIENTS IN EXPANSION

LITEK=LOGICAL IHPUT UNIT

LOTEK=OPERATOR OUTPUT UNIT FOR PROMPTING AND DISPLAY

LPT=LOGICAL OUTPUT UNIT FOR PERMANENT RECORD

NF $=$ FREQUENCY IHDEX

NFT=KUHBER OF FREQUENCIES USED IN FITTING EQUATION

NFTT =TOTAL NUMBER OF FREQUENCIES MEASURED IN RDGANA

NP=PROPERTY IHDEX

HPROPH= MAXIMUH HUHBER OF PROPERTIES CALCULATED( $=7$ NOW)

HPT $=$ TOTAL NUHBER OF SETS OF PROPERTY VALUES USED FOR THE FIT

NPTT=VALUE OF HPT READ FROM FILE 30, TOTAL POINTS FROM BIGRDG

SOME SETS OF ROGS FROM FILE 30 MAY NOT BE USED; MPTT.GE.HPT

HPRINT=PRIHT AND TRANSFER IHDEX.

HSTOP=IHDEX TO STOP THE IHSTRUMENT READINGS

VAR NAME HPOL $X$, NF) FUHCTIOH IS

NHFT 1 MAGITUDE FUNCTION NUMBER

HMPT 2 MAGNITUDE POLYHOMIAL DEGREE

MPFT 4 PHASE FUNCTION NUMBER

$\begin{array}{ll}\text { NPPT } & 5 \\ \text { PHASE POLYHOHIAL DEGREE }\end{array}$

HPCT 6 PHASE-HAG CROSS TERMS - 1

CHARACTER CONDITIONS 40 , PROHAM $(7) \star 4$, HPROBE*6

CHARACTER $* 79$ FIT1, FIT2,ERR1,ERR2

C THE APPROPRIATE NUMBERS SHOULD BE IHSERTED IH THE FOLLOUIHG DIMENSIOH STATEMENTS;

C

DIMENSIOH READHG $(781,16), \operatorname{PRO}(780), \operatorname{PROP}(7), \operatorname{MBITF}(6)$

DIMENSIOH TMAG $(780,6)$, PHASE $(780,6), \operatorname{FREQ}(6), \operatorname{GAIN}(6)$

DIMENSIOH TKDFT(6), PHDFT(6), COE(15)

DIMENSIOH RDG1(15), HPOL $(6,6)$

C

DIMENSIOH THAG1(6), PHASE1(6)

C DATA that MaY MEED tO BE CHANGED:

DATA HPT/780/,HPRIHT/O/,LPT/8/,LOTEK/6/,MRDG/30/,LID/37/,LOO/42/

DATA IRDPRH/15/,IR/1/, HCHS/6/, HPROPH/7/, HPROPT/1/,

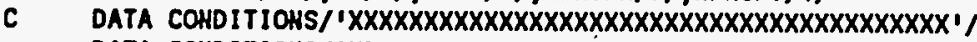

DATA CONDITIONS/'HRC TUBE W TUBE-SHT, MAG, CU, DEF, THK'/

DATA NFTT/6/,HFT/3/,HPROP/5/

DATA HPCT, HPPT, HPFT, HMPT, HMFT $/ 2,2,1,2,1$ /

DATA SDIFH/0.100/, SDRIFH/0.15/,ERHINO/.2/,DIFMIHO/.2/

C

DATA HFREQO/1/,NFIT/64/,DIFHIH/.2/,ERHIH/.2/

C PRINT TITLE AND DATE

TIHE AND DATE ARE PRINTED

CALL GETTIH(IHR, IMN, ISE, IFR)

CALL GETDAT(IYR, IMO, IDA)

IYR $=$ IYR -1900 


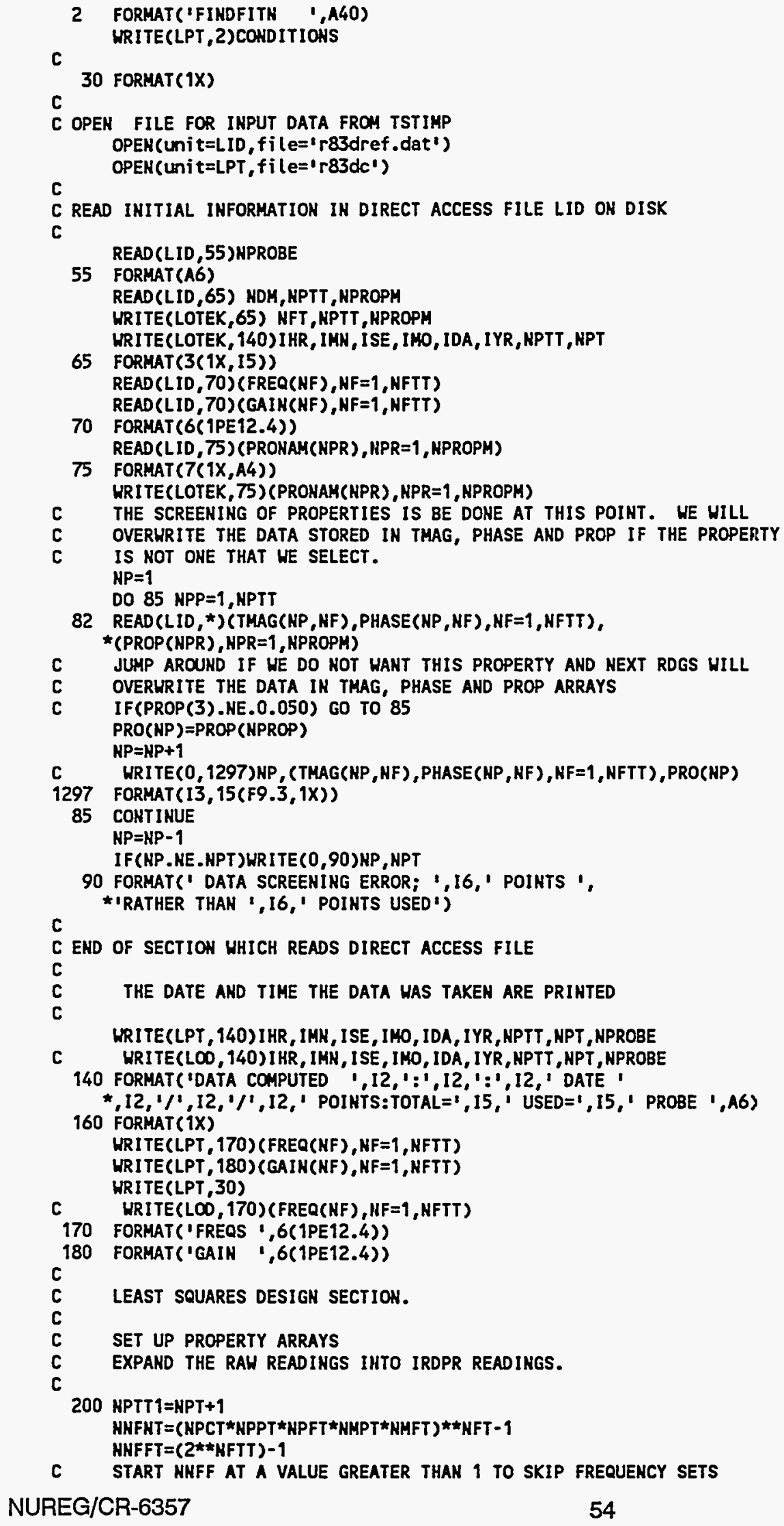


DO 1005 NHFF $=$ HFREQO, NHFFT

MFF $=$ HNFF

HSUM $=0$

DO $235 \mathrm{H}=1$, NFTT

$\operatorname{MBITF}(H)=H O O(H F F, 2)$

$M F F=H F F / 2$

NSUMH $=$ HSUH + HBITF(N)

235 CONTIHUE

IF(HSUH. NE. HFT)GO TO 1005

IF(NBITF(HF).EQ.1) HFF $=$ HFF+1

C CYCLE OVER THE OFFSET COUNTER, NOFS $=1,1$ FOR NO OFFSET, NOFS $=1,2$

DO 1004 NOFS $=1,2$

IOFSET $=$ NOFS -1

DO $250 \mathrm{HF}=1, \mathrm{HFTT}$

DO $250 \mathrm{HC}=1,6$

HPOL (NC, HF) $=0$

250 COHTINUE

C hMFH CAN Be staRted at the last value RUN to finish ah

C INTERUPTED RUN

DO 1000 ANFH=HFIT, NHFHT

$\mathrm{HF}=0$

MNFH=NHFN

$300 \mathrm{MF}=\mathrm{HF}+1$

IF (NBITF(NF).NE.1)GO TO 310

NPC $=$ HOD (MNFN, NPCT)

HNFN=HHFN/NPCT

$N P P=H O D($ KNFN, NPPT $)+1$

MAFH=HAFN/HPPT

$M P F=2 \star M O D$ (HHFH, HPFT $)+1$

MHFN=MHFN/NPFT

NMP $=$ MOO (MNFN , NMPT $)+1$

MNFN=MNFN/NMPT

NKF $=$ KOO (MNFN , NHFT $)+1$

HAFH=HHFH/ HMFT

NPOL $(1, N F)=$ NHF

$\operatorname{MPOL}(2, \mathrm{NF})=\mathrm{HHP}$

$\operatorname{HPOL}(4, \mathrm{NF})=\mathrm{HPF}$

$\operatorname{NPOL}(5, \mathrm{HF})=\mathrm{HPP}$

HPOL $(6$, NF $)=$ HPC

310 IF(MHFN.GT.0)GO TO 300

IRDPR $=$ IOFSET

DO $320 \mathrm{HF}=1$, NFTT

$I R D P R=N P O L(2, H F)+H P O L(5, H F)+H P O L(6, H F)+I R D P R$

320 CONTIKUE

IF(IRDPRH.LT.IRDPR)GO TO 1000 IRDPR $1=$ IRDPR +1

470 DO $480 \mathrm{JF}=1$, NFTT

$\operatorname{TMDFT}(J F)=0$.

PHDFT(JF) $=0$.

480 CONTINUE

$H R=1$

DO 490 NP=1, HPT

DO $481 \mathrm{JF}=1$, NFTT

TMAGI (JF) $=$ TMAG (NP , JF)

PHASEI (JF)=PHASE (HP, JF)

481 CONTIKUE

C

CALL RDGEXP(RDG1, THAG1, PHASE1, HPOL, IOFSET, TMDFT, PHDFT, IRDPRH, NFTT)

C URITE(0, 1298)HP, (RDGI(IR), IR=1, IRDPRH)

1298 FORHAT (13, 15(F9.3, 1X))

DO 485 IRD =1, IRDPRM

READNG (NR, IRD) $=$ RDGI (IRD)

485 CONTINUE

$\mathrm{NR}=\mathrm{NR}+1$

490 COHTINUE

$N R F=K R-1$

C

C DO THE LEAST SQUARES FIT OF THE READINGS TO THE PROPERTIES. 
CALL ALSQS (READNG, PRO, COE, RSOS, NPT, IRDPR, HPTT1, IRDPR1)

500 SSDRIF $=0$.

SSDIFF $=0$.

KR=1

DO $570 \mathrm{KP}=1, \mathrm{HPT}$

DRIFT $=0$.

DO $515 \mathrm{JF}=1$, MFTT

TMAGI (JF) $=$ TMAG (NP, JF)

515

PHASE1 (JF) $=$ PHASE $(N P, J F)$

CONTINUE

DO $540 \mathrm{JF}=1$, $\mathrm{MFTT}$

IF (HBITF (JF).EQ.0360 TO 540

C

DO $530 \mathrm{KC}=1,2$

C ONE MAGNITUDE OR PHASE DRIFT IS SET ON AT A TIME.

C TYPICAL ERROR IS 0.005 IN THE MAGNITUDE AND 0.01 IN THE PHASE

IF(NC.EQ.1)THDFT(JF) $=0.005$

$1 F$ (NC.EO.2) PHDFT (JF) $=.01$

CALL RDGEXP(RDG1, TMAG1, PHASE1, NPOL, IOFSET, TMDFT, PHDFT, IRDPRM, NFTT)

C

C THE POLYMOMIAL IS CALCULATED

SUM $=0$.

DO 520 IR=1, IRDPR

SUM $=S U H+C O E(I R) * R D G I(I R)$

520 CONTINUE

DRIFT=DRIFT+ABS(READHG(HR, IRDPRI)-SUM)

TMDFT (JF) $=0$.

$\operatorname{PHDFT}(J F)=0$.

530 CONTINUE

540 COHTINUE

DIFF=PRO(NR) -READNG(NR, IRDPR1)

SSDIFF $=S S D I F F+D I F F * D I F F$

SSDRIF $=S S D R I F+D R I F T * D R I F T$

$565 \quad \mathrm{NR}=\mathrm{NR}+1$

570 CONTIHUE

HRD $=$ KR -1

IF (NPT . NE. HRF .OR.NPT . ME. NRD) URITE(LOTEK, *) 'READING ERROR:

* ASSUMED $=1$, NPT, I FIT $=1$, NRF,' DRIFT=1, NRD

SDRIF=SORT (SSDRIF/FLOAT (NPT))

SDIFF=SORT (SSDIFF/FLOAT (NPT))

ERROR=SQRT (SDRIF*SDRIF+SDIFF*SDIFF)

IF(ERROR.GT.ERMIN.AND.SOIFF.GT.DIFHIN) GO TO 575

IF(ERROR.LT _ERMIN.AHD.SDIFF.LT.DIFMIN) GO TO 571

IF (SDIFF.LT.DIFHIN) HRITE(FIT1, 585) IOFSET, PRONAM(NPROP)

*, SDIFF, SDRIF, (HPOL (2, JF), MPOL (5, JF), JF=1, MFTT)

IF(SDIFF.GT.DIFHIN) MRITE(ERR1, 586) IOFSET, PROHAM(NPROP)

*, SDIFF, SDRIF, (HPOL (2,JF), MPOL (5,JF), JF=1, NFTT)

IF(ERROR.LT.ERMIN) URITE(ERR2,587) NMFN, NNFF,

*ERROR, (NPOL ( $3, J F), N P O L(6, J F), J F=1, N F T T)$

IF(ERROR.GT.ERMIN) HRITE(FIT2,588) NNFN, HNFF,

*ERROR, (HPOL $(3, \mathrm{JF}), \operatorname{NPOL}(6, \mathrm{JF}), \mathrm{JF}=1, \mathrm{MFTT})$

GO TO 574

571 URITE(FIT1, 585) IOFDSET, PRONAM(NPROP)

*, SDIFF, SDRIF, (NPOL(2, JF), MPOL (5, JF), JF=1, NFTT)

HRITE(ERR1, 585) IOFSET, PRONAM (NPROP)

*, SDIFF, SDRIF, (NPOL (2, JF), NPOL(5, JF), JF=1, NFTT)

HRI TE(FIT2,587) HNFN, NHFF,

*ERROR, (MPOL (3,JF), $\operatorname{NPOL}(6, J F), J F=1, M F T T)$

URI TE(ERR2, 587) NNFN, NNFF,

*ERROR, (MPOL $(3, J F), N P O L(6, J F), J F=1$, NFTT)

574 IF (ERROR.LT.ERMIH)ERHI H=ERROR 


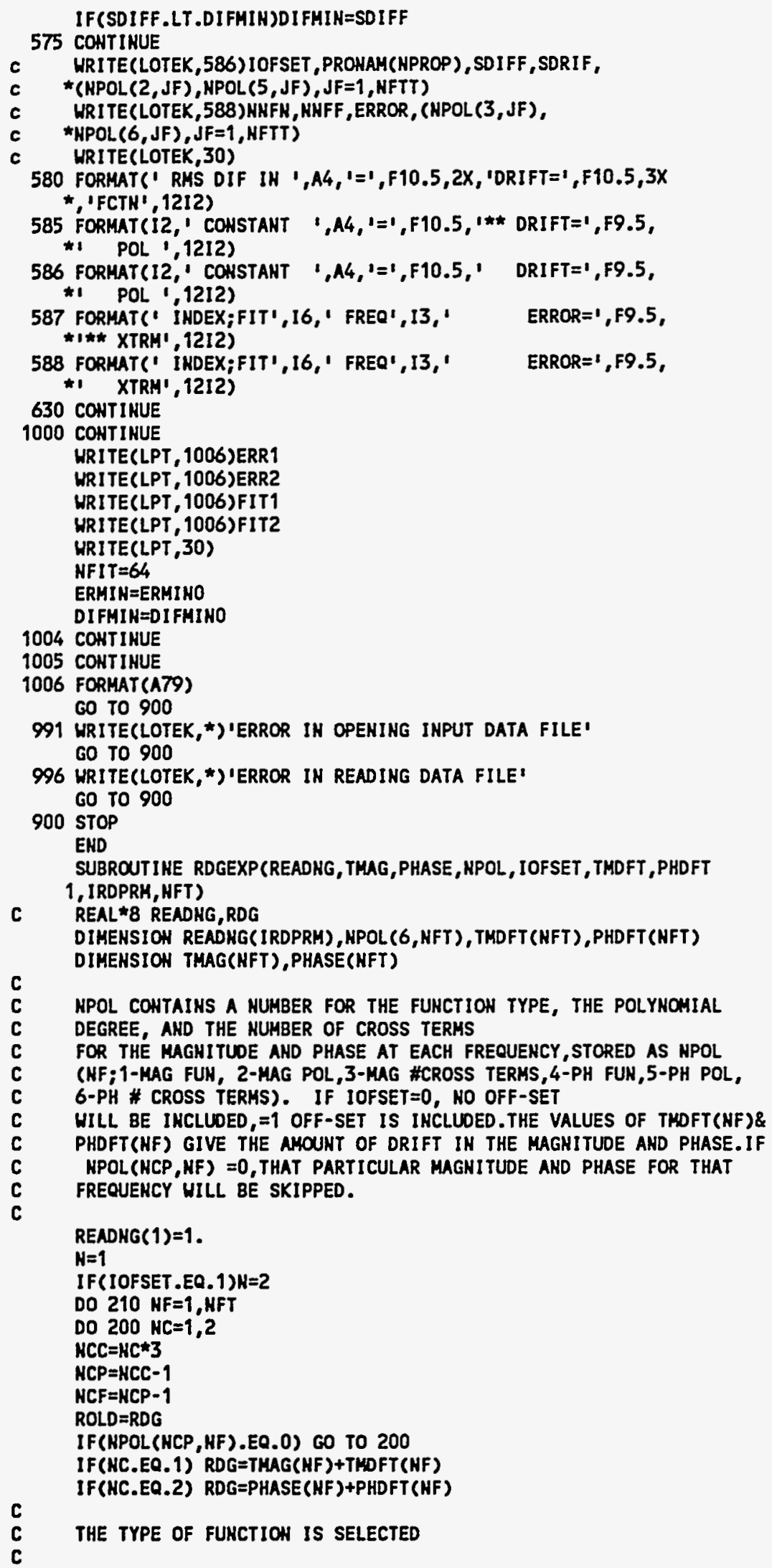




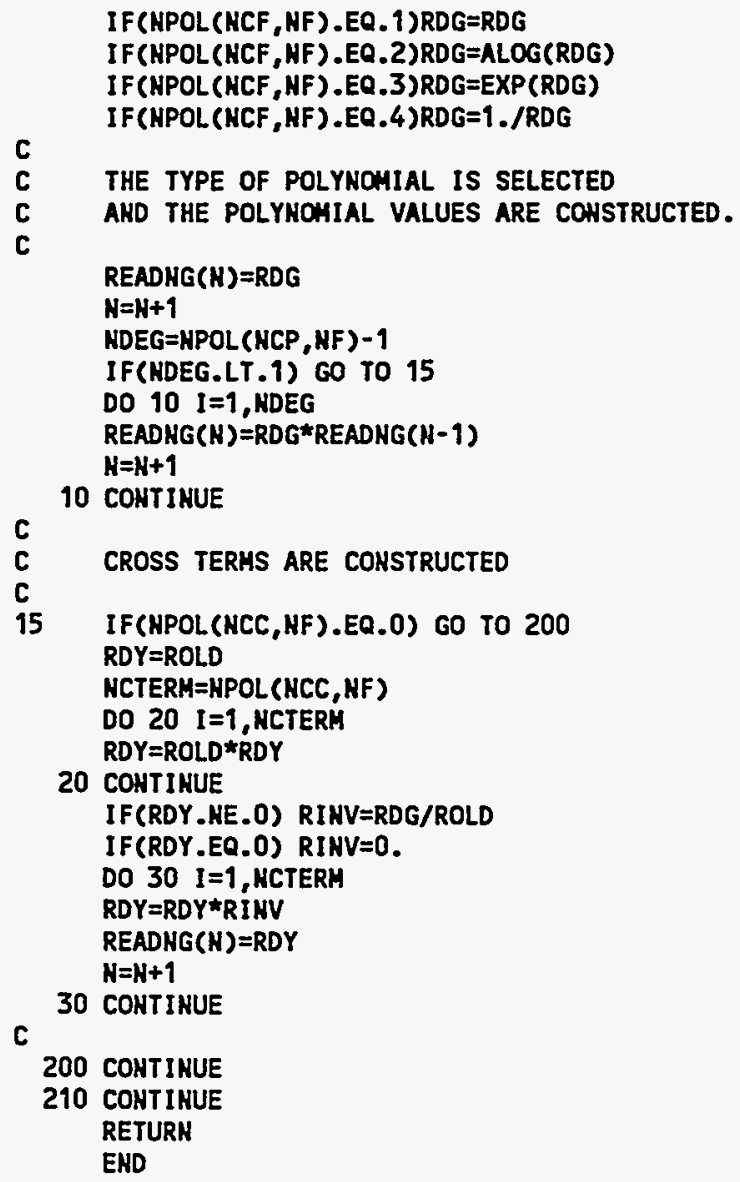

A IS AH ARRAY CONTAINING THE LEAST SQUARES MATRIX. UPON RETURN THE $(M+1)$-TH COLUMM CONTAINS THE APPROXIMATING VECTOR AB.

$Y$ IS THE VECTOR TO BE FIT

B CONTAINS UPOH RETURH THE COEFFICIENTS OF THE FIT.

R2 CONTAINS UPON RETURN THE RESIDUAL SUM OF SQUARES.

$N$ IS THE NUMBER OF ROWS IN THE LEAST SQUARES MATRIX.

$M$ IS THE NUMBER OF COLUMNS IN THE LEAST SQUARES MATRIX.

NA IS THE FIRST DIMENSION OF THE ARRAY A.

CALL ALSQS (READHG, PRO, COE, RSOS, NPT , IRDPR, NPTT1 , IRDPRI)

CALL ALSQSS A, Y, B, R2, NH, MH, HA, NB)

DIMENSION A(NA, HB), Y(NH), B(MH)

$H=N H$

$N 1=N+1$

$M=M M$

$M 1=M+1$

MM1 $=M-1$

REDUCE THE LEAST SQUARES MATRIX TO UPPER TRIANGULAR FORM

DO $60 L=1, M$

SS $=0$. 


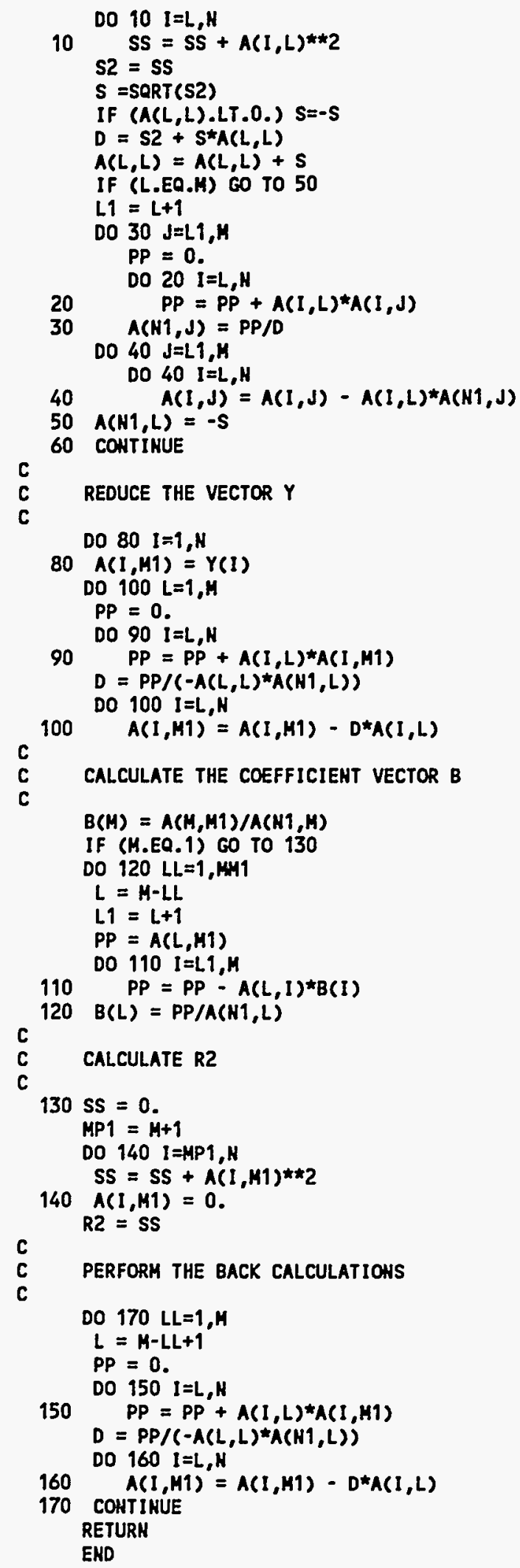




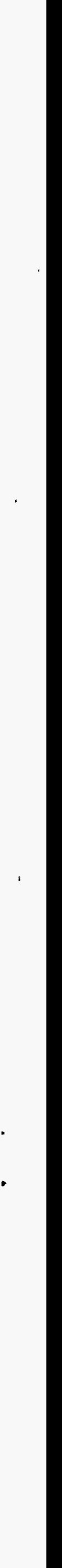


APPENDIX D 


\section{Appendix D: Neural network program}

This appendix describes the neural net program used for the automatic analysis of eddycurrent data from the array probe. The program, when presented with training data taken on samples with known properties (such as defect depth or wall thickness), extracts the features of the data associated with the property of interest and learns the relationship between the data and the properties so that, when given an unfamiliar set of data, the program can respond by giving the value of the property most likely associated with that set of data. For the neural net program to be able to perform the analysis of data from unknown tubes adequately, the data in the training set must include examples of every type of signal that it is likely to be presented to the neural net. If, for example, the neural net is to be taught to recognize the defect depth in a tube, the training set must include scans of many types of defects such as notches and holes, and will also preferably include scans of tubes with more realistic degradation such as IGA and ODSCC. It is necessary in the training set for each type of degradation to be scanned in the presence of other artifacts which may occur near defects in the unknown tubes; therefore tube supports, magnetite deposits, and copper deposits must be placed at different locations relative to the defects in the training samples. The neural net can be expected to interpolate successfully between data sets given it in training so that if it is trained on defects of depth $40 \%$ and $60 \%$ of wall thickness, it should be able to recognize defects of depth $50 \%$ of wall thickness, but the neural net cannot be expected, for example, to recognize or be able to characterize a defect in the presence of a deposit of a type not included in the training set. The algorithm used by the neural net is the backpropagation algorithm, which is described in many books.

The first step in training the neural net is to acquire data on the training samples using programs SCAN18.C or SCAN30.C described in an earlier report. The neural net program is designed to read files written in the format of these programs. The number of training data files must be entered in the program variable nfiles, and the names of these files must be assigned to the elements of the file array. The number of position coordinates in each file must be given in the naxes array and a number identifying which tube was scanned to obtain the data should be entered in the standard array. Finally a set of positions for each axis at which a software null may be performed should be given in the nullpos array. In addition to the data which are contained in the file, it is necessary to specify the value of the property to be learned at each point in the tube at which data were taken. While this information can be, and in the past has been, included in the data file itself, it is usually more convenient to have a subroutine in the program which knows the value of the property at each point in each tube and which can thus calculate the actual value of the property based on the position and the tube identification.

After the modifications described above have been made in the neural net program, it can be compiled by executing a script with the following commands:

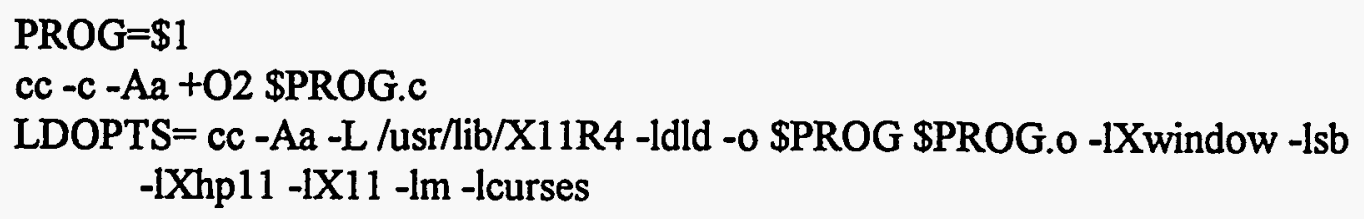


When the program is run it will first ask whether the user wants to restore a previously saved weights file to begin training. This is useful if it is necessary to interrupt and then resume training at a later time. If the user tells the program that he does not want to restore a file, the program will automatically assign small random numbers to all weights. The program then asks how many layers the user wishes to include in the neural net. The usual response is 3 . The next question asked by the program is the number of elements for the input layer. The correct response to enter here is one greater than the number of readings in each data point. For example, if the data used for training contains readings taken at four frequencies with two components at each frequency, there are eight readings at each data point, so the correct resoponse to the question would be nine. The program next asks how many elements should be included in the hidden layer of the network. The usual response here is a number from four to nine. The program then asks how many elements should be in the output layer. If the user is training the network to output a single property value, the correct response here is two. The program will then ask for a value for the momentum parameter and for the learning rate. Any number less than one can be entered in response to these questions.

At this point the program will read the input data files and begin training. At the end of a number of training attempts determined by the program variable nna, the program will print out the average rms error over the last nna training passes. While the program is running it accepts the commands described below.

\begin{tabular}{|c|l|}
\hline Command & \multicolumn{1}{|c|}{ Action } \\
\hline $\mathrm{e}$ & $\begin{array}{l}\text { At the end of each nna training attempts the program will, in addition to } \\
\text { calculating the average rms error over the last training cycle, make a pass } \\
\text { through the entire data set and calculate the true rms error with the weights in } \\
\text { their state at that point. If the rms error has reached a new low, the weights are } \\
\text { automatically saved in a disk file. }\end{array}$ \\
\hline 1 & The program will prompt the user for a new value for the learning rate. \\
\hline $\mathrm{m}$ & The program will prompt the user for a new value for the momentum parameter. \\
\hline $\mathrm{q}$ & The program will halt execution. \\
\hline $\mathrm{s}$ & The program will save the weights to a disk file. \\
\hline
\end{tabular}

After the training has been completed, the weight files stored in the format of the neural net program can be read by the analysis program SECORT described in an earlier report to apply the results of the training to eddy-current data not included in the training set.

The program is listed below.

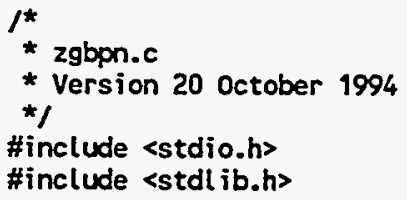




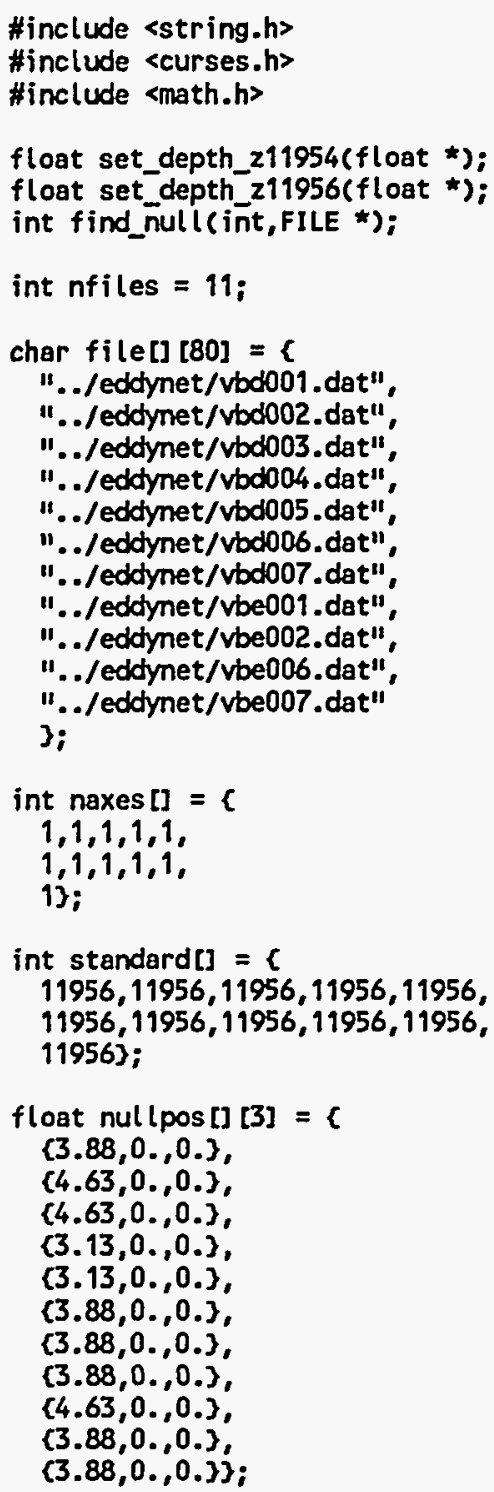

float nullval [4] [2];

void main(void)

i

FILE *strdat, *strut, *strout; char wts in [80], wtsout [80];

int found_null;

int eoftst;

floot $\times[3]$;

int is_null_pos;

int $\mathrm{npt}=0$;

int $i, j, k, l$;

int nlayers:

int ninput, whidden, noutput;

int restore from_file;

int pattern;

int ch;

int tmpdatr, tmpdati;

int data [4] [2];

int print period $=1$;

int calculate_error $=0$; 


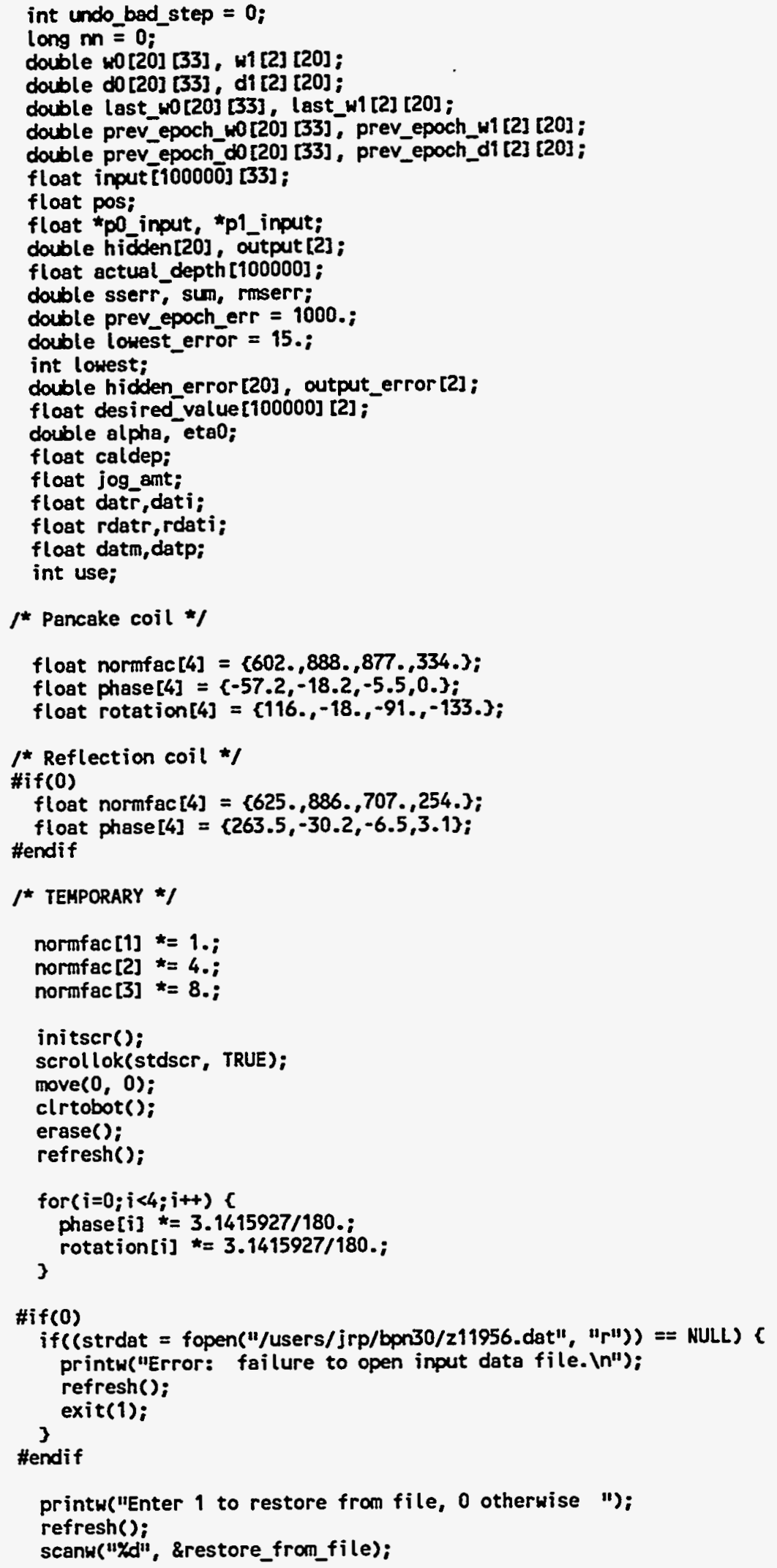




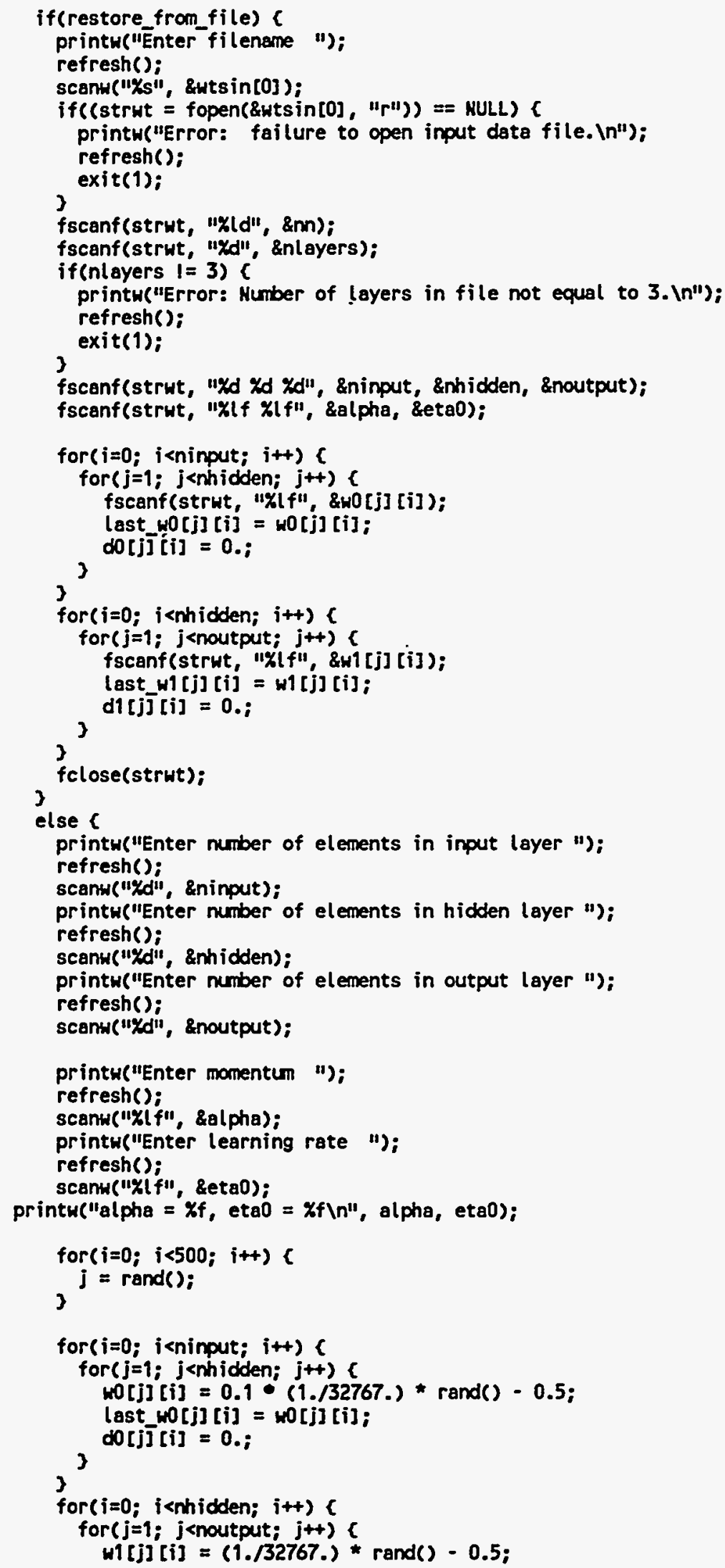




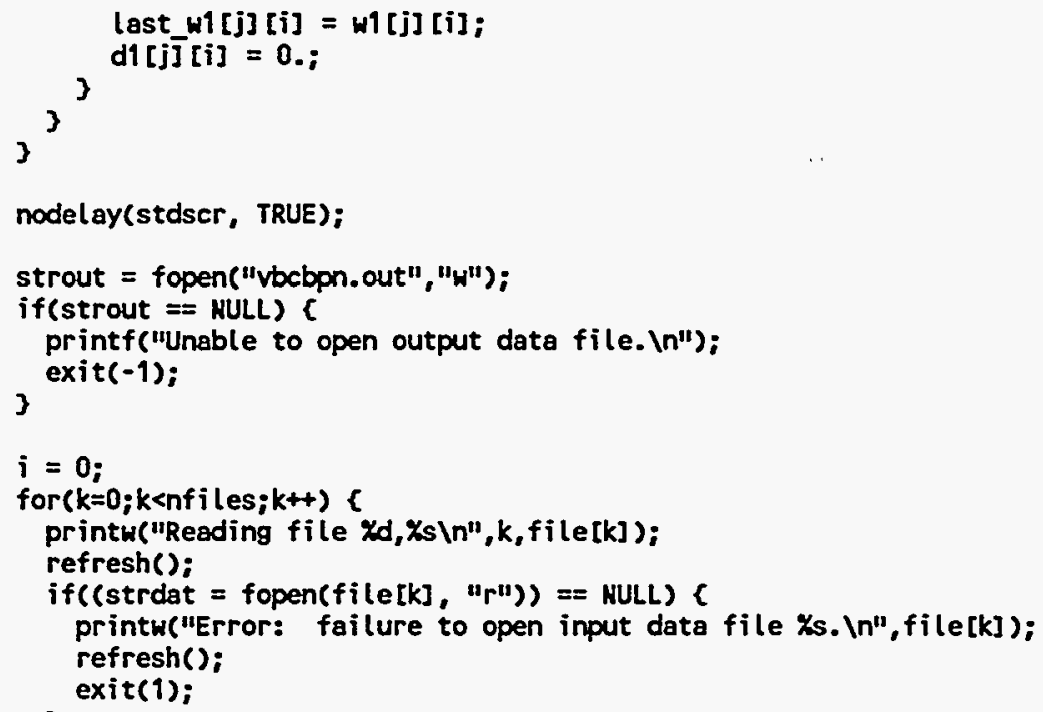

1 * Discard data points we don't want *

if (standard $[k]==11954)($

if $(f a b s(x[0]-2.50)<0.005)<$

3 use $=0$;

else $C$ 


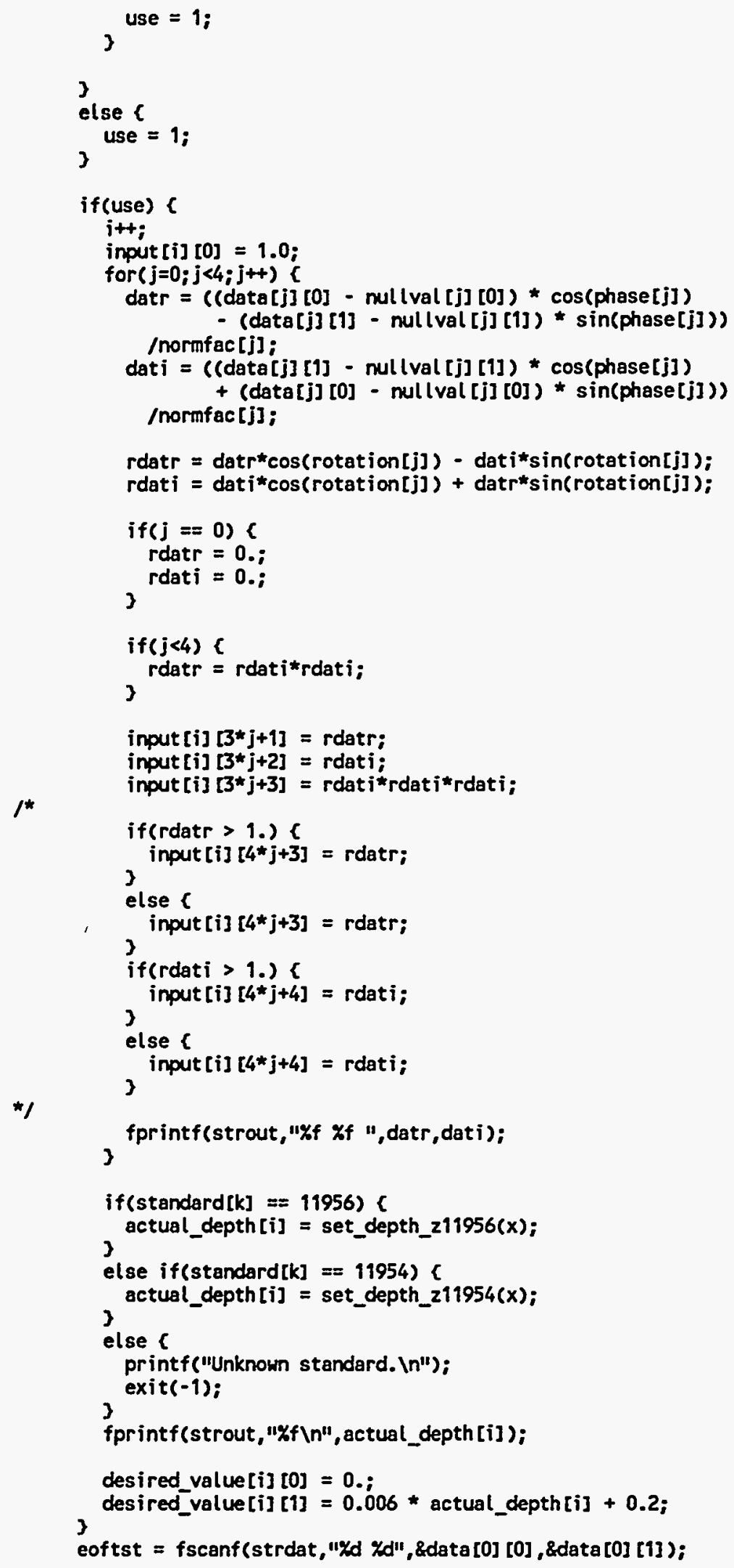




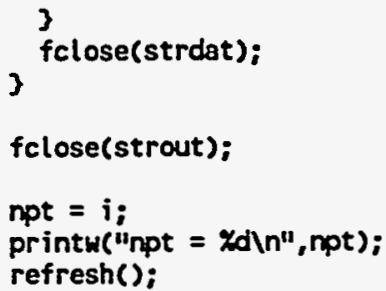

lbl1:

sserr $=0$.;

hidden $[0]=1.0$;

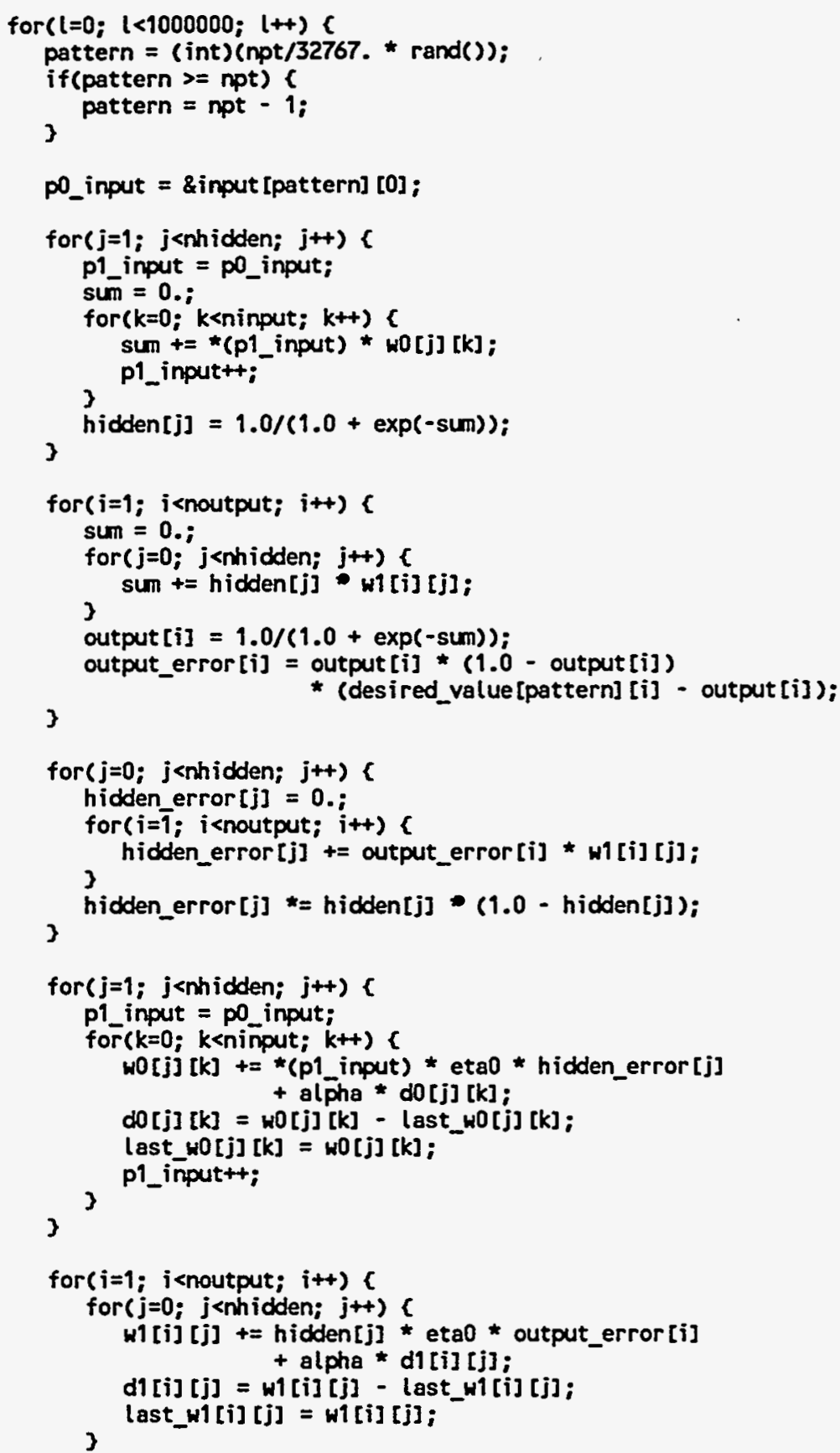




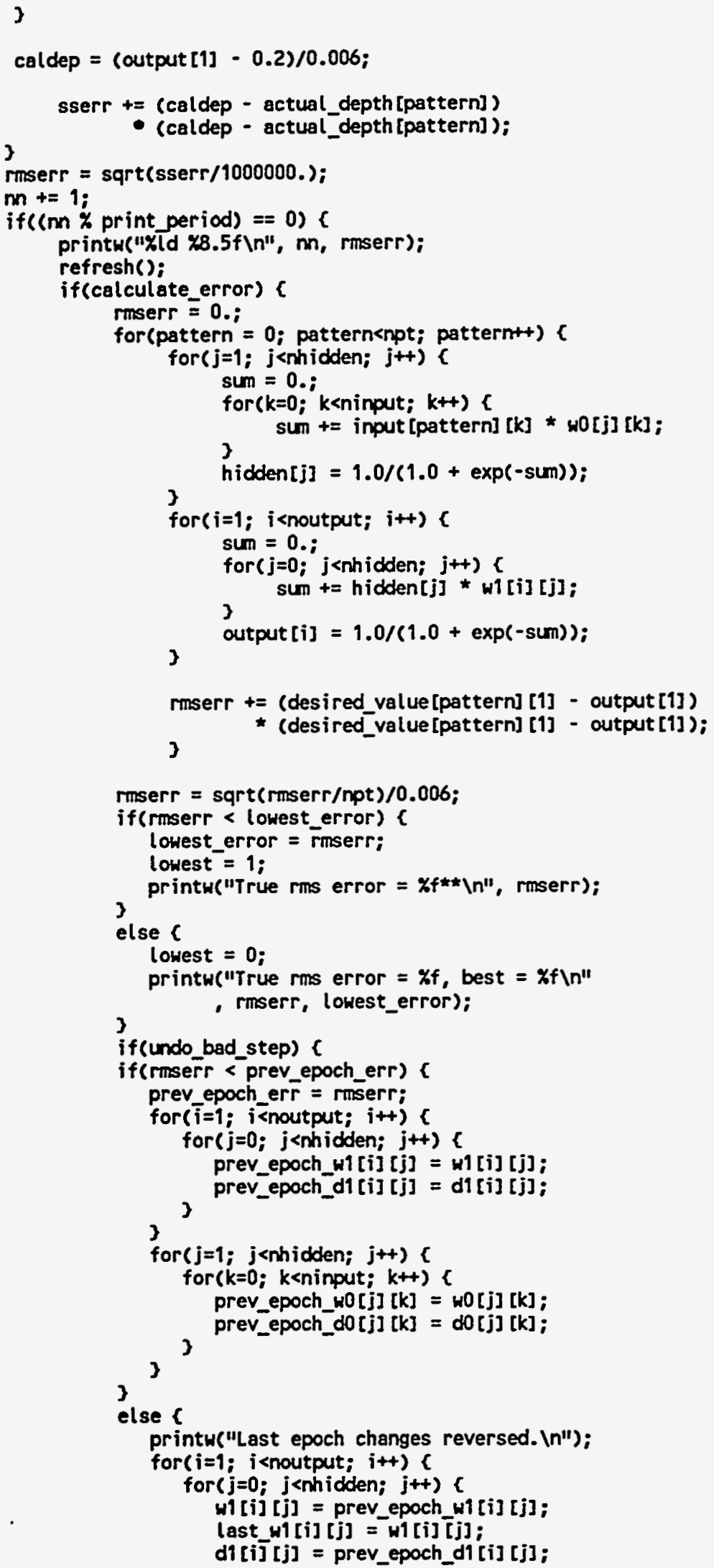




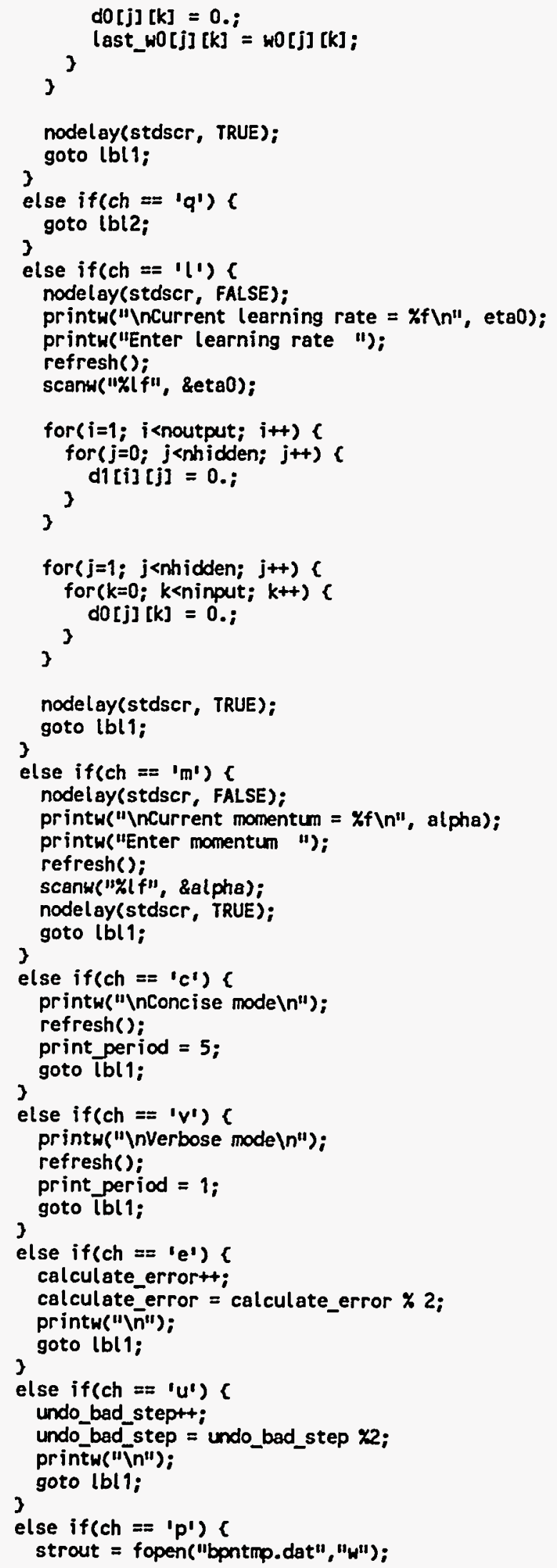




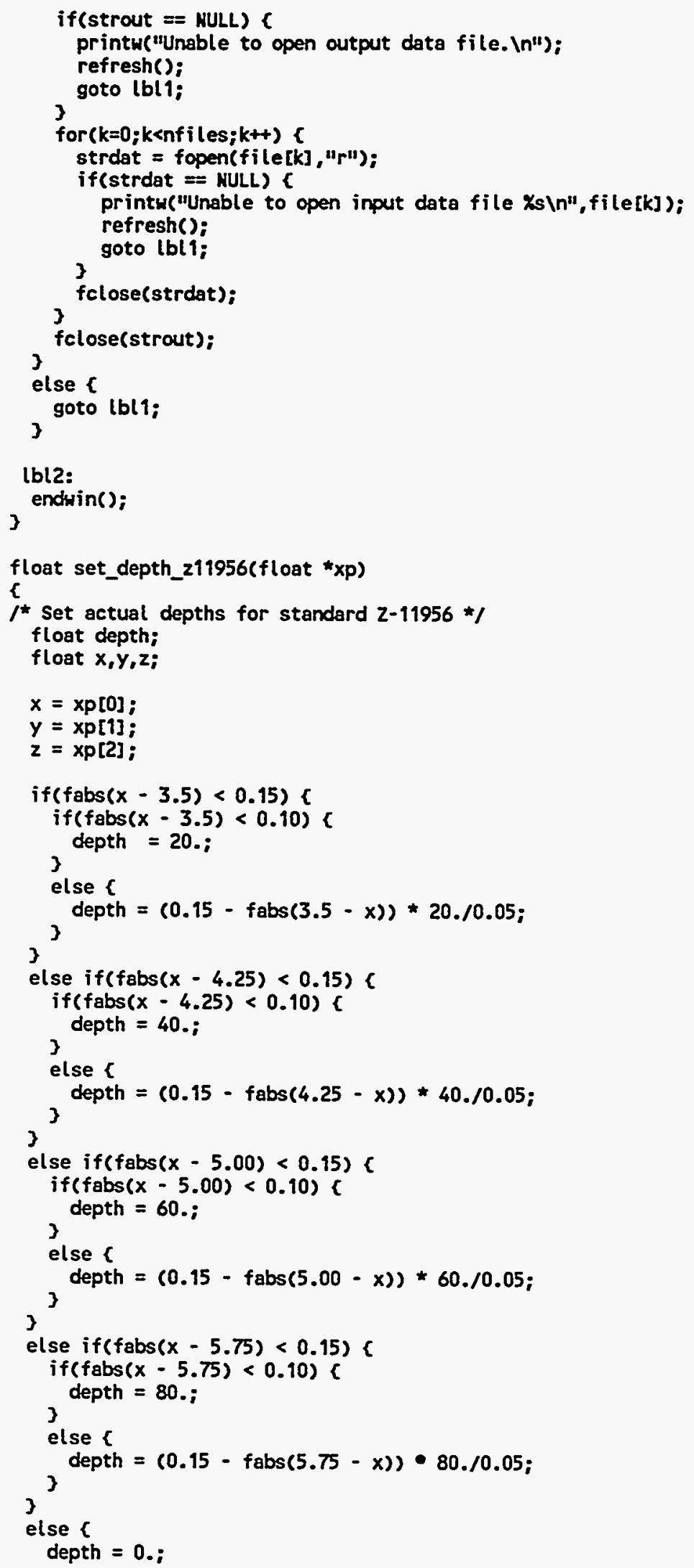




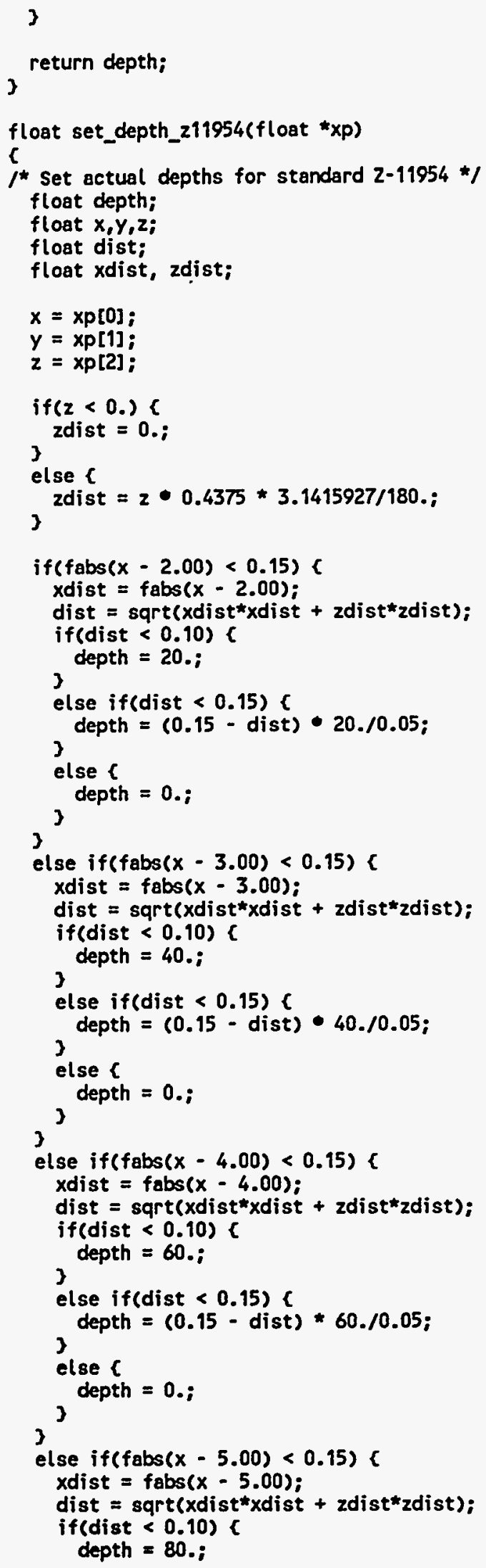




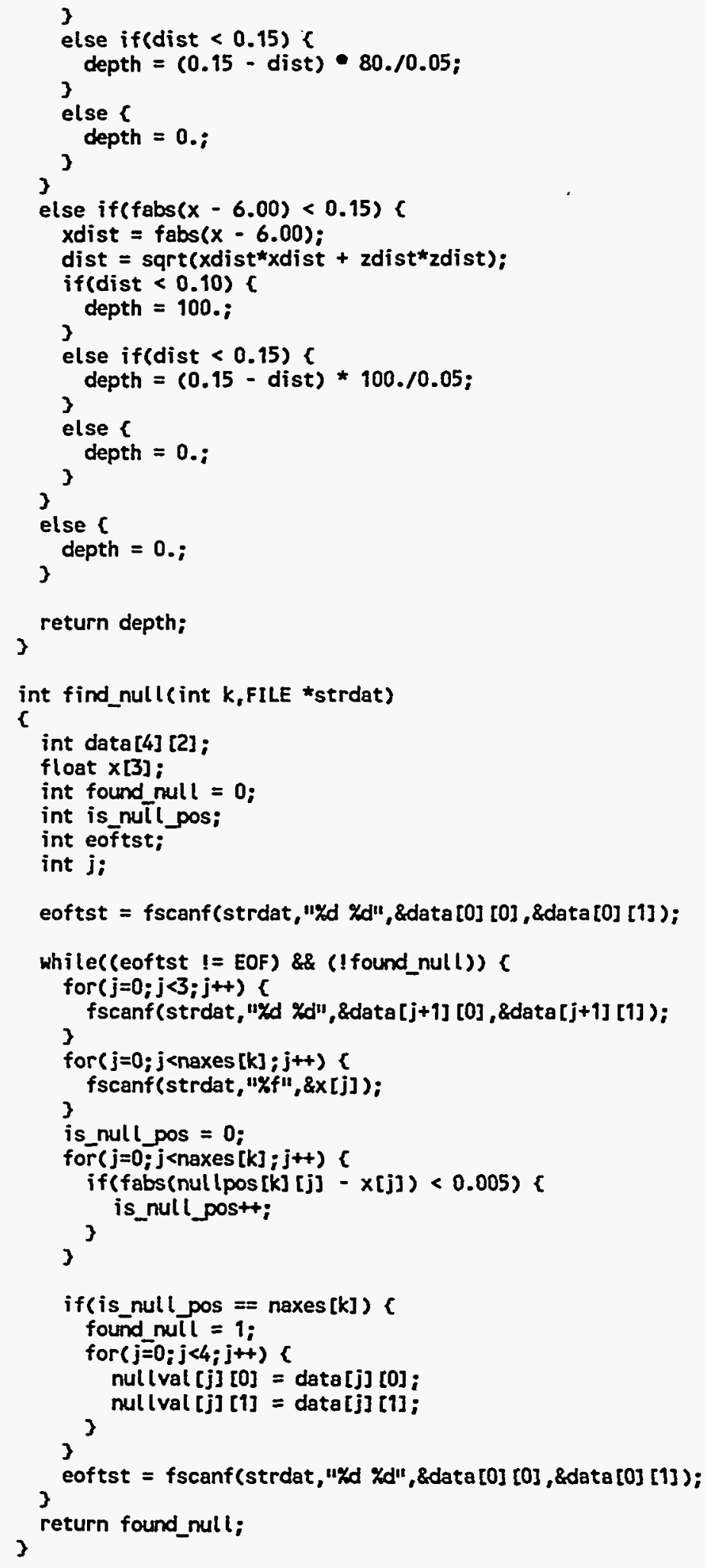




\section{INTERNAL DISTRIBUTION}

$\begin{aligned} \text { 1. } & \text { W. R. Corwin } \\ 2 . & \text { L. D. Chitwood } \\ 3 . & \text { D. F. Craig } \\ 4 . & \text { S. A. David } \\ 5-9 . & \text { C. V. Dodd } \\ \text { 10. } & \text { H. W. Hayden, Jr. } \\ \text { 11-16. } & \text { D. J. McGuire } \\ \text { 17. } & \text { R. K. Nanstad } \\ 18 . & \text { J.R. Pate }\end{aligned}$
19. C. E. Pugh
20. W. A. Simpson
21-22. M\&C Records Office
23. ORNL Patent Section
24. Central Research Library
25. Document Reference Section
26-27. Laboratory Records Department
28. Laboratory Records (RC)
29. Nuclear Safety Information Center

\section{EXTERNAL DISTRIBUTION}

30-31. NRC, OFFICE OF NUCLEAR REGULATORY RESEARCH, Washington, DC 20555
J. Craig
M. E. Mayfield
J. Muscara
C. Z. Serpan

32.-33. ELECTRIC POWER RESEARCH INSTITUTE, P.O. Box 217097, Charlotte, NC 28221
M. Elmo
K. Kryzwosz

34. BATTELLE PACIFIC NORTHWEST LABORATORIES, P.O. Box 999, Richland, WA 99352

B. Ferris

35. Steven D. Brown, 23 Greensburg Street, Delmont Borough, PA 15626

36. DOE, OAK RIDGE OPERATIONS OFFICE, Oak Ridge, TN 37831-8600 Office of Assistant Manager for Energy Research and Development

37. DOE, OFFICE OF SCIENTIFIC AND TECHNICAL INFORMATION, P. O. Box 62, Oak Ridge, TN 37831

38-286. Given distribution as shown in category RF (NTIS-10) 


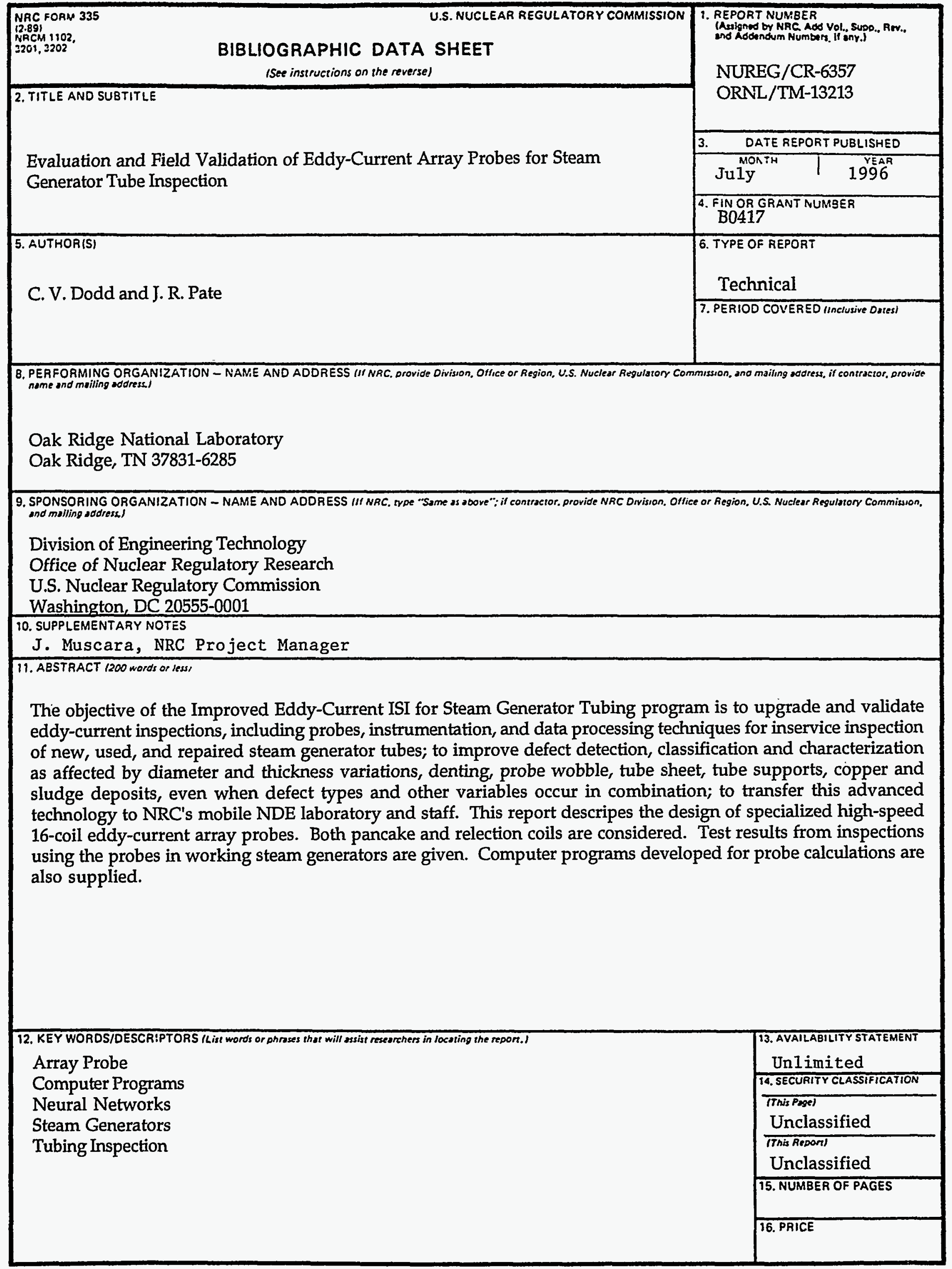




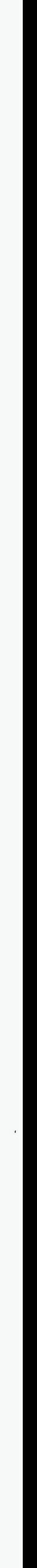

